\title{
Molecular and Cellular Complexity of Glioma. Focus on Tumour Microenvironment and the Use of Molecular and Imaging Biomarkers to Overcome Treatment Resistance
}

\author{
Silvia Valtorta ${ }^{1,2}\left(\mathbb{D}\right.$, Daniela Salvatore ${ }^{1,2}$, Paolo Rainone ${ }^{1,2}$, Sara Belloli ${ }^{2,3}$, Gloria Bertoli ${ }^{3, *(D)}$ \\ and Rosa Maria Moresco ${ }^{1,2,3, *}$ \\ 1 Department of Medicine and Surgery and Tecnomed Foundation, University of Milano-Bicocca, \\ 20900 Monza, Italy; silvia.valtorta@unimib.it (S.V.); daniela.salvatore@unimib.it (D.S.); \\ paolo.rainone@unimib.it (P.R.) \\ 2 Nuclear Medicine Department, San Raffaele Scientific Institute (IRCCS), 20132 Milan, Italy; \\ sara.belloli@ibfm.cnr.it \\ 3 Institute of Molecular Bioimaging and Physiology (IBFM), CNR, 20090 Segrate, Italy \\ * Correspondence: gloria.bertoli@ibfm.cnr.it (G.B.); rosa.moresco@unimib.it (R.M.M.)
}

Received: 21 July 2020; Accepted: 3 August 2020; Published: 6 August 2020

\begin{abstract}
This review highlights the importance and the complexity of tumour biology and microenvironment in the progression and therapy resistance of glioma. Specific gene mutations, the possible functions of several non-coding microRNAs and the intra-tumour and inter-tumour heterogeneity of cell types contribute to limit the efficacy of the actual therapeutic options. In this scenario, identification of molecular biomarkers of response and the use of multimodal in vivo imaging and in particular the Positron Emission Tomography (PET) based molecular approach, can help identifying glioma features and the modifications occurring during therapy at a regional level. Indeed, a better understanding of tumor heterogeneity and the development of diagnostic procedures can favor the identification of a cluster of patients for personalized medicine in order to improve the survival and their quality of life.
\end{abstract}

Keywords: glioma; cell heterogeneity; tumor-microenvironment; miRNA; therapy resistance; molecular imaging; PET; predictive biomarkers; prognostic biomarkers

\section{Background}

Glioma is the most diffused Central Nervous System (CNS) tumour in adults that accounts for the $75 \%$ of all the primary brain cancers [1]. Glioblastoma (GBM, WHO classification IV grade glioma), covers up to $54 \%$ of all gliomas and $16 \%$ of the total primary brain tumours [2]. The standard therapy relies on the Stupp protocol, officially proposed in $2005[3,4]$. The Stupp protocol is based on tumour surgical resection, followed by postoperative radiotherapy (RT), 60 Gy/30 fractions as standard, and concomitant plus adjuvant Temozolomide (TMZ) treatment [5]. Despite an increase in overall survival, the prognosis remains poor because of the development of GBM resistance to TMZ [6]. Alternative treatments are under evaluation, but the high intra- and inter-tumour heterogeneity of GBM and its intracranial localisation make the development of new therapies for this tumour a big challenge [7]. An important role in lesion heterogeneity is played by the tumour microenvironment (TME), composed by different cell populations, as immune cells, fibroblasts, precursor cells, endothelial cells, signalling molecules, and extracellular matrix (ECM) components [8,9]. In recent years, the use of new epigenetic molecules, such as non-coding RNA and microRNAs (miRNAs), has emerged 
in GBM characterization [10]. miRNAs are small non-coding RNA, able to modulate the level of expression of their mRNA targets at the post-transcriptional level, influencing in this way all cancer hallmark functions [11]. These molecules could be isolated in human tissues as well as in biofluids (saliva, urine, tears, cerebrospinal fluid, etc) and could represent tumor biomarkers thanks to their cell-specificity, expression, and stability [12,13]. In GBM, miRNAs represent potential biomarkers for the diagnosis, prognosis, and prediction of therapeutic response [14-16]. In addition, modulation of miRNA expression represents a suitable target for the development of new therapeutic tools [17]. The high heterogeneity and biochemical complexity of GBM make the development of preclinical models that recapitulate human disease a crucial issue [18]. In this context, the availability of non-invasive techniques that allow the longitudinal monitoring of tumour modifications during growth or under treatment is relevant for a better characterization and comparison of animal models representing patients [19]. Magnetic Resonance Imaging (MRI) represents state-of-the-art processes in the diagnostic management of glioma [20]. On the other hand, in vivo Positron Emission Tomography (PET) molecular imaging, associated with selected radiopharmaceuticals, allows the in vivo evaluation of specific biological features of the tumour and of its microenvironment at both clinical and preclinical levels [21]. In this review, molecular and cellular mechanisms involved in GBM resistance will be presented and discussed with the potential use of an in vivo multimodal imaging approach for the in vivo monitoring of morphological and molecular modifications in tumour cells and in the surrounding tissues and their association with response, resistance, or relapse to therapy.

\section{Glioblastoma Cell Heterogeneity, Mutations, and Models}

The morphology and biology of GBM present several challenges for treatment development, including infiltrative growth, pathological angiogenesis, the presence of necrotic regions that favour treatment resistance, and lesion relapse or recurrence [22-24]. One of the biggest issues is represented by inter and intra-tumour heterogeneity [25]. As described by Patel et al., a heterogeneous population of cells with different gene expression profiles rules GBM and this heterogeneity has been described also within the same lesion [26]. In addition, chemotherapy selects drug resistant cells that progressively replace the sensitive clones [27]. Recent advances in single-cell RNA-sequencing techniques have revealed the genomic landscape of GBM; indeed, GBM usually presents different genetic alterations that drive aberrant development programs and make GBM cells different between each other [28]. In particular, GBM is a hierarchically arranged tumour where cancer stem-like cells (CSCs) receive critical support signalling from their microenvironment [29]. The CSCs lodge in perivascular niches where the close adjacency to the endothelial vascular cells favours their stem cell-like state [30]. However, another stem-like tumour cell subpopulation resides in hypoxic regions far to the blood vessels, because of their capability to adapt to a low oxygen microenvironment, as recently reviewed by Najafi M et al. [31-33]. Tumour stem, non-stem, and normal cells incur in a communication stream to provide signals for the supporting of the cell state [34]. Differentiated progeny and blood vessels stimulate CSC maintenance through the production of cytokines, nitric oxide, Notch ligands, and the extracellular matrix [35-38]. CSCs are not passive receivers of microenvironmental stimuli, indeed CSCs support angiogenesis through angiogenic growth factor signalling, lead the differentiation of progeny, and regulate lineage plasticity toward vascular pericytes $[39,40]$. The CSC plasticity state is, therefore, influenced by the cellular microenvironment which couples autonomous and extrinsic cues [41]. In addition, GBM exhibits an exclusive tumour microenvironment that regulates immunity response, growth stimuli, invasion, and adaptation to hypoxia [42]. For these reasons, there is the need for a deeper comprehension for the genetic and epigenetic switches that promote GBM heterogeneity to better understand tumour development and the clinical outcome of specific patients' subpopulations. Several studies that investigated GBM heterogeneity by single-cell RNA-sequencing strongly suggest that cellular heterogeneity in GBM is closely related to gene expression programs that are normally active during neurodevelopment [43-45]. Indeed, the GBM cell differentiation state often reflects a hybrid condition with similarity to various neuronal lineages [46]. An important 
question that arises from this is whether partial similarity to a neurodevelopmental cell line also implies that GBM cells preserve the phenotypes and functions of their healthy counterparts [47]. Bhaduri and colleagues have addressed this question investigating GBM heterogeneity by single-cell RNA-sequencing and dissecting its cellular composition. The authors observed that individual GBM tumours have heterogeneous cellular organization, with sub-populations of cells which partially recapitulate the expression programs of glial and neuronal lineages at various degrees of differentiation. Several of these cellular subpopulations also expressed recognized markers for glioma stem cells [48]. Their findings are focused on a cluster of GBM cells that present similarities to outer radial glia (oRG) cells, expressing the oRG marker PTPRZ1 [49]. The oRG cells are widely known to be neural stem cells involved in normal brain development, with an important migratory behaviour called mitotic somatic translocation (MST). The authors demonstrated that PTPRZ1 positive cells undergo MST and confirmed their role in the invasion of GBM cells, suggesting that this mechanism of normal oRG migration is active in a subset of GBM cells and may promote their invasion into brain parenchyma [50].

Previous studies, realised on the patients-derived tumour tissue, led by The Cancer Genome Atlas (TCGA) and the Repository for Molecular Brain Neoplasia Data (REMBRANDT) have grouped genomic, transcriptomic, and proteomic data which were annotated with clinical and, in some cases, MRI data [51,52]. These projects allowed glioblastomas to be grouped at the level of RNA expression. A recent report published in Science by Puchalski et al. introduced the Ivy Glioblastoma Atlas, a free accessible online database that correlates the molecular and anatomical features of GBM and provides a precious resource to investigate tumour heterogeneity [53]. Indeed, single cell RNA sequencing showed that glioblastoma subtype biomarkers are variably expressed at cellular levels within the same tumour. Importantly, this work also defined the potential prognostic implications of intra-tumour heterogeneity, adding an anatomical point of view to these approaches. The Atlas was based on 42 glioblastomas that had been resected from 41 patients. Histopathological assessment and RNA in situ hybridization were performed on the whole cross sections of the tumour samples, by laser microdissection, and were separated in five anatomical areas with differential profiles. The areas were classified into infiltrating tumour, cellular tumour, leading edge, pseudo-palisading cells around necrosis (PAN), and microvascular proliferation (MVP) [26]. The most representative prognostic marker to be investigated in the Atlas was the O6-methylguanine-DNA-methyl transferase (MGMT) promoter hypermethylation, which is overexpressed in the tumour tissue and is considered essential for the GBM cellular organisation network [54]. MGMT overexpression confers resistance to alkylating agents and its function is inhibited by MGMT promoter hypermethylation [55]. Nevertheless, several tumours show resistance to treatment despite the detectable hypermethylation of the MGMT promoter and one possible explanation resides in intratumor heterogeneity that limits the results obtained by tissue sampling [56]. Moreover, the detected pathways from the results of the Ivy Glioblastoma Atlas suggest that different pathways are involved, including that of neuronal development in the leading edge, precursors differentiation in the cellular tumour, the hypoxia inducible factor (HIF) system in PAN, and the tumour necrosis and HIF in MVP, which also displayed a hyperactivation of $\mathrm{PI} 3 \mathrm{~K} / \mathrm{AKT} / \mathrm{mTOR}$ signalling [53].

Theoretically, the tumour complexity and the low survival time after GBM diagnosis requires an opportune platform for tumour modelling and therapy testing. Nowadays, preclinical models include cell lines, organoids, xenografts, and genetically engineered mouse models [57]. Conventional GBM models regard either in vitro cell culture models, which do not recapitulate the heterogeneity of the primary tumour and lack the TME, or in vivo animal models that are logistically complex and limited by across species variations including genetically engineered models [58-60]. Patient-derived xenograft (PDX) models from human GBM are actually considered the most accurate strategy to study in vivo cancer cells' environmental interactions. However, the use of PDX models is often hampered by donor availability, limited propagation, and lack of a functional immune system [61].

An emerging alternative, that may integrate the advantages of both of these classical approaches, is represented by the organoids generated from human samples. In 2016, Hubert et al. generated 
Organoid-derived Glioblastoma xenografts (GBOs), using patient-derived glioma stem cells (GSCs) and induced Pluripotent Stem Cells (iPSCs) to recapitulate tumour invasion, hypoxic gradients, and tumour stem cell heterogeneity using an updated procedure [62]. Afterwards, in two recent studies of Ogawa et al. and Linkous et al. human cerebral organoids were generated, adapting the culture method of Lancaster and Knoblich, and subsequently combining patient-derived GSCs with human embryonic stem cells (hESCs), in order to generate a cerebral organoid-derived glioblastoma model (GLICO). Although promising, these models lack the in vivo microenvironment, neuronal circuits, vascular circulation, and immune system [63-65]. To address this problem, Mansour et al. observed that only organoids developing vascularization can survive, following implantation into immunodeficient mice. To provide a vascularised and functional in vivo model of brain organoids, they established an efficient engraftment method using iPSCs cells. The authors demonstrated that the combination of human neural organoids and an in vivo physiological environment into the adult mouse brain may better reproduce the disease model [66]. In a recent study, Jacob et al., through single cell RNA sequencing and histopathology assays, confirmed the observations of Mansour et al. on in vivo GBO models, such as hypoxia gradients, vasculature, TME composition, mutations, and cell heterogeneity of parental tumours, generating a living GBO biobank thus making an attractive preclinical model to reproduce the lesion biology of patients [67].

\section{MicroRNA and GBM Microenvironment}

MiRNAs are an endogenous class of about 20 nucleotides in length non-coding RNAs which are very abundant in the cells, with several regulatory functions. Indeed, miRNAs have a main role in the regulation of mRNA transcription by silencing or the degradation of target sequences. The complementarity of the mature miRNA sequence and the seed sequence (i.e., the sequence recognised by the miRNA on its putative target) determines the physiological role of the miRNA within the cell. Therefore, on the basis of the complementarity of the miRNA sequence with that of the seed sequence, the formation of a double strand allows the degradation of the target mRNA or its silencing due to the translation block $[68,69]$. The expression level of a selected miRNA could be easily determined by real time-PCR (RT-PCR) amplification, either on a tissue biopsy sample or on human biofluids [70,71]. Furthermore, in situ hybridization could be helpful in the localization of a specific miRNA inside the cells or tissues and in its quantification [72]. This feature allows miRNAs to be used either as diagnostic or prognostic biomarkers able to indicate the course of the pathology [73]. Moreover, the possibility of exogenous modulation on miRNAs makes them interesting molecules as a potential therapeutic target. Indeed, in vitro experiments on cell lines using synthetic oligonucleotides with a reverse and complement sequence of a miRNA could be used as an antisense sequence, to silence an endogenous molecule [74]. Vice versa, if a GBM has a decreased miRNA, the use of a synthetic sequence "mimicking" the silenced miRNA could re-establish its expression level, preventing the further development, growth, or metastasis of the GBM cells [17].

The main challenge in miRNA use is to identify the correct single or group of miRNAs with a primary role in GBM onset, development, or response to therapy. Bioinformatics in silico analyses help the biologists in the selection of miRNAs with a differential expression in GBM compared to normal tissues (diagnostic miRNAs) or those with a differential expression in different grade of the pathology, or those able to predict the prognosis of the patients (prognostic miRNAs) [75]. For instance, in 2013 Moller and colleagues proposed a miRNA signature of 256 upregulated miRNAs (notably miR-10b, miR-17-92 cluster, miR-21, and miR-93) and 95 downregulated miRNAs (including miR-7, miR-34a, miR-128, and miR-137) for the diagnosis of GBM [76,77]. Furthermore, individual miRNAs have been correlated with different glioma stages, such as in a work of Malzkorn and colleagues, where 12 upregulated miRNAs (miR-9, miR-15a, miR-16, miR-17, miR-19a, miR-20a, miR-21, miR-25, miR-28, miR-130b, miR-140, and miR-210) and two downregulated miRNAs (miR-184 and miR-328) were found to be associated to the spontaneous progression of GBM from the WHO grade II to the WHO grade IV [78]. 
Each miRNA could regulate more than a hundred targets and as a single mRNA could be the target of more than one miRNA, this creates a complicate regulatory network that impacts on several hallmark functions of different tumours, including GBM [79]. This regulatory network could possibly also affect the extracellular space, as several miRNAs could be secreted in the surrounding environment, including in cerebrospinal fluids, tears, saliva, or blood/serum [80]. This makes miRNAs important molecules for the intercellular or tissue communication, together with cytokines and chemokines [81]. The exact mechanism of miRNA secretion is not clear, but some hypotheses identify cells and apoptotic bodies as a source of secreted miRNAs; gap junctions, exosomes, extracellular vesicles, and tunnelling nanotubes were described in many tumours as possible passages for miRNAs from cell to cell [82].

Regarding the communication of a GBM cell with the surrounding environment, several miRNAs released from GBM are able to influence the angiogenesis. This process favours the tumour growth and potentially its invasion and metastasis. The increase in tumour mass can generate hypoxic areas, in which cellular metabolism also changes in relation to the surrounding microenvironment. Increased vascular endothelial growth factor (VEGF) release and other pro-angiogenic factor levels stimulate endothelial cell proliferation and the formation of leaky blood vessels, which are ineffective in supplying oxygen and chemotherapy, thus promoting hypoxia and the development of treatment resistance [83].

Several miRNAs have been described to have a role in angiogenesis. We summarized some of them in Table 1. For example, miR-613 was decreased in glioma cells and in vitro experiments revealed that its overexpression suppressed invasion, proliferation, and angiogenesis. Vascular endothelial growth factor A (VEGFA) was found as one of the targets of miR-613; in GBM the loss of miR-613 caused increased levels of VEGFA, which, in turn, led to increased angiogenesis [84].

On the contrary, miR-26a is amplified in GBM, where it has a main role in glioblastoma stem cell control: in this population, miR-26a is highly expressed and secreted by exosomes. These structures transport miR-26a into microvascular endothelial cells, where it silences PTEN expression, activating the PI3K-Akt pathway [85].

The miR-9 is also frequently up-regulated in glioma cells, where it enhances cell proliferation, migration, invasion, and new vessel formation, possibly by the inhibition of COL18A1, THBS2, PTCH1, and PHD3 and the promotion of the HIF-1 $\alpha$ /VEGF signalling pathway [86]. Moreover, its target RGS5 plays a central role in vascular growth [87]. The silencing of RGS5 by siRNA treatment or by miR-9 overexpression, such as in GBM, stimulates endothelial growth [88]. The glioma microenvironment is mainly composed of microglia, astrocytes, and macrophages [89]. These cells represent the brain immune system displaying different homeostasis functions and regulating synaptic activity by the production of cytokines, chemokines, growth factors, and metabolites [90]. Few studies demonstrated the correlation between the number of microglia/macrophage cells and glioma, describing an activated state morphology particularly for the high-grade [91-93]. This population has been defined as glioma-associated microglia/macrophages (GAMMs) and could be influenced by the tumour microenvironment to support invasion [94].

Glioma cells produce IL-1, a potent inducer of angiogenesis and invasion, that in glial cells strongly upregulates miR-155 implicated in inflammation-mediated cancer development [95]. Other IL-1-induced miRNAs involved in inflammation are miR-21 and miR-146, upregulated in gliomas [96]. On the contrary, miR-146 is a negative regulator of astrocyte-mediated inflammation, migration, and invasion, and it decreases the expression of TRAF6 and MMP16 [97,98]. 
Table 1. Some of the miRNAs involved in angiogenesis in Glioblastoma (GBM) (publications of the last 5 years).

\begin{tabular}{|c|c|c|c|c|}
\hline miRNA & GBM Expression Level & Function & Target & References \\
\hline miR-7 & Down & Inhibits angiogenesis & EGFR, IRS-1, IRS-2, FAK, OGR & [76] \\
\hline miR-296 & Up & Promotes angiogenesis & HGS & [99] \\
\hline miR-15b & Up & Inhibits angiogenesis & $N R P-2$ & {$[100,101]$} \\
\hline miR-93 & $\mathrm{Up}$ & Promotes angiogenesis & Integrin B8 & [102] \\
\hline miR-16 & Down & Inhibits angiogenesis & BMI-1 & [103] \\
\hline miR-613 & Down & Inhibits angiogenesis & VEGFA & {$[84]$} \\
\hline miR-26a & $\mathrm{Up}$ & Promotes angiogenesis & PTEN and PI3K/Akt & [85] \\
\hline miR-9 & $\mathrm{Up}$ & Promotes angiogenesis & COL18A1, THBS2, PTCH1 and PHD3; HIF-1 $\alpha /$ VEGF & [86] \\
\hline miR-9-5p, miR-22-3p, miR-182-5p & Up & Promotes angiogenesis & $R G S 5, S O X 7$, and $A B C B 1$ & [104] \\
\hline miR-126/126-3p & Down & Inhibits angiogenesis & epidermal growth factor-like protein 7 (EGFL7) & [106] \\
\hline miR-124-3p & Down & Inhibits angiogenesis & NRP-1/GIPC1 pathway & [107] \\
\hline miR-129-5p & Down & Inhibits angiogenesis & WNT5a & [108] \\
\hline $\operatorname{miR}-378$ & Up & Promotes angiogenesis & VEGFR2 & [109] \\
\hline $\operatorname{miR}-518 \mathrm{~b}$ & Down & Inhibits angiogenesis & platelet-derived growth factor receptor $\beta$ (PDGFRB) & [110] \\
\hline $\operatorname{miR}-29 b$ & Up & Promotes angiogenesis & $B C L 2 L 2$, which in turn regulates $A n g-2$ and $V E G F$ & [111] \\
\hline miR-520d-5p & Down & Inhibits angiogenesis & Pituitary Tumour Transforming Gene 1 (PTTG1) & [112] \\
\hline miR-148a and miR-31 & Up & Promotes angiogenesis & $\begin{array}{l}\text { factor inhibiting hypoxia-inducible factor } 1 \text { (FIH1), and } H I F 1 \alpha \\
\text { and Notch. }\end{array}$ & [113] \\
\hline
\end{tabular}




\section{Chemoresistance and Treatments}

\subsection{Resistance to Temozolomide}

Lack of response to TMZ may be present from the beginning of therapy or acquired during the treatment. The reasons are complex and only partially known, but a non-complete response favours tumour relapse and recurrence [114]. The MGMT promoter methylation status is a key parameter for counteracting TMZ cytotoxicity. Low MGMT promoter methylation entails a higher enzyme activity, a phenomenon which helps to acquire resistance to TMZ [115].

Cells lacking MGMT or which have defective Homologous Replication (HR) are responsive to TMZ treatment [116]. For this reason, MGMT is indicated as a biomarker for TMZ treatment response in a clinical setting [116-119].

Another mechanism by which TMZ affects DNA repair systems is mediated by N3-methyladenine and N7-methylguanine adducts, which are Base Excision Repair process (BER) targets. In fact, these residues induce Poly (ADP-ribose) polymerase (PARP) nuclear enzyme activation, which, by the PARylation (poly-ADP-ribose chain synthesis), recruit three components on the DSBs areas (XRCC1, pol-beta, and DNA ligase), by triggering the BER activation [120]. Since the PARP plays a key role in the BER mechanism, PARP inhibitors (PARPi) have been proposed and studied in combination to TMZ treatment for overcoming the currently defined resistance to TMZ [121].

Briefly, in a recent study of Higuchi et al., TMZ sensitivity has been restored by treating mismatch repair mechanism (MMR)-deficient resistant gliomas with PARPi by a BER-independent mechanism [120].

Beyond DNA, post-translational modifications on histones are also able to play a pivotal role in mediating gene expression, and this phenomenon might help to elucidate why MGMT is not always an efficient response biomarker to TMZ treatment. In fact, in a work of Chen et al. in 2018, an enhancer was described to activate MGMT gene expression, despite its highly methylated promoter. In detail, they have identified an enhancer sequence positioned between the promoters of MGMT and of Ki67 (a widely recognised marker of cell proliferation, also in GBM) which was able to activate not only MGMT expression but also Ki67 expression, by favouring GBM proliferation, both in vitro and in vivo. Moreover, the authors have also shown that the acetylation levels of the nucleosome H3K27, which borders the K-M enhancer, are capable of promoting MGMT expression in spite of its methylated promoter. They have observed the abrogation or the delay of resistance to TMZ treatment through the inhibition of the K-M enhancer [122].

Another important factor involved in resistance to TMZ is represented by the BER system activity, which counteracts cytotoxic effects of TMZ: when BER is abrogated, TMZ is able to exert its cytotoxic power [123]. This year, Belter et al. have shown that TMZ is able to totally augment the rates of the main epigenetic marker contained in tumour cells' DNA, the 5-methylcytosine (m5C), in different GBM cell lines, by inducing a cellular hypermethylation state. During the reaction, S-adenosyl methionine (SAM) results in the unique Alkyl residues donor [124].

TMZ, beyond its alkylating effect, is able to induce other cellular mechanisms, such as the Endoplasmic Reticulum (ER) stress, Reactive Oxygen Species (ROS) production, and autophagy activation [125]. The tight relationship between the ER-stress and chemoresistance to TMZ has been already described, since TMZ toxicity also relies on promoting the chaperone protein folding role and on enhancing the degradation pathways, as the ER-mediated and the autophagic ones [126].

In a recent work, GBM MGMT-deficient cells with acquired resistance to TMZ treatment showed increased expression of dynein, cytoplasmic 2, heavy chain 1 (DHC2 or DYNC2H1), which is strictly related to TMZ-mediated cytoskeletal rearrangements [127].

In another recent study, the role of the bradykinin-bradykinin receptor B1 (BDKRB1) axis has been shown to modulate some GBM genes and pathways, as the Aquaporin-4 (AQP4/aqp4) expression and the calcium release within the cytosol. This process leads the mitogen-activated protein kinase (MAPK) pathway activation. The authors have demonstrated that the bradykinin/BDKRB1 increased 
the aqp4 expression through BDKRB1 mediated Ca2+ influx, which induces MEK4 phosphorylation and, consequently the downstream ERK1/2-NF-KB induction both in vitro and in vivo in human and murine cells. Overall, these data have suggested the key-role of bradykinin-BDKRB1-aqp4 action on cytoskeleton and morphological changes, as GBM oedema formation and its invasive and migratory power [128].

\subsection{Pharmacological Strategies to Overcome GBM Resistance}

Several therapeutic strategies have been developed in order to prolong patients' overall survival (OS) and to overcome GBM resistance. Some of these therapies have completed clinical trials or are under clinical evaluation alone or in combination with TMZ; others are still confined to a pre-clinical scenario.

The angiogenic inhibitor Bevacizumab (a humanized monoclonal antibody targeting VEGF) has been approved by the Food and Drug Administration (FDA), but not by the European Medicines Agency (EMA), for patients with recurrent GBM. Despite the initial expectation based on the mechanism of action of the drug, no effect on OS, and only an increase of response rate in a subset of patients has been reported [129]. However, in a phase III clinical trial (EORTC 26101), the addition of Bevacizumab to Lomustine in $432 \mathrm{GBM}$ patients previously treated, showed an increase in the time to disease progression or death compared to Lomustine alone (median progression-free survival $=4.2 \mathrm{vs}$. 1.5 months, $\mathrm{HR}=0.52,95 \%$ confidence interval $=0.41-0.64)[130]$.

Lomustine is a cross-linking agent able to produce amino acid carbonylation. In a recent study, Herrlinger et al. showed in a phase III randomized trial that Lomustine (CCNU) associated with RT/TMZ prolonged OS in comparison with an RT/TMZ standard regimen (median OS of 48.1 months versus 31.4 months, respectively) [131,132].

Lomustine has been recently evaluated in patients with recurrent GBM in combination with regorafenib (REGOMA), an inhibitor of angiogenic, stromal, and oncogenic receptor tyrosine kinase. Regorafenib plus Lomustine increased patients' overall survival, being 7.4 months (95\% CI 5.8-12.0) in the regorafenib group and 5.6 months (4.7-7.3) in the Lomustine group [133].

The block of hyperactivated Epidermal Growth Factor Receptors (EGFRs) represents another potential strategy. Specific interaction between Nimotuzumab, a humanized anti-EGFR antibody, and the constitutively activated EGFRvIII receptor, was able to inhibit EGFR signalling intracellular cascade, thus abrogating tumour proliferation, angiogenesis, and chemoresistance. The drug has been evaluated in different clinical trials; however, its effect is still controversial [134]. Recently, Du and colleagues evaluated in a phase II trial (NCT03388372) the efficacy of Nimotuzumab associated with TMZ/RT and concomitant TMZ in patients with newly diagnosed GBM carrying EGFRvIII [135]. The median OS and PFS were 24.5 and 11.9 months, respectively. These data may be of interest for a phase III clinical randomized controlled trial [136].

The PARP family of enzymes is an attractive target for the sensitization of GBM to chemotherapy because of their activity on DNA repair and metabolism. PARP inhibitors (PARPi) have been evaluated in different clinical trials, in association with TMZ, for treating newly diagnosed and recurrent glioblastoma patients [120]. In preclinical studies the association of TMZ and Veliparib showed promising results in GBM models $[137,138]$. In addition, Veliparib increased the TMZ cytotoxic effect in the PDX of newly diagnosed GBM with high MGMT promoter methylation [139]. However, in a phase II clinical study, Veliparib added to an RT/TMZ standard treatment in unmethylated MGMT patients with newly diagnosed GBM resulted in no ameliorated outcomes compared to the standard regimen [140]. A phase III clinical trial (NCT02152982) in which this drug is added to TMZ in treating MGMT-methylated, newly diagnosed GBM patients, is still ongoing [141]. Another PARPi, Olaparib, has been included in a phase I dose escalation study (OPARATIC trial) in combination to the standard therapy in recurrent GBM patients. The results of the study have been encouraging, with $45 \%$ of patients showing a PFS at six months. At the moment, researches are focused on the identification of potential markers of treatment efficacy [142]. 
An emerging strategy is represented by oncolytic viruses. Kiyokawa et al. reported the preclinical efficacy of the combination therapy of TMZ with the oncolytic adenovirus DNX-2401 (also named Delta-24-RGD) [143]. This drug and other oncolytic viruses are currently undergoing clinical evaluation alone or in combination with other drugs (check-point inhibitors, as, for instance, Pembrolizumab alone or in combination with the Heat Shock Protein Peptide Complex-96, HSPPC-96) in phaseI/II trials. Despite the efforts, the results obtained so far are not encouraging [144-147]. The metabolism and immune system represent emerging targets, but mainly under preclinical or early clinical investigation. Check-point inhibitors, IFN- $\beta$ of human bone marrow derived-mesenchymal stem cells (MSC-IFN- $\beta$ ), the janus kinase (JAK) 1/2 inhibitor Momelotinib (MTB or even CYT387), or the biguanide Metformin, showed encouraging results when associated with TMZ or other molecules; however, clinical data, when present, are not definitive [148-154]. A list of the molecules cited above is reported in Table 2.

Table 2. The most recent molecules adopted in clinical and preclinical scenarios to treat GBM.

\begin{tabular}{|c|c|c|c|}
\hline Molecule & Cellular/Molecular Target & $\begin{array}{l}\text { Clinical Trial in } \\
\text { Glioma }\end{array}$ & References \\
\hline Bevacizumab * & VEGF & Phase III & {$[5,155-158]$} \\
\hline Lomustine * & Amino acid carbonylation & Phase III & {$[131,132]$} \\
\hline Nimotuzumab * & EGFRvIII & Phase II & {$[135,136]$} \\
\hline Veliparib/ABT-888 * & PARP & Phase II/III & [137-141,159] \\
\hline Olaparib * & PARP & Phase I & {$[142,160]$} \\
\hline DNX-2401/Delta-24-RGD * & $\mathrm{Rb}$ pathway-defective glioma cells & Phase I/II & {$[144,145]$} \\
\hline Pembrolizumab * & PD-1 & Phase I/II & {$[146,147]$} \\
\hline MSC-IFN- $\beta$ * & MGMT via p53 gene induction & & [148] \\
\hline Momelotinib/MTB/CYT387* & JAK $1 / 2$ & & [149] \\
\hline Metformin * & AMPK, p53, mTORC1, mtComplex I & Phase I/II & [150-154] \\
\hline Bevacizumab and Lomustine & $\begin{array}{l}\text { VEGF and Amino acid carbonylation } \\
\text { Amino acid carbonylation and }\end{array}$ & Phase III & {$[130]$} \\
\hline Lomustine and Regorafenib & $\begin{array}{l}\text { angiogenic, stromal, and oncogenic } \\
\text { receptor tyrosine kinases }\end{array}$ & Phase II & {$[133]$} \\
\hline Nivolumab & PD-1/PD-L1 & Phase II/III & [161-163] \\
\hline DS-100b & IDH1 & Phase I & {$[164-166]$} \\
\hline $\begin{array}{l}\text { Bevacizumab and } \\
\text { Pembrolizumab }\end{array}$ & VEGF and PD-1 & Phase II & {$[167,168]$} \\
\hline Anti-TIM-3 and Anti-PD-1 & TIM-3 and PD-1 & & [169] \\
\hline Anti-TIGIT and anti-PD-1 & TIGIT and PD-1 & & [170] \\
\hline
\end{tabular}

\subsection{Role of miRNAs in GBM Chemoresistance}

The current grading system, based on the histological classification, does not give any indication of the correct therapeutic approach for the patients [171]. The identification of drug sensitive patients with an affordable, reliable, and easy-to-use method could be helpful in addressing the patients to the right therapeutic option. In this view, miRNAs could be presented as indicative molecules for patient selection for a specific treatment. The choice of the right miRNA to be used as a drug-resistance associated molecule is still a challenge. The recent literature proposes several examples of miRNAs that could be used as potential biomarkers for the patients' classification.

Looking for "microRNAs and glioblastoma and chemoresistance" publications of the last five years in PubMed, we found 30 papers. Two have been shelved because they speak of long non-coding RNA, and one was withdrawn by the authors before the publication. Twenty-seven manuscripts were analyzed to understand the role of miRNAs in the chemoresistance development (summarized in Table 3 and Figure 1). Most of the publications describe the role of single miRNA in this process, without proposing a miRNA signature associated with chemoresistance. 


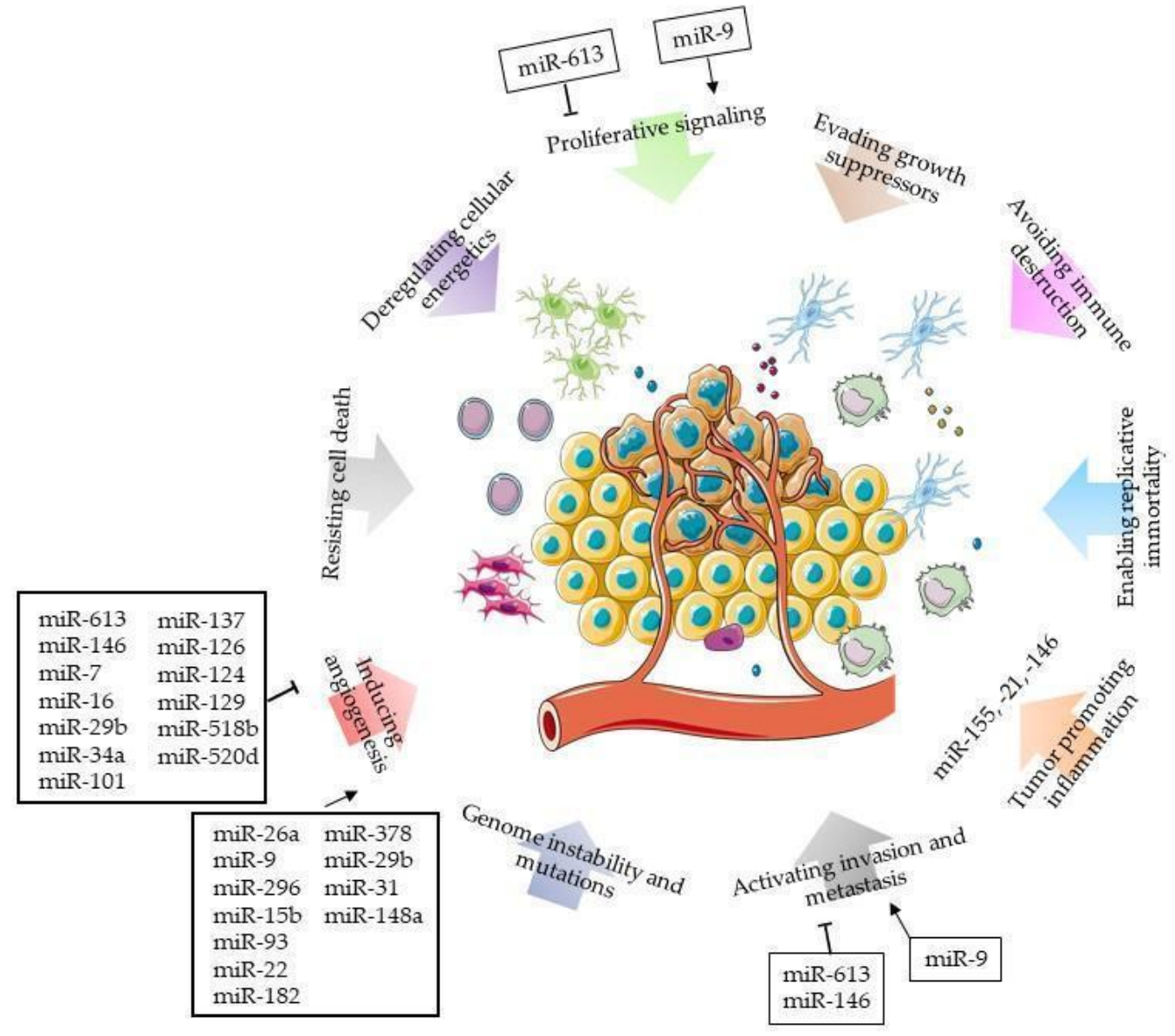

Figure 1. Role of miRNAs in GBM.

Several papers proposed a single miRNA with a role in the development of glioblastoma resistance to Temozolomide; one of the most frequent reported in the literature is miR-1238. This miRNA was found upregulated in TMZ-resistant glioblastoma cell lines and their exosomes, and in clinical tissues and sera of patients; its overexpression was able to modulate the CAV1/EGFR pathway. The presence of this miRNA in exosomes could influence the behaviour of the surrounding tissue, leading to the spreading of the resistant phenotype to surrounding tumour cells [172]. It has been already discussed that exosomal miRNAs allow the communication of the tumour cells to the neighbouring ones, as occurs with exosomal miR-151. Indeed, exosomal miR-151a enhances chemosensitivity to TMZ in drug-resistant GBM, possibly controlling XRCC4-mediated DNA repair. XRCC4 encodes for a vital protein of the double strand break repairing process: XRCC4 protein forms with DNA ligase IV a heterodimer that covalently joins the broken DNA ends to help cell survival. XRCC4 expression levels are found significantly downregulated in glioma tissue, indicating crucial roles of XRCC4 in brain carcinogenesis [173].

The exosomal communication among cells has been also been proven to increase the tumorigenicity of the glioma stem cells, by demonstrating the release of miR-1587 from glioma-associated mesenchymal stem cells [174]. This miRNA is able to inhibit the hormone receptor co-repressor-1 (NCOR1), a tumour suppressor of glioblastoma cancer stem cells, after extracellular vesicular transfers [82].

Indeed, chemoresistance to TMZ in glioblastoma could also be mediated by the presence of several CSCs, which are reported to be CD133+ cells. This population is associated with poor prognosis and resistance to chemotherapy [175]. In CD133+ cells deriving from T98G and U87MG tumours, miR-29a is significantly downregulated. The miR-29a overexpression improved sensitivity to cisplatin treatment in these cells and suppressed tumour growth in animal model of GBM [176]. A miRNA of 
the same family, miR-29c, has been demonstrated to be a sensitizer for TMZ treatment of resistant glioblastoma. Indeed, miR-29c targets specifically Sp1, thus reducing MGMT expression. In this way, the reduction of this enzyme allows the increased efficacy of TMZ treatment. The overexpression of miR-29c correlates with a good prognosis, suggesting the use of circulating miR-29c low levels as a prognostic biomarker of resistance [177].

The miR-423-5p, increased in glioblastoma, directly targets the nuclear protein Inhibitor of Growth 4 (ING-4). The inhibition of ING-4 leads to the upregulation of important signalling molecules, such as p-AKT and p-ERK1/2, strengthening glioma cell proliferation, angiogenesis, and invasion. The miR-423-5p overexpression, sustaining neurosphere formation and stemness, rendered glioma cells resistant to TMZ and increased p-AKT and p-ERK1/2 expression [178]. The same authors demonstrated that other miRNAs, let-7i, miR-151-3p, and miR-93, were downregulated in TMZ-resistant chinese GBM samples [179].

Recently, miR-126-3p expression has also been proposed as a modulator of GBM chemosensitivity. The authors found decreased expression of miR-126-3p in TMZ-resistant GBM tissues and cells. High levels of miR-126-3p, targeting SOX2 mRNA and blocking Wnt/ $\beta$-catenin signalling, enhanced TMZ sensitivity, inhibiting cell viability, reducing colony forming potential, and inducing apoptosis [180].

The same AKT/NF- $\mathrm{kB}$ pathway is also a final target of TMZ-upregulated miR-146b-5p [181]. By modulating the expression of tumour necrosis factor receptor-associated factor 6 (TRAF6) protein, miR-146b-5p enhanced the resistance against TMZ. TRAF6 is a signal transducer of TNFR family and Toll/interleukin-1 (IL-1) and its overexpression promotes the tumour cell proliferation in several solid tumours, i.e., breast, colon, and lung cancer [182]. TRAF6 is a known regulator of chemoresistance; it has been found upregulated in TMZ-resistant GBM tissues, and its overexpression increases the resistance of colon cancer cells to 5-Fluorouracil and to Bortezomib, respectively [183]. Overexpression of miR-146b-5p or TRAF6 knockdown significantly modulates the AKT/NF- $\mathrm{KB}$ pathway, decreasing the level of p-AKT and p-p65, activators of NF-KB [181]. The AKT/NF-KB pathway is involved in the regulation of autophagy, a process that emerging evidences suggests contributes to the development of TMZ resistance [184].

The pathway of PI3K/Akt is also target of miR-223: the exogenous expression of this miRNA promotes the survival of the cells exposed to TMZ by suppressing the PAX6 target gene, a known tumour suppressor in glioma cells $[185,186]$.

In computational analyses it was shown that miR-93 and -193 could target Cyclin D1, a major regulator of cell cycle progression. Indeed, this protein regulates the progression of the cells from $\mathrm{G} 1$ to $S$ phase. These two miRs also decreased cell cycling quiescence and induced resistance to TMZ [187].

The miR-7-5p has been described as a tumour suppressor in multiple cancers and it has been found significantly downregulated in TMZ resistant LN229 cells. Further experiments demonstrated that miR-7-5p has a role in the regulation of Yin Yang 1 (YY1), a transcription factor acting as a tumour promoter $[188,189]$. In glioblastoma, YY1 is able to interact with the NF- $\mathrm{kB}$ family member RelB, thus controlling both the proliferation of the cells as well as the pro-inflammatory cytokines leading to infiltration of glioma-associated macrophages [189]. The silencing of YY1 in cisplatin-resistant glioblastoma LN-229 cells was also obtained by overexpressing miR-186 which sensitizes the cells to drug treatment [190].

The miRNAs are also involved in the modulation of the hypoxia-induced autophagy process in different cancers. In glioblastoma, HIF $1 \alpha$ increase and miR-224-3p decrease were simultaneously observed. It has been described that HIF $1 \alpha$ knockout inhibited chemosensitivity by negatively regulating miR-224-3p expression under hypoxic condition, while hypoxia induced the expression of ATG5, a transcription factor possibly involved in the autophagic process. The researchers described a HIF-1 $\alpha /$ miR-224-3p/ATG5 pathway that, in hypoxic condition, could influence the chemosensitivity of LN-229 cells to TMZ both in vitro and in the animal model [191]. 
Another miRNA involved in the control of autophagy is miR-519a. In U87 cells, made resistant to $\mathrm{TMZ}$, it was found downregulated in comparison to the parental cell line. The exogenous overexpression of miR-519a dramatically enhanced TMZ-induced autophagy and apoptotic cell death through the inhibition of the STAT3/Bcl-2/Beclin-1 pathway [192].

The miR-138 is also upregulated in TMZ-resistant GBM, both in cell lines and in human tissue samples. BIM mRNA is the direct target of this miRNA, and miR-138/BIM axis promotes cell survival after TMZ treatment by regulating the autophagy process [193].

Some miRNAs are modulated indirectly by TMZ treatment: DNA methyltransferase (DNMT) is downregulated in TMZ-resistant GBM and this effect reduced miR-20a promoter methylation, leading to upregulation of miR-20a in TMZ-resistant cells. Vice versa, methyltransferase overexpression increases TMZ-sensitivity of GBM cells, reducing miR-20a expression [194].

Another miRNA involved in the control of both chemoresistance and metastasis is miR-139, being able to control glial fibrillary acidic protein (GFAP) gene expression. GFAP encodes for a protein of the cytoskeleton, mainly expressed in the astrocytes. This protein is highly expressed in high-grade brain tumours and involved in aggressive phenotype [195]. The polymorphisms of GFAP, especially those affecting the miR-139 tumour suppressor seed, have been found and correlated with the malignant phenotype. Indeed, the lack of miR-139 binding on GFAP mRNA increases the expression of GFAP protein, which in turn favours the assembly and stabilisation of the cytoskeleton and increases the chemoresistance to cytotoxic drug [196].

Possible changes in miRNA processing, such as the dysregulation of miR-221/222 processing by apurinic/apyrimidinic endonuclease 1 (APE1) mRNA, could also impact on chemoresistance process. APE1 is a member of the base excision repair process; it acts as a master regulator of the cellular response to genotoxic damage. In response to oxidative damage, APE1 stimulates the DNA repair by promoting the initiation of transcription of SIRT1, of the multidrug resistance gene (MDR1) and the phosphatase and tensin homolog (PTEN) tumour suppressor $[197,198]$. The miR-221 and miR-222, belonging to a polycistronic cluster, are involved in the regulation of PTEN expression, and have been already associated with chemoresistance in breast and in lung cancer [199-201]. APE1, being able to bind double-stranded RNA, can bind a precursor form of miR-221/222, and the silencing of APE1 results in decreased maturation of the miR-221/222 cluster. Upregulation of APE1, leading to an increase in miR-221/222 cluster expression, has been associated with the development of radio-resistance, cancer growth stimulation and invasion by inhibiting PTEN and with the development of multidrug resistance and altered response to chemotherapy [200-203]. Thus, it seems that interfering with APE1/miR-221/222 cluster regulation could impact on the chemosensitization of the GBM cells.

The oestrogen responsive miR-191 has been correlated with the aggressive mesenchymal phenotype of GBM [204]. Its expression was found to be altered by the aromatase inhibitor Letrozol in glioma cells [205]. Aromatase enzymes are necessary for the synthesis of the oestrogen hormone which, after binding to oestrogen receptor (ER) alpha and beta, interacts with oestrogen responsive elements (ERE) in the promoter region of miR-191, mediating the chemoresistance effect observed in several cancers and in GBM. Letrozole treatment reduces oestrogen-mediated binding of the ER to the ERE, reducing miR-191 expression. The evaluation of miR-191 function as a potential anti-tumoral drug and as a sensitizer of GBM cells should be still evaluated [206].

miR-101 is significantly downregulated in TMZ-resistant GBM cells (TMZ resistant forms of U251 and A172) and human samples and over-expression of miR-101 sensitizes resistant GBM cells to TMZ through the downregulation of glycogen synthase kinase $3 \beta$ (GSK3 $\beta$ ). This gene encodes for an enzyme involved in the regulation of protein synthesis, glycogen metabolism, cell proliferation and survival, and chemoresistance [207]. Several studies show that GSK3 $\beta$ plays a critical role in the development and progression of various malignancies and that targeting GSK3 $\beta$ may represent a novel strategy for the treatment of chemoresistant cancers $[208,209]$. 
Table 3. UP- or DOWN-regulated miRNAs involved in chemoresistant GBM are listed, with their target mRNAs or processes.

\begin{tabular}{|c|c|c|c|}
\hline miRNA & Target mRNA or Process & In Chemo-Resistant GBM & References \\
\hline miR-1238 & CAV1/EGFR pathway & miRNA is UPregulated & [172] \\
\hline miR-151 and miR-151a & XRCC4-mediated DNA repair & miRNA is UPregulated & [173] \\
\hline miR-1587 & NCOR1 in glioma-associated mesenchymal stem cells & miRNA is UPregulated & {$[82,174]$} \\
\hline $\operatorname{miR}-29 a$ & cancer stem cells & miRNA is DOWNregulated & {$[176]$} \\
\hline $\operatorname{miR}-29 \mathrm{c}$ & Sp1, MGMT & miRNA is DOWNregulated & [177] \\
\hline miR-423-5p & ING-4, that controls p-AKT and p-ERK $1 / 2$; sustain stemness & miRNA is UPregulated & [178] \\
\hline miR-123-3p & SOX2, WNT/beta-Cat pathway & miRNA is DOWNregulated & [180] \\
\hline Let-7i, miR-151-3p, and miR-93 & unknown & miRNAs are DOWNregulated & [179] \\
\hline miR-146b-5p & TRAF6, AKT/NF-кB pathway & miRNA is DOWNregulated & {$[181,184]$} \\
\hline miR-223 & PAX, PI3K/Akt pathway & miRNA is UPregulated & {$[185,186]$} \\
\hline miR-93; miR-193 & Cyclin D1 and cell cycle progression & Both miRNA are UPregulated & [187] \\
\hline miR-7-5p; miR-186 & YY1, in the RelB pathway & Both miRNA are DOWNregulated & [188-190] \\
\hline miR-224-3p & HIF- $1 \alpha /$ miR-224-3p/ATG5 pathway & miRNA is UPregulated & [191] \\
\hline $\operatorname{miR}-519 a$ & STAT3/Bcl-2/Beclin-1 pathway & miRNA is DOWNregulated & [192] \\
\hline $\operatorname{miR}-138$ & miR-138/BIM axis and autophagy & miRNA is UPregulated & [193] \\
\hline miR-20a & Under the control of DNMT & miRNA is UPregulated & [194] \\
\hline miR-139 & GFAP in cytoskeleton & miRNA is DOWNregulated & {$[195,196]$} \\
\hline miR-221/222 & APE1/miR-221/222 axis regulates SIRT1/MDR1 and PTEN & miRNA is DOWNregulated & {$[197,198,200,201]$} \\
\hline miR-191 & Controlled by ER alpha and beta & miRNA is DOWNregulated & [206] \\
\hline miR-101 & GSK3 $\beta$ & miRNA is DOWNregulated & {$[207]$} \\
\hline $\begin{array}{c}\text { seven miRNAs' profile: } \\
\text { miR-1280, miR-1238, miR-938, and miR-423-5p; } \\
\text { let-7i, miR-151-3p, and miR-93 }\end{array}$ & & $\begin{array}{l}\text { miRNAs are Upregulated } \\
\text { miRNAs are DOWNregulated }\end{array}$ & [179] \\
\hline $\begin{array}{l}\text { seven miRNAs' profile: } \\
\text { miR-9, }-182 \text {, and }-221 ; \\
\text { miR-29c, }-93,-101 \text {, and }-130 a\end{array}$ & miR-101 controls GSK3 $\beta$ & $\begin{array}{l}\text { miRNAs are Upregulated; } \\
\text { miRNAs are DOWNregulated }\end{array}$ & [210] \\
\hline
\end{tabular}


An attempt of description of miRNA profiles able to select TMZ-sensitive from resistant GBM patients was proposed in two papers. In 2015, by in silico analysis, the authors proposed seven miRNAs, four of which (miR-1280, miR-1238, miR-938, and miR-423-5p) overexpressed in TMZ-resistant samples and three of which (let-7i, miR-151-3p, and miR-93) downregulated in TMZ-sensitive GBM human samples [179]. These miRNAs were used to classify an independent dataset of samples, demonstrating that two over seven are able to correctly classify TMZ-resistant patients. No hypothesis was made on possible miRNA targets, that could justify their different expression in TMZ-sensitive or -resistant cells. In 2016, another miRNA profile was proposed on U251 and A172, made resistant to TMZ. In this paper, the authors analyzed microarray results of these two cell lines and found common miRNAs, associated with TMZ-resistant phenotype. In particular, they found miR-9, -182 and -221 to be upregulated, while miR-29c, -93, -101, and -130a were to be downregulated. These results were confirmed in 12 TMZ-resistant human tumour samples compared to primary tumours. Focusing on miR-101, the in silico analysis of possible targets revealed that this miRNA could control the expression of GSK $3 \beta$, VEGF, and COX-2. In particular, the authors demonstrated that miR-101 is able to downregulate the serine/threonine protein kinase GSK3 $\beta$. The loss of miR-101, observed in TMZ-resistant cells, caused an increase in GSK3 $\beta$ expression, leading to drug resistance development and the inhibition of apoptosis. This regulation could be possibly due to the control of GSK3 $\beta$ on the methylation of the MGMT promoter. Loss of miR-101 was correlated with poor GBM patient prognosis [210].

\section{In Vivo Imaging for the Study of GBM Heterogeneity and Microenvironment}

Imaging techniques cover a pivotal role in the management of GBM patients [211]. In particular, in the clinical scenario the combinations of diffusion-weighted MRI (DWI-MRI) and amino acid-based PET techniques are challenging diagnostic procedures for the clinical management of patients. In addition, the multimodal MR-PET imaging offers new insights for a better understanding of GBM heterogeneity [212,213]. In a clinical setting, the conventional MRI sequences include: T1-weighted alone or with Gadolinium contrast agents (T1w-Gd) to evaluate the blood-brain barrier (BBB) permeability and tumour vascularization and T2-weighted and fluid attenuation inversion recovery (FLAIR) to define tumour oedema, border, and presence of necrosis [212]. Emerging techniques give complementary information. Diffusion-weighted MRI (DWI) provides information about the reorganization of cellular tissue and tumour invasion, by calculating the apparent diffusion coefficient (ADC) and its variant diffusion-tensor MRI (DTI) permits to distinguish the dominant white matter tracts through the tractographic information and to obtain and foresee the GBM invasive power. Perfusion-weighted imaging (PWI), with the perfusion acquisition modalities Dynamic susceptibility contrast (DSC) and Dynamic contrast-enhanced (DCE), furnishes data on cerebral blood flow and cerebral blood volume [214]. In addition, arterial spin labelling (ASL), using magnetically labelled arterial blood water protons as an endogenous tracer, is able to evaluate perfusion. Finally, MR spectroscopy (MRS) allows for the identification of the regional distribution of tissue metabolites [215]. However, despite advances in methodologies, the identification of necrosis, tumour margin, recurrence, and grading still represents a critical issue [216]. The use of PET and selected radiopharmaceuticals has allowed to image in vivo different biological features of tissue, such as glucose metabolism, cell proliferation, tissue hypoxia, inflammation, and matrix metalloproteinases that are associated with the tumour or tumour microenvironment. Here, are discussed the main cancer hallmarks relevant for GBM and TME and the potential use of radiopharmaceuticals for their in vivo measurement both at clinical and preclinical levels, after a research of the publications of the last five years in PubMed. Radiotracers and targets are summarized in Table 4. In the following paragraphs, different biological features of cancer and tumour microenvironment are described together with specific radiopharmaceuticals already available or under development for the in vivo imaging. 
Table 4. PET radiotracers for CNS tumours and tumour microenvironment.

\begin{tabular}{|c|c|c|c|}
\hline Imaging Target & Molecular Target & Radiotracer & References \\
\hline Glucose metabolism & GLUT-1; HK-1 & {$\left[{ }^{18} \mathrm{~F}\right] \mathrm{FDG}$} & [217] \\
\hline Glutamine metabolism & ASCT2 & {$\left[{ }^{18} \mathrm{~F}\right] \mathrm{F}-\mathrm{G} \ln$} & [218-220] \\
\hline & MCT; ACSS2 & {$\left[{ }^{11} \mathrm{C}\right]$ Acetate } & {$[221,222]$} \\
\hline $\begin{array}{l}\text { pathway/immune } \\
\text { tolerance }\end{array}$ & IDO1 & {$\left[{ }^{11} \mathrm{C}\right]$ AMT; L-1- $\left[{ }^{18}\right.$ F]FETrp } & {$[212,223-227]$} \\
\hline Aminoacids & LAT1/2 & $\begin{array}{c}{\left[{ }^{11} \mathrm{C}\right] \mathrm{MET} ;\left[{ }^{[8} \mathrm{F}\right] \mathrm{FET} ;\left[{ }^{18} \mathrm{~F}\right] \mathrm{FELP} ;\left[{ }^{18} \mathrm{~F}\right] \mathrm{FIMP} ;} \\
{\left[{ }^{18} \mathrm{~F}\right] \text { Fluciclovine }}\end{array}$ & [228-230] \\
\hline Cell proliferation & TK1 & {$\left[{ }^{18} \mathrm{~F}\right] \mathrm{FLT}$} & [231-236] \\
\hline Choline metabolism & CK & {$\left[{ }^{11} \mathrm{C}\right]$ Choline } & {$[237,238]$} \\
\hline Vasculature and hypoxia & $\begin{array}{c}\text { Tumor hypoxia } \\
\alpha_{V} \beta_{3} \text { ligand-binding domain }\end{array}$ & $\begin{array}{c}{\left[{ }^{64} \mathrm{Cu}\right] \mathrm{ATSM} \text {; nitroimidazole compounds; }} \\
\text { CAIX agents } \\
{\left[{ }^{64} \mathrm{Cu}\right] \mathrm{RaftRGD}}\end{array}$ & $\begin{array}{c}{[239-244]} \\
{[242]}\end{array}$ \\
\hline $\begin{array}{l}\text { Glioma associated } \\
\text { macrophages and } \\
\text { microglia (GAMMs) }\end{array}$ & TSPO & $\begin{array}{c}{\left[{ }^{11} \mathrm{C}\right](\mathrm{R}) \mathrm{PK} 11195 ;\left[{ }^{18} \mathrm{~F}\right] \mathrm{DPA}-714 ;} \\
{\left[{ }^{18} \mathrm{~F}\right] \mathrm{GE}-180 ;\left[{ }^{18} \mathrm{~F}\right] \mathrm{VC} 701}\end{array}$ & [245-253] \\
\hline $\begin{array}{l}\text { Endothelial } \\
\text { cells/astrocytes }\end{array}$ & PSMA & $\begin{array}{c}{\left[{ }^{68} \mathrm{Ga}\right] \mathrm{PSMA} ;\left[{ }^{18} \mathrm{~F}\right] \mathrm{DCFPyL} ;} \\
{\left[{ }^{89} \mathrm{Zr}\right] \mathrm{Df}-\mathrm{IAB2M} \text { anti-PSMA minibody }}\end{array}$ & [254-266] \\
\hline $\begin{array}{l}\text { Matrix-metallo } \\
\text { proteinases }\end{array}$ & $\begin{array}{l}\text { MT1-MMP (MMP-14); MMP-2; } \\
\text { MMP-9 }\end{array}$ & $\begin{array}{c}\left.{ }^{89} \mathrm{Zr}\right] \mathrm{ZFO}-\mathrm{LEM} 2 / 15 ;\left[{ }^{18} \mathrm{~F}\right] \mathrm{BR}-351 ; \\
{\left[{ }^{18} \mathrm{~F}\right] \text { iCREKA; }\left[{ }^{18} \mathrm{~F}\right]-\text {-FP-chlorotoxin; }} \\
{\left[{ }^{68} \mathrm{Ga}\right] /\left[{ }^{46} \mathrm{Cu}\right]-\mathrm{MMP}-14 \text { binding peptide }}\end{array}$ & {$[246,267-270]$} \\
\hline $\begin{array}{c}\text { Carcinoma-associated } \\
\text { fibroblast }\end{array}$ & FAP & {$\left[{ }^{117} \mathrm{Lu}\right] /\left[{ }^{68} \mathrm{Ga}\right] \mathrm{FAPI}-02 / 04$} & [271] \\
\hline
\end{tabular}

\subsection{Cancer and Metabolism}

Altered glucose metabolism is a characteristic of invasive cancers. Since 1927, Otto Warburg noticed that cancer cells preferentially converted glucose into lactic acid instead of pyruvate even in presence of sufficient oxygen, for this reason the "Warburg Effect" is also called aerobic glycolysis [272,273]. On this basis, 2-deoxy-2-[fluorine-18]fluoro-D-glucose $\left(\left[{ }^{18} \mathrm{~F}\right] \mathrm{FDG}\right)$ is the most used radiotracer in cancer; indeed, most cancers display increased glucose uptake and phosphorylation and there is a tight correlation between $\left[{ }^{18} \mathrm{~F}\right] \mathrm{FDG}$ uptake and cell viability [217]. Unfortunately, the brain tumour imaging represents a unique challenge because of the high background uptake due to normal grey matter which makes it very difficult to efficiently visualize with $\left[{ }^{18}\right.$ F]FDG PET [274].

Nevertheless, glioma shows several altered metabolic pathways which can be exploited with other markers to study cancer progression and to develop new metabolism-based therapeutic strategies [275]. Glutamine (Gln) is the second most abundant nutrient (after glucose) in blood circulation and supplies most of the carbon, nitrogen, and free energy and reduced equivalents necessary to support cell growth and division [276]. Gln is used by proliferating tumour cells to generate $\alpha$-ketoglutarate which can be metabolised through the tricarboxylic acid (TCA) cycle to generate oxaloacetate (OAA) [277]. Tardito et al., analysing the metabolic role of Gln in sustaining the growth both in vitro (in human established GBM cell lines, in primary GBM stem-like cells, and in normal astrocytes) and in vivo (xenograft murine models and in GBM patients), found a tight collaboration between cancer cells and astrocytes. Indeed, Glutamine Synthetase (GS) is found in the majority of human GBM and its expression is associated with poor prognosis $[278,279]$. GS expression is greatly variable in tumour cells ranging from negative to high as in normal astrocytes. GS-positive astrocytes and/or GBM cells (potentially GSC) excrete Gln that supports the growth of GS-negative GBM cells [278]. Using imaging, Gln metabolism can be visualized with PET and ${ }^{18} \mathrm{~F}-(2 \mathrm{~S}, 4 \mathrm{R}) 4$-fluoroglutamine $\left(\left[{ }^{18} \mathrm{~F}\right] \mathrm{F}-\mathrm{G} / n\right)$ or with Nuclear Magnetic Resonance (NMR) Spectroscopy [280]. In 2015, Venneti et al. characterised $\left[{ }^{18} \mathrm{~F}\right] \mathrm{F}-\mathrm{Gln}$ uptake both in healthy mice and in several orthotopic murine models of glioma. Compared to $\left[{ }^{18} \mathrm{~F}\right] \mathrm{FDG},\left[{ }^{18} \mathrm{~F}\right] \mathrm{F}-\mathrm{G}$ ln uptake was not observed in the brain of healthy mice and in animals with a permeable blood-brain barrier or neuroinflammation. On the contrary, $\left[{ }^{18} \mathrm{~F}\right] \mathrm{F}-\mathrm{Gln}$ was able to identify very well both glioma margin in different murine models and tumor reduction after five days of treatment with TMZ. In addition, $\left[{ }^{18} \mathrm{~F}\right] \mathrm{F}-\mathrm{Gln}$ avidity was observed in patients with the progressive disease [218]. The ability to visualize orthotopic glioma was also confirmed by other groups [219]. Clinical safety and pharmacokinetics in several tumours among glioma were also assessed. In particular, high-grade glioma with IDH 
mutation showed high uptake of $\left[{ }^{18} \mathrm{~F}\right] \mathrm{F}-\mathrm{G}$ ln. Moreover, authors observed that $\left[{ }^{18} \mathrm{~F}\right] \mathrm{F}-\mathrm{G} \ln$-avid tumours were uniformly $\left[{ }^{18} \mathrm{~F}\right] \mathrm{FDG}$-avid but not vice versa [220].

At the moment, using NMRS is possible to quantify the abundance of the glutamate and glutamine pool defined as Glx and it has been observed an increase in Glx in high grade glioma or in invasive regions [281,282]. In other studies, authors have investigated the relationship between the presence of the IDH mutation and the presence of Glx and they found an inverse correlation between the presence of the oncometabolite 2-hydroxglutarate (2HG) and a significant decrease of Glx [283,284]. Heiland et al. associated the presence of specific metabolites to the subtypes of GBM on the basis of the gene mutations, in detail clustering of normalised Glx (nGlx) revealed two groups: one with high nGlx being attributed to the neural subtype and one with low nGlx associated with the classical subtype [285]. Considering the great importance to specifically identify Gln metabolism, Hangel et al. set up a reconstruction method, patch-based super-resolution (PBSR), in association with 7T MRSI to separate the peak of glutamate to that of Gln [286].

Additional metabolic pathways that have received considerable attention in GBM are fatty acid synthesis (FAS) and fatty acid B-oxidation (FAO) $[287,288]$. In vivo studies performed in orthotopic mouse models of malignant glioma using ${ }^{13} \mathrm{C}$ show that acetate contributes over half of oxidative activity within these tumours $[289,290]$. Kant et al. observed that FAO "high" phenotype was enriched in mesenchymal tumours, whereas proneural tumours were mainly characterized by FAO "low" phenotype indicating that a specific treatment could be used based on the GBM phenotype [287]. In addition, inhibition of either fatty acid synthesis or beta-oxidation reduces proliferation of glioma cells [291,292]. [ ${ }^{11}$ C]Acetate is a radiotracer that is related to enhanced lipid synthesis and it is rapidly transported into cells through monocarboxylic acid transporters (MCTs) and metabolised into acetyl-CoA [293]. Kim et al. evaluated that $\left[{ }^{11} \mathrm{C}\right]$ Acetate PET/CT is able to differentiate between lowand high-grade glioma and, specifically, grade III from IV. Authors also found a correlation between the expression of acetylcoenzyme A synthetase (ACSS2), glioma grade and prognosis indicating ACSS2 as a potential drug target [221]. Finally, in a preclinical study Koyasu $S$ et al. reported that U251 tumours carrying a mutation in IDH1 gene (R132H) display a higher uptake of $\left[{ }^{14} \mathrm{C}\right]$ Acetate compared to U251 wt tumours [222].

In recent years, the tryptophan (TRP) metabolic pathway emerged as an important node both for the GBM progression and for resistance to therapy because it actively contributes towards immune suppression in particular in mesenchymal and classical molecular subtypes [294]. Tryptophan metabolism appears to play the most dominant role in immune tolerance in GBM, with over a two-fold increase in Tregs and a strong trend in decreased CD8+ T cells. TRP is an essential amino acid necessary for protein synthesis. The bulk of TRP is therefore available for metabolism via four pathways to produce physiologically important metabolites including serotonin, melatonin, tryptamine, and kynurenine (KYN). Over $95 \%$ of TRP is metabolized to KYN via the kynurenine pathway (KP). Through local TRP depletion and the production of the toxic metabolites, the KP fosters an immunosuppressive tumour microenvironment $[295,296]$. Three distinct enzymes are able to complete the initial and rate-limiting step of the metabolism of TRP to $\mathrm{N}$-formylkynurenine (NFK): indoleamine 2,3-dioxygenase 1 (IDO1), indoleamine 2,3-dioxygenase 2 (IDO2), and tryptophan 2,3-dioxygenase 2 (TDO2) [224]. IDO1 is expressed in a wide variety of cell types, including dendritic cells, endothelial cells, macrophages, fibroblasts, and mesenchymal stromal cells, as well as in neurons and in cancer cells themselves [297]. Moreover, as observed by Ozawa et al., IDO1 is also highly expressed in glioma stem cells [298]. Given the importance of the kynurenine pathway in numerous cancers, it is increasingly recognised as a prominent target for cancer imaging and therapy. Currently, radiotracer alpha- $\left[{ }^{11} \mathrm{C}\right]$ methyl-L-tryptophan $\left(\left[{ }^{11} \mathrm{C}\right] \mathrm{AMT}\right)$ is used for PET imaging of the IDO-mediated kynurenine pathway in clinical and preclinical research [223,224]. In two studies, Bosnyak et al. evaluated the ability of $\left[{ }^{11} \mathrm{C}\right] \mathrm{AMT}$ to differentiate between meningioma and grade II and grade III gliomas and the prognostic role of the radiotracer, finding that GBM patients with higher pre-treatment tumoral tryptophan uptake, expressed as tumour/cortex SUV-ratios, showed longer survival [225,299]. 
In two different studies, John et 1 . have used combined MRI and $\left[{ }^{11} \mathrm{C}\right] \mathrm{AMT}$ PET for discriminating non-enhancing GBM regions which are challenging to detect with MRI only. They have suggested the importance of the amino acid uptake as a key player in distinguishing metabolically active subregions in the tumour from the areas with necrosis and oedema, which correspond, respectively, to enhancing and non-enhancing tumour zones. In fact, GBM showed very heterogeneous regions within the tumour with high-uptake regions often extending into the non-enhancing brain with high cellularity and the non-resection of these areas predicted the site of post-treatment progression. Furthermore, they have suggested the high uptake of tryptophan in contrast-enhancing subregions as an independent imaging biomarker for detecting the prolonged survival in newly diagnosed GBM patients [212,226]. Guastella et al. observed that PDXs generated by injection in mice of GBM cells or tumour fragments derived from patients with different uptake of $\left[{ }^{11} \mathrm{C}\right] \mathrm{AMT}$ and expression of TRP pathway markers recapitulate the same TRP metabolic characteristics of the primary patient tumour underling as these models can be used to test new therapeutic approaches [224].

Nevertheless these interesting results, the use of $\left[{ }^{11} \mathrm{C}\right] \mathrm{AMT}$ is limited to a few PET centres due to its short half-life $(20 \mathrm{~min})$ and the complex radiosynthesis [300]. So, a number of fluorine-18 labelled tryptophan analogues have been developed for cancer imaging, among them L-1- $\left[{ }^{18} \mathrm{~F}\right]$ fluoroethyl-tryptophan (L-1- $\left.\left[{ }^{18} \mathrm{~F}\right] \mathrm{FETrp}\right)$. L-1- $\left[{ }^{18} \mathrm{~F}\right]$ FETrp uptake was tested in several cancer cell lines, both in vitro and in vivo, including 73C-glioma cells. Intracranial brain 73C-glioma transplanted mice confirmed the capability of L-1- $\left[{ }^{18} \mathrm{~F}\right] \mathrm{FETrp}$ to pass the BBB and to efficiently visualize the tumour suggesting that L-1- $\left[{ }^{18} \mathrm{~F}\right] \mathrm{FETrp}$ is a promising radiotracer for PET imaging of cancer [227].

The most widely used radiolabelled amino acid is the essential amino acid methionine, labelled with ${ }^{11} \mathrm{C}$, which is taken up by the L-type amino acid transporters (LAT) 1 (SLC7A5) and 2 (SLC7A8) and incorporated into the protein. $\left[{ }^{18} \mathrm{~F}\right]$ fluoroethyltyrosine (FET) is a substrate for LAT1 and LAT2 and is widely used in place of methionine considering that it has a longer half-life (109 $\mathrm{min}$ ) compared to that of C-11 (20 $\mathrm{min})$ [301]. Both radiotracers are able to visualise low and high glioma but with difficulty it is possible to differentiate them. The radioligand $\left[{ }^{18} \mathrm{~F}\right] 3^{\prime}$-deoxy- $3^{\prime}$-fluorothymidine (FLT), substrate of thymidine kinase that is overexpressed during S-phase of cell cycle, reflects cell proliferation [302]. Since $\left[{ }^{18} \mathrm{~F}\right]$ FLT does not cross intact the BBB, it does not accumulate in low-grade tumours or stable lesions but it is detectable in high-grade (grade III or IV) tumours with a disrupted BBB [303]. It is used for imaging early treatment response and for predicting clinical outcome in brain tumours [231]. It is widely used in preclinical research to evaluate early response to standard or new therapeutic approaches [232-236].

Because of enhanced cell proliferation and resulting elevated levels of cell membrane synthesis during tumorigenesis, choline metabolism is also involved in brain cancer. Choline is a precursor for the synthesis of the phospholipid components of the cell membrane. Cellular choline is phosphorylated by choline kinase (CK) yielding phosphocholine (PCho), which further reacts with CTP to yield $\mathrm{CDP}$-choline. The de novo synthesis (Kennedy pathway) of phosphatidylcholine (PC) then results from the reaction of CDP-choline with diacylglycerol. In the clinical setting, two imaging modalities allow for the examination of choline met abolism, namely proton magnetic resonance spectroscopy $\left({ }^{1} \mathrm{H}-\mathrm{MRS}\right)$ and PET using $\left[{ }^{11} \mathrm{C}\right]$ Choline. MRS provides non-invasive measurements of tissue concentrations of metabolites, such as total choline-containing compounds (tCho), total creatinine ( $\mathrm{tCr})$, and $\mathrm{N}$-acetylaspartate (NAA). Increased tCho levels result from elevated cell membrane turnover and cellular density [237].

Wehrl et al. performed a comparative in vivo study assessing tCho levels by MRS using chemical shift imaging (CSI) and $\left[{ }^{11} \mathrm{C}\right]$ Choline metabolism by PET with morphologic parameters, in a murine orthotopic glioma mouse model obtained with murine SMA-560 (spontaneous murine astrocytoma) glioma cells. Authors found an increase in $\left[{ }^{11} \mathrm{C}\right]$ Choline uptake in the tumour paralleled to a decrease in tCho levels. Only a small overlap between tumour volumes, as identified by CSI and PET, was found; in detail, CSI highlights the areas of high choline concentration, which seems to be localized to 
the tumour rim, whereas $\left[{ }^{11} \mathrm{C}\right]$ Choline PET identifies the regions of high choline turnover. Therefore, MRS and PET seems to give complementary information about choline metabolism [237].

MRS and DTI-MRI are used to identify metabolic changes in the invasive margin of glioblastomas and to monitor therapy response [281,304]. In a recent study, Takei et al. evaluated if PET with multi tracers was able to differentiate glioma according to the 2016 World Health Organization (WHO) classification of tumours of the CNS. $\left[{ }^{11} \mathrm{C}\right]$ Methionine, $\left[{ }^{11} \mathrm{C}\right] \mathrm{Choline}$ and $\left[{ }^{18} \mathrm{~F}\right] \mathrm{FDG}$ uptake was higher in the anaplastic astrocytoma (AA) IDH-wt group than in the IDH-mut group, whereas in GBM only $\left[{ }^{11} \mathrm{C}\right]$ Methionine and $\left[{ }^{11} \mathrm{C}\right]$ Choline uptake were significantly higher in IDH-wt group than in IDH-mut group suggesting that PET is able to differentiate IDH-wt and IDH-mut tumours [238].

\subsection{Cancer and Hypoxia}

Hypoxia is a key driver of tumour adaptation promoting tumour progression and resistance to therapy. In particular, hypoxia and hypoxia-related factors, such as HIF- $1 \alpha$, are associated with pseudo-palisading necrotic regions that protect stem cells niche, contributing to the aggressive profile of these tumours. HIF- $1 \alpha$ protein expression in glioblastoma promotes angiogenesis by inducing VEGF [305]. For these reasons, it is pivotal to have therapies that counteract this situation and imaging techniques that allow one to identify hypoxic regions within the tumour. In a systematic review, Raccagni et al. perform an overview on PET radiotracers dedicated to visualise hypoxia including $\left[{ }^{18} \mathrm{~F}\right]$-labelled nitroimidazole compounds $\left(\left[{ }^{18} \mathrm{~F}\right] \mathrm{FMISO}\right.$ and $\left.\left[{ }^{18} \mathrm{~F}\right] \mathrm{FAZA}\right)$, radiolabelled copper-ATSM complexes, Carbonic anhydrase 9 (CAIX) agents, and new generation tracers such as $\left.{ }^{18} \mathrm{~F}\right] \mathrm{EF} 5$ and $\left[{ }^{18} \mathrm{~F}\right] \mathrm{EF} 3,\left[{ }^{18} \mathrm{~F}\right] 3-\mathrm{NTR}$ and $\left[{ }^{18} \mathrm{~F}\right] \mathrm{HX} 4$ [239]. Among these, $\left[{ }^{64} \mathrm{Cu}\right] \mathrm{ATSM}$ results are very interesting for GBM. This radiotracer can be used both as an imaging and as a therapeutic agent, and it is considered as an independent prognostic biomarker of survival in high-grade glioma $[240,241] .{ }^{64} \mathrm{Cu}$ is a promising theranostic radionuclide owing to its suitable half-life $(12.7 \mathrm{~h})$ with multiple decay modes, including $\beta+(18 \%)$, which is used for PET imaging, $\beta-(39 \%, 0.95-1.4 \mathrm{~mm}$ tissue range), and Auger electron $(43 \%, \sim 126 \mathrm{~nm}$ tissue range), which are used for therapeutic radiation. Jin et al. in a GBM mouse model obtained with the injection in the right flank of U87MG human glioblastoma cells evaluated the intra-tumour distribution of $\left[{ }^{64} \mathrm{Cu}\right]$-cyclam-RAFT-c(-RGDfK- $)_{4}\left(\left[{ }^{64} \mathrm{Cu}\right] \mathrm{RaftRGD}\right)$, a radiotracer for $\alpha_{V} \beta_{3}$ integrin and $\left[{ }^{64} \mathrm{Cu}\right] \mathrm{ATSM}$ and their therapeutic efficacy. Mice were treated with 18.5 or $37 \mathrm{MBq}$ of $\left[{ }^{64} \mathrm{Cu}\right] \mathrm{RaftRGD}$ or $\left[{ }^{64} \mathrm{Cu}\right] \mathrm{ATSM}$, or a combination of both at a dose of $18.5 \mathrm{MBq}$ for each agent. Interestingly, the distribution of the two radiotracers was different but complementary. The single administration of $18.5 \mathrm{MBq}$ did not show any significant effect on tumour growth, whereas the combination of both at a dose of $18.5 \mathrm{MBq}$ inhibited tumour cell proliferation and prolonged mice survival versus the single treatment with $37 \mathrm{MBq}$ [242]. Similarly, Yoshii et al. in the same mouse model, tested the efficacy of different single doses of $\left[{ }^{64} \mathrm{Cu}\right] \mathrm{ATSM}(18.5,37,74,111$, or $148 \mathrm{MBq}$ or saline as a control) and of multiple administrations $(37 \mathrm{MBq} \times 4)$. Multiple administrations significantly inhibited tumour proliferation and increased survival also compared to the highest single doses, without causing haematological toxicity [243]. Recently, Peres et al. examined the biodistribution of $\left[{ }^{18} \mathrm{~F}\right]$ FMISO and $\left[{ }^{64} \mathrm{Cu}\right] \mathrm{ATSM}$ in an orthotopic GBM model obtained with the inoculation of $\mathrm{C} 6$ cells in male Wistar rats. $\left[{ }^{64} \mathrm{Cu}\right] \mathrm{ATSM}$ displayed a higher uptake in the tumour compared to $\left[{ }^{18} \mathrm{~F}\right] \mathrm{FMISO}$ and also a higher extension of the signal. $\left[{ }^{64} \mathrm{Cu}\right]$ ATSM localised in hypoxic regions where there was expression of pimonidazole marker, but also in non-hypoxic regions with high expression of CD68 and GFAP used to assess inflammation and astrogliosis [244].

\subsection{Cancer and Inflammation}

A large proportion of the tumour microenvironment consists of inflammatory infiltrate predominated by microglia and macrophages, which are thought to be subverted by glioblastoma cells for tumour growth [306]. Thus, GAMMs are logical therapeutic targets [307]. In addition to GAMMs, other inflammatory cells are present, such as tumour-infiltrating lymphocytes, neutrophils, and cancer-associated fibroblasts [308]. Inflammatory cells promote tumour growth, invasion, and 
tumour-to-therapy resistance thanks to the release of specific molecules and factors that favour anti-inflammatory activity (TGF-B, ARG1 and IL10), tissue remodelling and angiogenesis (VEGF, MMP2, MMP9). In addition, inflammatory cells influence glioma-stem cells through the release of the matrix metalloproteinase MMP9 [309].

The translocator protein (TSPO; $18 \mathrm{kDa}$ ) is a peripheral benzodiazepine receptor, composed of a transmembrane multimeric protein complex of $18-\mathrm{kDa}$, situated in the outer mitochondrial membrane. TSPO is widely distributed in most peripheral organs. In addition, TSPO is also minimally expressed in resting microglial cells in the healthy brain but is substantially upregulated in reactive astrocytes and predominantly during the microglia activation process, due to neurodegenerative and neuroinflammatory diseases [310]. Moreover, most glioma cells express the TSPO. Different studies demonstrated a positive correlation between TSPO expression and grade of malignancy and a negative correlation with survival [311]. The most used TSPO radiotracer is $\left[{ }^{11} \mathrm{C}\right](\mathrm{R}) \mathrm{PK} 11195$. Su et al. found that $\left[{ }^{11} \mathrm{C}\right](\mathrm{R}) \mathrm{PK} 11195$ uptake in high-grade gliomas was significantly higher than in low-grade astrocytomas and low-grade oligodendrogliomas. TSPO in gliomas was expressed predominantly by neoplastic cells, and its expression correlated positively with uptake in the tumours indicating that $\left[{ }^{11} \mathrm{C}\right](\mathrm{R}) \mathrm{PK} 11195 \mathrm{can}$ be used to stratify patients [245]. Considering the short half-life of ${ }^{11} \mathrm{C}$-labelled compounds, other new generations TSPO specific ligands have been developed, such as $\left[{ }^{18} \mathrm{~F}\right] \mathrm{DPA}-714$ and $\left[{ }^{18} \mathrm{~F}\right] \mathrm{GE}-180$. In a human glioma-injected mouse model, obtained after the injection in the brain of Gli36dEGFR-LITG, Zinnhardt et al. performed multi tracer imaging PET studies $\left(\left[{ }^{18} \mathrm{~F}\right] \mathrm{FET},\left[{ }^{18} \mathrm{~F}\right] \mathrm{DPA}-714\right.$, and $\left[{ }^{18} \mathrm{~F}\right] \mathrm{BR}-351$, this last for MMPs) to evaluate the inflammatory tumour microenvironment. Authors found that the three radiotracers only partially overlapped; glioma cells overexpressed TSPO contributing to the most of $\left[{ }^{18} \mathrm{~F}\right] \mathrm{DPA}-714$ uptake, but also infiltrating glioma associated myeloid cells (GAMs) showed an important TSPO and MMP expression [246]. In another study performed in patients with glioma, authors found a strong relationship $(\mathrm{r}=0.84, p=0.009)$ between the $\left[{ }^{18} \mathrm{~F}\right] \mathrm{DPA}-714$ uptake and the number and activation level of GAMs. TSPO expression was mainly restricted to human leukocyte antigen D related-positive (HLA-DR+) activated GAMs, particularly to tumour-infiltrating HLA-DR+ myeloid-derived suppressor cells and tumour-associated macrophages indicating that TSPO radiotracer could be useful to study tumour microenvironment [247]. At the same time, in a preclinical model obtained with human GBM cells from patient, $\left[{ }^{18} \mathrm{~F}\right] \mathrm{DPA}-714$ was able to detect glioma infiltration into the contralateral brain earlier than $\left[{ }^{18} \mathrm{~F}\right] \mathrm{FET}$. In parallel, DWI MRI provides microstructure information. Authors also found an abundance of CD11b+ GAMs inside and around the tumour [248]. We have recently developed and characterised a new TSPO radiotracer, $\left[{ }^{18} \mathrm{~F}\right] \mathrm{VC} 701$ in neuroinflammation models [249]. Similarly, in an orthotopic glioma model obtained with murine GBM cells, the GL261 ones, we observed an earlier TSPO uptake signal compared to $\left[{ }^{18} \mathrm{~F}\right] \mathrm{FLT}$ uptake (Figure 2).

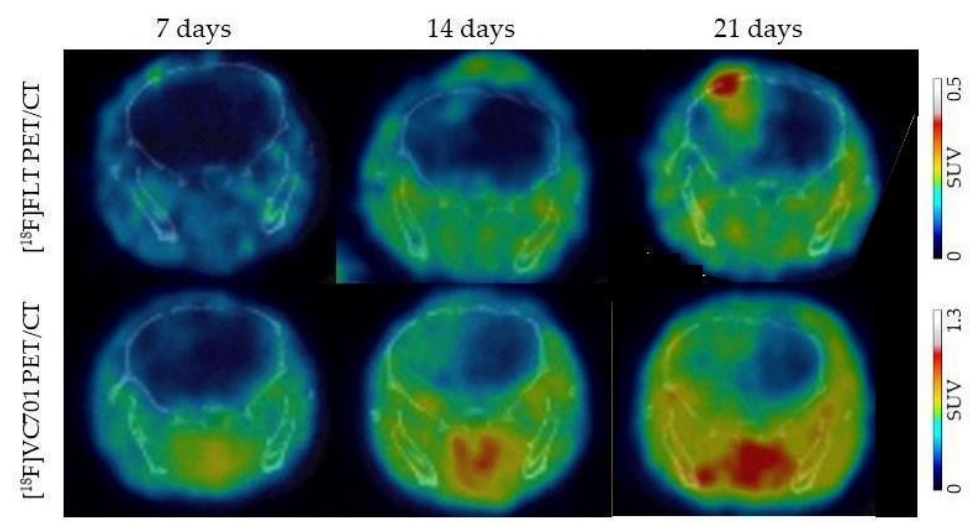

Figure 2. Representative $\left[{ }^{18} \mathrm{~F}\right] \mathrm{FLT}$ and $\left[{ }^{18} \mathrm{~F}\right] \mathrm{VC} 701 \mathrm{PET} / \mathrm{CT}$ images of a mouse bearing GL261 glioma tumour after 7,14 , and 21 days from cell injection. $\left[{ }^{18} \mathrm{~F}\right]$ VC701 uptake is visible before $\left[{ }^{18} \mathrm{~F}\right] \mathrm{FLT}$ signal. Colour scale is expressed as Standardized Uptake Value (SUV). 
Furthermore, the radiotracer $\left[{ }^{18} \mathrm{~F}\right] \mathrm{GE}-180$ seems to provide interesting results in patients and the uptake correlates with the grade of tumour $[250,251]$. Other radiotracers are now under development to increase the specificity to TSPO $[252,253]$.

\subsection{Other Targets of Tumour Microenvironment}

Prostate-specific membrane antigen (PSMA) is a type II transmembrane glycoprotein receptor with glutamate carboxypeptidase/folate hydrolase activity [312]. PSMA is highly expressed in prostate cancer and has recently emerged as a target for radionuclide imaging and treatment of this tumour [313]. PSMA is expressed not only in prostate cancer, but also in other solid tumours including brain tumours and correlates with the WHO grade. PSMA expression was found in endothelial cells associated with neovascularization and, for these reasons, can be a very interesting marker for monitoring anti-angiogenic drugs [314]. Several PET radiotracers for PSMA have been developed, such as $\left[{ }^{68} \mathrm{Ga}\right] P S M A-H B E D-C C,\left[{ }^{18} \mathrm{~F}\right] \mathrm{DCFPyL}$, and $\left[{ }^{89} \mathrm{Zr}\right] \mathrm{Df}-\mathrm{IAB} 2 \mathrm{M}$ anti-PSMA minibody. At the moment, only few studies evaluating PSMA targeted imaging of gliomas/glioblastomas in clinical practice are currently available. Moreover, most of these studies are case reports or case series [255-264,315]. Although limited, these studies confirmed that high-grade glioma/glioblastoma are PSMA-avid compared to low-grade and PSMA radioligand mainly binds vascular endothelial cells. A more detailed review is present in the paper of Van de Wiele et al. [265]. This year, a preclinical study in which the authors compared the uptake of two PSMA radioligands ([ $\left.{ }^{68} \mathrm{Ga}\right]-\mathrm{PSMA}$ and $\left.\left[{ }^{18} \mathrm{~F}\right] \mathrm{DCFPyL}\right)$ in three rat glioma models (F98, 9L, or U87) has been published. Radiotracers' uptake was evaluated ex vivo with autoradiography and in vivo with PET. Uptake data were then correlated to immunofluorescence staining for blood vessels, microglia, astrocytes, and the presence of PSMA. Both radiotracers displayed a higher uptake at the rim of the tumours where CD11b staining demonstrated low presence of activated microglia but a strong GFAP staining indicating the presence of reactive astrocytes. Very few astrocytes were noted in the centre of the tumours. These data suggest that PSMA radioligand could also visualize astrocytes activation [266].

Matrix metallo-proteinases (MMPs) are other attractive biomarkers for tumour therapy and imaging. MMPs are linked to increased cell proliferation, tumour invasion, migration, and poor prognosis in glioma patients [316]. Moreover, MMPs facilitate microglia-mediated glioma invasion by degrading the basement membrane and proteins of the ECM. Besides that, MMPs affect the neuroinflammatory milieu by modulating the expression and activity of chemokines, inflammatory cytokines, growth factors, and receptor turnover [317]. Several molecules have been recently developed to study MMPs. For example, de Lucas et al. evaluated an immunoPET tracer for the membrane-type 1 matrix metallo-proteinase (MT1-MMP or MMP-14), $\left[{ }^{89} \mathrm{Zr}\right] \mathrm{DFO}-\mathrm{LEM} 2 / 15$, in xenograft and orthotopic brain GBM models. This tracer displayed the higher uptake after $24 \mathrm{~h}$ post injection in tumours with high expression of MT1-MMP but a severe disruption of the BBB is needed to visualise intra brain tumours [267]. Zinnhardt and colleagues, in a multiple tracers study to evaluate the inflammatory microenvironment in an orthotopic glioma model, used the MMP inhibitor compound (R)-2-(N-benzyl-4-(2-[ $\left[{ }^{18} \mathrm{~F}\right]$ fluoroethoxy)phenylsulphonamido)-N-hydroxy-3-methylbutanamide $\left(\left[{ }^{18} \mathrm{~F}\right] \mathrm{BR}-351\right)$, which binds to the activated forms of MMP-2, $-8,-9$, and -13 . Areas of exclusive $\left[{ }^{18} \mathrm{~F}\right] \mathrm{BR}-351$ were observed at the outer borders of the tumour volume and the area of radiotracer uptake agreed with in situ zymography, indicating elevated levels of activated MMP-2 and MMP-9 [246]. Wang et al. synthesized a membrane-penetrating cyclic peptide, named iCREKA, labelled by fluorescein isothiocyanate (FITC) and positron emitter ${ }^{18} \mathrm{~F}$. The cyclic peptide iCREKA reaches tumour tissues via blood circulation. CREKA is expected to specifically bind to the fibrin-fibronectin complexes that are widely and abundantly distributed in tumour stroma. MMP-2/9 recognize and cleave iCREKA between CREKA and the membrane-penetrating peptide, while hydrolytic enzymes hydrolyze the disulfide bond. As a result, the fluorescent or radionuclide-labelled membrane penetrating peptide is released, which enters the plasma membrane and the tumour cells. The microPET/CT imaging demonstrated that $\left[{ }^{18} \mathrm{~F}\right]$ iCREKA could target U87MG xenograft tumour in vivo from 
$30 \mathrm{~min}$ to $2 \mathrm{~h}$ after injection [268]. Zhao et al. investigated the biodistribution and uptake of $\left[{ }^{18} \mathrm{~F}\right]$-fluoropropionyl-chlorotoxin $\left(\left[{ }^{18} \mathrm{~F}\right]-\mathrm{FP}\right.$-chlorotoxin), which binds to MMP-2 in an orthotopic rat $\mathrm{C} 6$ glioma model. The uptake of the tracer in the normal brain is very low and a high accumulation was found in the glioma tissue. The tumour to normal brain ratio of $\left[{ }^{18} \mathrm{~F}\right]-\mathrm{FP}$-chlorotoxin was higher than that of $\left[{ }^{18} \mathrm{~F}\right] \mathrm{FDG}$ with the maximum uptake at $90 \mathrm{~min}$ [269]. Kasten and colleagues designed an MMP-14-activatable dual PET/NIRF peptide probe for imaging and guiding resection of glioma. The peptide probe combined (1) a NIRF reporter and quencher pair separated by a peptide sequence (MMP-14 "substrate peptide") that is cleaved specifically by activated MMP-14 to release the quencher and allows visualization of the NIRF dye; and (2) a chelate for radionuclides attached to a peptide sequence, that binds to MMP-14 (MMP-14 "binding peptide") and enables PET imaging. For PET imaging the peptide was labelled with $\left[{ }^{68} \mathrm{Ga}\right]$ or $\left[{ }^{64} \mathrm{Cu}\right]$ and biodistribution was evaluated in an orthotopic glioma model obtained with PDX JX12 tumour. Both $\left[{ }^{68} \mathrm{Ga}\right]$ binding-peptide and $\left[{ }^{64} \mathrm{Cu}\right]$ binding-peptide allow to visualize PDX tumours. PET and NIRF signals correlated linearly in the orthotopic PDX tumours and the signals co-localized with MMP-14 expression identified with immunohistochemistry [270].

A further PET radiotracer can be the Fibroblast Activation Protein (FAP) ligand.

Recently, Röhrich and colleagues have shown the potential of the targeting FAP-PET-based imaging $\left({ }^{68} \mathrm{Ga}-\mathrm{FAPI}-01\right.$ and -04$)$ in retrospectively studying 13 patients with wild type-IDH glioblastomas. FAP-positive signalling of extracranial tumours is attributed to activated Cancer Associated Fibroblasts (CAFs) that are located in the stromal compound of these tumours and overexpress FAP. In parallel, patients underwent multimodal MRI. FAP specific PET and rCBV MRI scans are modestly correlated and no correlation between the FAP-based PET and the ADC sequence has been observed, suggesting that FAP-specific PET could be useful in biopsy organization and discrimination between pseudo-progression and tumour progression after radiation therapy for GBM imaging [318].

In a paper of Henderson and colleagues, two recurrent GBM patients have been chosen for validating $\left[{ }^{18} \mathrm{~F}\right]$ Fluciclovine-based PET/CT imaging in GBM, a synthetic amino acid used as PET tracer. In this study, it has been reported the ability of this radiotracer, approved by FDA for prostate cancer care in 2016 and used since 2015 for gliomas treatment but not still approved, to be feasibly used for discriminating areas with the highest cancer recurrence from the ones where the most prevailing treatment efficacy is observable [228].

Considering the importance of the L-amino acid transporter 1 (LAT1), other radiotracers have been exploited and investigated.

In a paper by Verhoeven et al., the radiotracer 2- $\left[{ }^{18} \mathrm{~F}\right]-2-$ fluoroethyl-l-phenylalanine $\left(2-\left[{ }^{18} \mathrm{~F}\right] \mathrm{FELP}\right)$, has been synthesized, tested both in vitro and in vivo in F98 models and compared to $\left[{ }^{18} \mathrm{~F}\right] \mathrm{FDG}$ and $\left[{ }^{18} \mathrm{~F}\right]$ FET. In vitro, $2-\left[{ }^{18} \mathrm{~F}\right]$ FELP has shown the highest affinity and a lower uptake in presence of one of the LAT1 inhibitors compared to the $\left[{ }^{18} \mathrm{~F}\right] \mathrm{FET}$ uptake, suggesting a specific LAT-1-mediated $2-\left[{ }^{18} \mathrm{~F}\right]$ FELP transport. Moreover, a similar trend in the in vivo data was observed. To recapitulate, being LAT1 overexpression a GBM distinctive marker and having $2-\left[{ }^{18}\right.$ F]FELP a very high and specific affinity for this amino acid transporter, this emerging tracer might be exploited for driving biopsy and primary brain tumour diagnosis, to plan and guide radiation treatment and for tumour recurrence and radio-necrosis discrimination after the starting therapy [229].

Another LAT1-specific radiotracer, the (S)-2-amino-3-[3-(2-18 F-fluoroethoxy)-4-iodophenyl]-2methylpropanoic acid ( ${ }^{18} \mathrm{~F}$-FIMP) has been synthetized and validated in LAT1-positive human glioblastoma cells and tumours. $\left[{ }^{18}\right.$ F]FIMP radiotracer specifically accumulated in LAT1-positive tumour tissues and not in inflamed tissue. Moreover, ex vivo analysis confirmed the stability of this radiotracer [230].

\section{5. miRNA and Imaging}

Several years of research correlating imaging features with histopathological data created a new branch of medicine: radiomics. Radiomics is an analysis approach to convert the image data into 
quantitative, mathematical output (features). Radiomics features are closely related to intra-tumour complexity and heterogeneity, representing the histopathological characteristics of the GBM. Imaging techniques could be helpful for tumour classification, analysis of the response to the treatment, and prognosis [319]. Radiogenomics is an emerging field that tries to link radiomics with the corresponding underlying genomic and epigenomic data. Radiogenomics analysis highlights the association between the radiomic quantitative data/features and molecular profile, including genomic, epigenomic, and metabolomic signatures, that are correlated with a clinical outcome [320]. The radiogenomics approach has been proposed for some types of cancer, from hepatocellular carcinoma to breast cancer [321,322]. Genomic data acquisition requires tissue biopsy, which is not always obtained in patients with GBM. Histopathological features, specific mutation pattern and molecular markers analysis revealed that GBM could be classified in four subtypes with different outcomes: proneural (the most favourable for the prognosis) neural, mesenchymal (the one associated with poor prognosis), and classical. Different subtypes react differently depending on treatment [323]. Radiogenomics can be applied to predict the GBM subtypes. Volumes of both contrast enhancement and necrosis are higher in GBM of the mesenchymal subtype compared to the proneural subtype. GBMs with less than $5 \%$ tumour enhancement are mostly of the proneural subtype.

Radiogenomics could also help in the prediction of the mutation status. Indeed, the IDH-mutant GBM is mainly localised in the frontal lobe and it is characterized by a higher percentage of non-contrast-enhancing part of the tumour and the presence of cysts on MRI. Left temporal lobe GBM are usually MGMT-methylated tumours, whereas MGMT-unmethylated GBM are more frequently found in the right hemisphere. $1 \mathrm{p} 19 \mathrm{q}$ co-deletion is linked to classical oligodendroglial MRI characteristics (heterogeneous T2 signal intensity and calcifications). Tumours with EGFR amplification, mainly localised in the left temporal lobe, present a significant higher percentage of contrast-enhancement and T2/FLAIR hyperintensity compared with those lacking EGFR amplification. The relation between MRI features and the expression of other molecular markers (phosphatase and tensin homolog, PTEN; platelet-derived growth factor receptor, PDGFRA; cyclin-dependent kinase inhibitor 2A, CDKN2A; retinoblastoma 1, RB1; tumour protein 53, TP53) is under investigation [213].

Some attempts have been made in the description of GBM heterogeneity on the basis of epigenetic profile (DNA methylation), associating it with patients' survival, MRI, and quantitative pathology (tumour morphology, proliferative activity, and microenvironment). From this work it emerges that mesenchymal cell subtype, associated with the worst prognosis, is enriched in hypomethylated promoter regions in EZH2, KDM4A, RBBP5, and SUZ12, as well as in regulators of pluripotency (NANOG, SOX2, POU5F1) and enriched in hypermethylated chromatin promoter of CTCF, EZH2, and KDM4A. MRI data reveals that the highest number of immune cells was in tumours of the mesenchymal subtype, showing also increased tumour size, fewer vital tumour areas, and increased oedema, while histopathology revealed lower cell density and large necrotic areas [324].

In 2012, Elkhaled et al. demonstrated that there is concordance between the presence of D-2-hydroxyglutarate (2HG), as detected by proton high-resolution magic angle spinning $\left({ }^{1} \mathrm{H}\right.$ HR-MAS) spectroscopy, and IDH1 mutation status, as determined by antibody staining and genetic sequencing, that was confirmed by Choi and colleagues $[325,326]$. These two studies revealed that there is a direct link between a genetic mutation and a behavioural or a metabolic phenotype observed by imaging analysis.

In 2018, a paper described a tentative correlation of data from quantitative MRI with transcriptomic profiles of 65 patients with primary glioblastoma [327]. Unsupervised clustering methods, confirming the data of Verhaak et al. revealed the existence of three different clusters, each associated with a different outcome $[327,328]$. Each cluster represented a distinct molecular classification of glioblastoma already described, classical type, proneural and neural types, and mesenchymal type. The first cluster was associated to the increased expression of anion channel activity, peroxisome, and the classical phenotype observed in Verhaak and colleagues' paper; the second cluster presented higher expression of genes of the mitosis, cell cycle and a proneural/neural subtype; the third cluster was characterized by 
altered expression of extracellular matrix molecules, defence response, immune signalling molecules, and the mesenchymal subtype molecules. These data suggest that radiomic data could provide information about molecular subtypes of GBM based on the transcriptomic profile [327,328].

Nowadays, a missing step is to demonstrate the existence of a correlation between the data extracted from MR imaging and the miRNA expression profiles.

Molecular imaging by the use of PET is increasingly being implemented into clinical practice for treatment planning and response monitoring in GBM. The potential clinical applications of PET include the monitoring of treatment response, as it could distinguish tumour recurrence from radiation necrosis or pseudoprogression. Correlation between different types of amino acid tracers in PET and molecular markers is currently under investigation [329].

A correlation between miRNA expression in tissue GBM and PET imagings has not been proven yet. Indeed, miRNAs free molecules or miRNAs associated to extracellular vesicles or exosomes released by GBM tumour have been considered as possible biomarkers in the liquid biopsy for GBM diagnosis [213].

Several miRNA profiles have been proposed for GBM diagnosis by liquid biopsy isolation (i.e., as proposed by Kopkova and colleagues and by Ebrahimkhani et al.), but no one has correlated their expression with PET imaging features [330,331].

Exosomal miR-21 is one of the plasma biomarkers proposed for GBM diagnosis and seems to be able to distinguish tumour progression from pseudoprogression or radionecrosis [332].

Recently, a noninvasive glioblastoma testing (NIGT) platform has been proposed, including a multimodal approach that combines the complexity and heterogeneity of GBM described by imaging techniques, with computational approaches, and the use of circulating biomarkers [213]. This could be especially helpful in the selection of patients in order to better address them to the best therapeutic approach.

\section{Final Considerations and Future Direction}

In this review, starting from the analysis of GBM cell heterogeneity, we focused on those aspects that sustain the development of TMZ resistance, in order to find out possible therapeutic solutions for clinical application. In particular, we highlighted the supporting role of microenvironment surrounding the tumour and the possible functions of several non-coding miRNAs, as possible targets for the development of new therapeutic strategies. In order to have a complete view of the gold standard treatment of GBM, we described the canonical treatment of TMZ and the main mechanisms involved in the development of resistance to TMZ. In addition, several possible alternative treatments to TMZ alone-based therapy have been discussed, including combinatorial pharmacological treatments, comprising radiotherapeutic approaches, antibodies, and miRNAs. To the view of the interesting role of miRNAs, new therapeutic strategies could include the combination of miRNAs and drugs, this field becoming an important opportunity to investigate [109,333-336].

Moreover, we discussed a significant number of PET tracers that can help to visualise and monitor cancer cells and tumour microenvironments including GAMMs, endothelial cells, fibroblasts, astrocytes, and stem cells (Figure 3). These PET radiopharmaceuticals, particularly when associated with information deriving from MRI, may be relevant also for the identification of lesion heterogeneity and for the clusterisation of subsets of patients potentially responding to treatment under development. In vivo diagnostic imaging data may be a useful platform to associate and monitor genetic and biological features of the tumour at sub-regional levels during time in a non-clinical model or associated with post-surgery analysis and outcome in patients. In turn, in vivo molecular imaging offers a potential tool to characterize the inter- and intra-tumour heterogeneity of GBM and clusterize the lesions. Moreover, new advanced technologies and analysis methods as combied PET/MRI scanners joined by textural features increase diagnostic accuracy of gliomas in the identification of specific genotypes guiding surgery. 

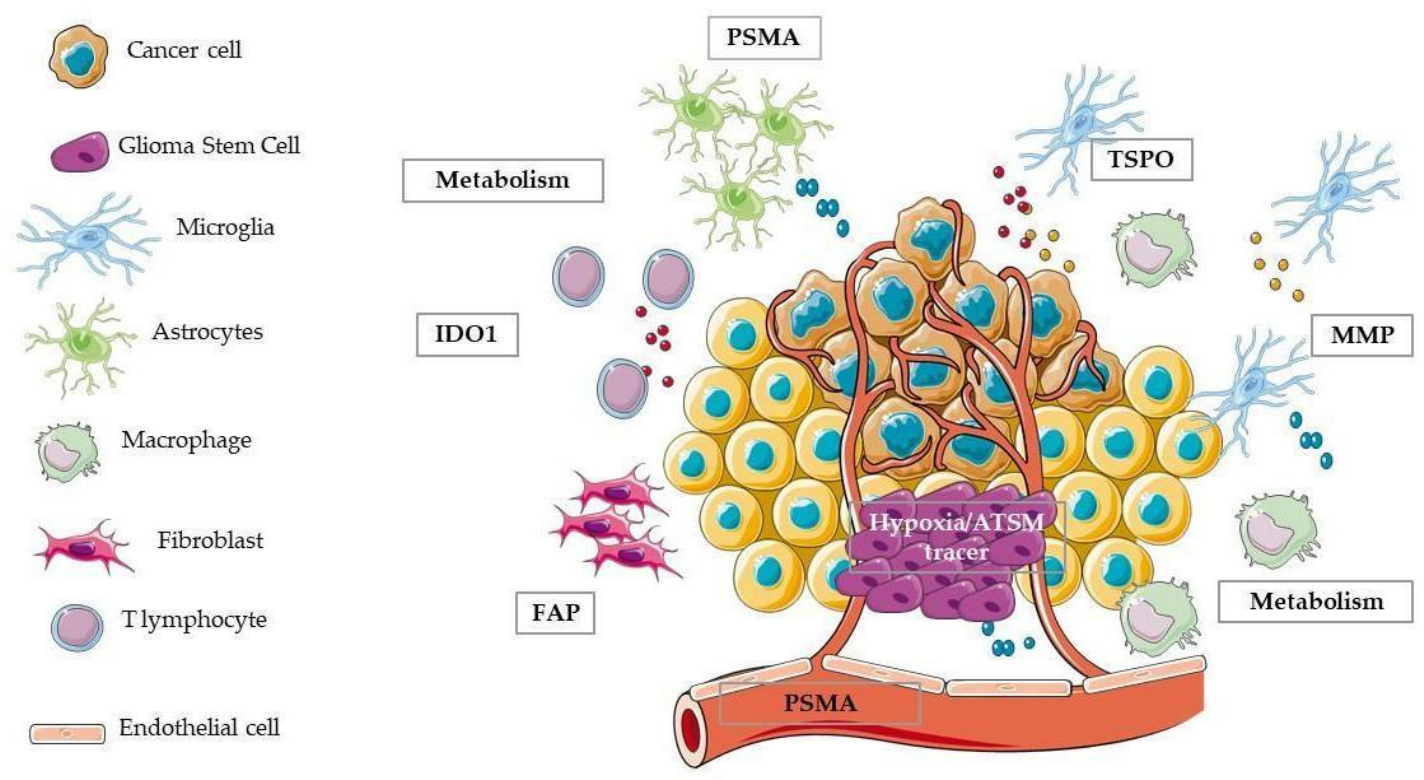

Figure 3. Targets of radiopharmaceutical used for in vivo imaging of tumour microenvironment in glioma.

In addition, PET tracers can be used for guiding targeted radionuclide therapy substituting the positron emitting radionuclide with a therapeutic beta-particle emitting radionuclide, either lutetium-177 or yttrium-90 as performed in other types of tumor. Although this application is not yet available or proof for glioma, the use of theranostic [177Lu]-PSMA has been already tested in brain metastasis indicating the potential feasibility for its application also in glioma [337].

\section{Conclusions}

In this review we have summarised the complex heterogeneity of GBM and the potential use of imaging to visualise differences at regional levels in biological features. We have described the main genetic and epigenetic mechanisms of drug resistance and the state-of-the-art research studies attempting to overcome it. It should be stressed that surgery remains the best treatment available. However, the delayed diagnosis and difficult identification of lesion margins and infiltrating cells limit its benefit. For these reasons, pharmacological as well as radiation therapies are necessary. Despite the efforts, information on the biology of GBM is still insufficient and the molecular classification limited to a selected portion of tumour. However, molecular and single-cell data suggest that treatment should act on common features, such as the metabolism or immune system, particularly using combined strategies. In this scenario, molecular imaging may help to better define GBM complexity and the modification occurring during therapy at regional level. This, together with biopsy or post-surgery in vitro single-cell imaging and bioinformatics, can help in the identification of cluster of patients with common biological traits and this is crucial for the proper development of novel pharmacological or radiation-based therapy.

Author Contributions: Conceptualization was done by S.V., G.B., R.M.M.; investigation by S.V., D.S., P.R. and G.B.; data curation by S.V., D.S., P.R. and G.B.; writing, original draft preparation by S.V., D.S., P.R., S.B., G.B. and R.M.M.; supervision by R.M.M.; funding acquisition by R.M.M. All authors have read and agreed to the published version of the manuscript.

Funding: The research leading to these results has received funding from AIRC under IG 2018-ID. 21635 project-P.I. Moresco Rosa Maria.

Conflicts of Interest: The authors declare no conflict of interest. 


\section{Abbreviations}

\begin{tabular}{|c|c|}
\hline ACSS2 & Acetylcoenzime A synthetase 2 \\
\hline $\mathrm{ADC}$ & Apparent diffusion coefficient \\
\hline AMPK & 5' AMP-Activated Protein Kinase \\
\hline ASCT2 & Alanine, Serine, Cysteine transporter 2 \\
\hline ASL & Arterial spin labelling \\
\hline BBB & Blood-brain barrier \\
\hline CAIX & Carbonic Anhydrase IX \\
\hline$\left[{ }^{11} \mathrm{C}\right] \mathrm{AMT}$ & alpha- $\left[{ }^{11} \mathrm{C}\right]$ methyl-L-tryptophan \\
\hline$\left[{ }^{11} \mathrm{C}\right] \mathrm{MET}$ & {$\left[{ }^{11} \mathrm{C}\right]$ methionine } \\
\hline CNS & Central Nervous System \\
\hline CSC/GSC & Cancer stem cell/Glioma stem cell \\
\hline$\left[{ }^{64} \mathrm{Cu}\right] \mathrm{ATSM}$ & {$\left[{ }^{64} \mathrm{Cu}\right]$-diacetyl-bis (N4-methylthiosemicarbazone) } \\
\hline$\left[{ }^{64} \mathrm{Cu}\right]$ RaftRGD & {$\left[{ }^{64} \mathrm{Cu}\right]$-cyclam-RAFT-c(-RGDfK-)4 } \\
\hline DCE-MRI & Dynamic contrast-enhanced Magnetic Resonance Imaging \\
\hline DSC & Dynamic susceptibility contrast \\
\hline DTI & Diffusion-tensor imaging \\
\hline DWI-MRI & Diffusion-weighted Magnetic Resonance Imaging \\
\hline ECM & Extracellular matrix \\
\hline EGFRvIII & Epidermal Growth Factor Receptor-vIII \\
\hline FAP & Fibroblast Activation Protein \\
\hline$\left[{ }^{18} \mathrm{~F}\right] \mathrm{BR}-351$ & (R)-2-(N-benzyl-4-(2-[ $\left.{ }^{18} \mathrm{~F}\right]$ fluoroethoxy)phenylsulphonamido)-N-hydroxy-3-methylbutanamide \\
\hline$\left[{ }^{18} \mathrm{~F}\right] \mathrm{DCFPyL}$ & $\begin{array}{l}\text { 2-(3-\{1-carboxy-5-[(6-[ }\left[{ }^{18} \text { F]fluoro-pyridine-3-carbonyl)-amino }\right] \text {-pentyl\}-ureido)-pentanedioic } \\
\text { acid }\end{array}$ \\
\hline$\left[{ }^{18} \mathrm{~F}\right] \mathrm{FDG}$ & 2-deoxy-2- $\left[{ }^{18} \mathrm{~F}\right]$ fluoro-D-glucose \\
\hline ז18 & N,N-diethyl2-(2-(4-(2-[ $\left[{ }^{18} \mathrm{~F}\right]$ fluoroethoxy)phenyl)-5,7-dimethylpyrazolo \\
\hline [ F]DPA-/14 & {$[1,5-a]$ pyrimidin-3-yl)acetamide } \\
\hline$\left[{ }^{18}\right.$ F]FELP & 2-[ $\left.{ }^{18} \mathrm{~F}\right]-2$-fluoroethyl-1-phenylalanine \\
\hline$\left[{ }^{18} \mathrm{~F}\right] \mathrm{FET}$ & {$\left[{ }^{18} \mathrm{~F}\right]$ fluoroethyltyrosine } \\
\hline$\left[{ }^{18} \mathrm{~F}\right] \mathrm{F}-\mathrm{G} \ln$ & {$\left[{ }^{18} \mathrm{~F}\right] \mathrm{F}-$ Glutamine } \\
\hline L-1- $\left[{ }^{18}\right.$ F]FETrp & L-1- $\left[{ }^{18} \mathrm{~F}\right]$ fluoroethyl-tryptophan \\
\hline$\left[{ }^{18} \mathrm{~F}\right] \mathrm{GE}-180$ & S-N,N-diethyl-9-[2- ${ }^{18}$ F-fluoroethyl]-5-methoxy-2,3,4,9-tetrahydro-1H-carbazole-4-carboxamide \\
\hline$\left[{ }^{18} \mathrm{~F}\right] \mathrm{FIMP}$ & (S)-2-amino-3-[3-(2-18 F-fluoroethoxy)-4-iodophenyl]-2-methylpropanoic acid \\
\hline$\left[{ }^{18} \mathrm{~F}\right] \mathrm{FLT}$ & {$\left[{ }^{18} \mathrm{~F}\right] 3^{\prime}$-deoxy-3'-fluorothymidine } \\
\hline GAMMs & Glioma associated-macrophages and microglia \\
\hline GFAP & Glial fibrillary acidic protein \\
\hline GLUT1 & Glucose transporter 1 \\
\hline HIF & Hypoxia-Inducible Factor \\
\hline HK & Hexokinase \\
\hline IDH-1 & Isocitrate Dehydrogenase-1 \\
\hline IDO1 & Indoleamine 2,3-dioxygenase 1 \\
\hline$\left[{ }^{68} \mathrm{Ga}\right] \mathrm{PSMA}$ & {$\left[{ }^{68} \mathrm{Ga}\right] P S M A-H B E D-C C$} \\
\hline GBM & Glioblastoma Multiforme \\
\hline JAK $1 / 2$ & Janus Kinases 1/2 \\
\hline $\mathrm{LAT} 1 / 2$ & L-type amino acid transporters 1 and 2 \\
\hline MCT & Monocarboxylate transporter \\
\hline MGMT & O6-methylguanine-DNA-methyl transferase \\
\hline miRNA & microRNA \\
\hline mTORC1 & mammalian target of rapamycin complex 1 \\
\hline MMP & Matrix-metallo proteinase \\
\hline MRI & Magnetic Resonance Imaging \\
\hline MSC-IFN- $\beta$ & Mesenchymal Stem/Stromal Cells-derived Interferon- $\beta$ \\
\hline mtComplex I & Mitochondrial Complex I \\
\hline NMRS & Nuclear Magnetic Resonance Spectroscopy \\
\hline p53 & Tumor Protein 53 \\
\hline PD-1 & Programmed Cell Death-1 \\
\hline
\end{tabular}




$\begin{array}{ll}\text { PD-L1 } & \text { Programmed Cell Death-Ligand-1 } \\ \text { PARP } & \text { Poly ADP Ribose Polymerase } \\ \text { PET/CT } & \text { Positron Emission Tomography/Computed Tomography } \\ \text { PSMA } & \text { Prostate-specific membrane antigen } \\ \text { Rb } & \text { Retinoblastoma } \\ \text { RT } & \text { Radio therapy } \\ \text { SUV } & \text { Standardized Uptake Value } \\ \text { TIGIT } & \text { T-Cell Immunoreceptor With Ig and ITIM Domains } \\ \text { TIM-3 } & \text { T-Cell Immunoglobulin Mucin-3 Receptor } \\ \text { TME } & \text { Tumor micro-environment } \\ \text { TMZ } & \text { Temozolomide } \\ \text { TSPO } & \text { 18 KDa translocator protein } \\ \text { VEGF } & \text { Vascular Endothelial Growth Factor } \\ \text { WHO } & \text { World Health Organization } \\ \text { [ }{ }^{89} \text { Zr]DFO-LEM2/15 } & \text { [ }{ }^{89} \text { Zr]labelled-MT1-MMP-specific mAb (LEM2/15) }\end{array}$

\section{References}

1. Wood, M.D.; Halfpenny, A.M.; Moore, S.R. Applications of molecular neuro-oncology-A review of diffuse glioma integrated diagnosis and emerging molecular entities. Diagn. Pathol. 2019, 14, 29. [CrossRef]

2. Tamimi, A.F.; Juweid, M. Epidemiology and Outcome of Glioblastoma. In Glioblastoma; De Vleeschouwer, S., Ed.; Codon Publications: Brisbane, Australia, 2017; ISBN 978-0-9944381-2-6.

3. Stupp, R.; Mason, W.P.; van den Bent, M.J.; Weller, M.; Fisher, B.; Taphoorn, M.J.B.; Belanger, K.; Brandes, A.A.; Marosi, C.; Bogdahn, U.; et al. Radiotherapy plus Concomitant and Adjuvant Temozolomide for Glioblastoma. N. Engl. J. Med. 2005, 352, 987-996. [CrossRef]

4. Kazda, T.; Dziacky, A.; Burkon, P.; Pospisil, P.; Slavik, M.; Rehak, Z.; Jancalek, R.; Slampa, P.; Slaby, O.; Lakomy, R. Radiotherapy of glioblastoma 15 years after the landmark Stupp's trial: More controversies than standards? Radiol. Oncol. 2018, 52, 121-128. [CrossRef]

5. Carter, T.C.; Medina-Flores, R.; Lawler, B.E. Glioblastoma Treatment with Temozolomide and Bevacizumab and Overall Survival in a Rural Tertiary Healthcare Practice. BioMed Res. Int. 2018, 2018, 6204676. [CrossRef]

6. Sorribes, I.C.; Handelman, S.K.; Jain, H.V. Mitigating temozolomide resistance in glioblastoma via DNA damage-repair inhibition. J. R. Soc. Interface 2020, 17, 20190722. [CrossRef]

7. Bergmann, N.; Delbridge, C.; Gempt, J.; Feuchtinger, A.; Walch, A.; Schirmer, L.; Bunk, W.; Aschenbrenner, T.; Liesche-Starnecker, F.; Schlegel, J. The Intratumoral Heterogeneity Reflects the Intertumoral Subtypes of Glioblastoma Multiforme: A Regional Immunohistochemistry Analysis. Front. Oncol. 2020, 10. [CrossRef]

8. Matarredona, E.R.; Pastor, A.M. Extracellular Vesicle-Mediated Communication between the Glioblastoma and Its Microenvironment. Cells 2020, 9, 96. [CrossRef] [PubMed]

9. Jeanmougin, M.; Håvik, A.B.; Cekaite, L.; Brandal, P.; Sveen, A.; Meling, T.R.; Ågesen, T.H.; Scheie, D.; Heim, S.; Lothe, R.A.; et al. Improved prognostication of glioblastoma beyond molecular subtyping by transcriptional profiling of the tumor microenvironment. Mol. Oncol. 2020, 14, 1016-1027. [CrossRef] [PubMed]

10. Cheng, J.; Meng, J.; Zhu, L.; Peng, Y. Exosomal noncoding RNAs in Glioma: Biological functions and potential clinical applications. Mol. Cancer 2020, 19, 66. [CrossRef] [PubMed]

11. Pottoo, F.H.; Javed, N.; Rahman, J.; Abu-Izneid, T.; Khan, F.A. Targeted delivery of miRNA based therapeuticals in the clinical management of Glioblastoma Multiforme. Semin. Cancer Biol. 2020. [CrossRef] [PubMed]

12. Wright, K.; de Silva, K.; Purdie, A.C.; Plain, K.M. Comparison of methods for miRNA isolation and quantification from ovine plasma. Sci. Rep. 2020, 10, 825. [CrossRef] [PubMed]

13. Kenny, A.; Jiménez-Mateos, E.M.; Zea-Sevilla, M.A.; Rábano, A.; Gili-Manzanaro, P.; Prehn, J.H.M.; Henshall, D.C.; Ávila, J.; Engel, T.; Hernández, F. Proteins and microRNAs are differentially expressed in tear fluid from patients with Alzheimer's disease. Sci. Rep. 2019, 9, 15437. [CrossRef] [PubMed]

14. Huang, S.-W.; Ali, N.; Zhong, L.; Shi, J. MicroRNAs as biomarkers for human glioblastoma: Progress and potential. Acta Pharmacol. Sin. 2018, 39, 1405-1413. [CrossRef] [PubMed] 
15. Sana, J.; Busek, P.; Fadrus, P.; Besse, A.; Radova, L.; Vecera, M.; Reguli, S.; Stollinova Sromova, L.; Hilser, M.; Lipina, R.; et al. Identification of microRNAs differentially expressed in glioblastoma stem-like cells and their association with patient survival. Sci. Rep. 2018, 8, 2836. [CrossRef] [PubMed]

16. Hayes, J.; Thygesen, H.; Tumilson, C.; Droop, A.; Boissinot, M.; Hughes, T.A.; Westhead, D.; Alder, J.E.; Shaw, L.; Short, S.C.; et al. Prediction of clinical outcome in glioblastoma using a biologically relevant nine-microRNA signature. Mol. Oncol. 2015, 9, 704-714. [CrossRef]

17. Petrescu, G.E.D.; Sabo, A.A.; Torsin, L.I.; Calin, G.A.; Dragomir, M.P. MicroRNA based theranostics for brain cancer: Basic principles. J. Exp. Clin. Cancer Res. 2019, 38, 231. [CrossRef]

18. Miyai, M.; Tomita, H.; Soeda, A.; Yano, H.; Iwama, T.; Hara, A. Current trends in mouse models of glioblastoma. J. Neurooncol. 2017, 135, 423-432. [CrossRef]

19. Ramasawmy, R.; Johnson, S.P.; Roberts, T.A.; Stuckey, D.J.; David, A.L.; Pedley, R.B.; Lythgoe, M.F.; Siow, B.; Walker-Samuel, S. Monitoring the Growth of an Orthotopic Tumour Xenograft Model: Multi-Modal Imaging Assessment with Benchtop MRI (1T), High-Field MRI (9.4T), Ultrasound and Bioluminescence. PLoS ONE 2016, 11. [CrossRef]

20. Thust, S.C.; Heiland, S.; Falini, A.; Jäger, H.R.; Waldman, A.D.; Sundgren, P.C.; Godi, C.; Katsaros, V.K.; Ramos, A.; Bargallo, N.; et al. Glioma imaging in Europe: A survey of 220 centres and recommendations for best clinical practice. Eur. Radiol. 2018, 28, 3306-3317. [CrossRef]

21. la Fougère, C.; Suchorska, B.; Bartenstein, P.; Kreth, F.-W.; Tonn, J.-C. Molecular imaging of gliomas with PET: Opportunities and limitations. Neuro-oncology 2011, 13, 806-819. [CrossRef]

22. Parsons, D.W.; Jones, S.; Zhang, X.; Lin, J.C.-H.; Leary, R.J.; Angenendt, P.; Mankoo, P.; Carter, H.; Siu, I.-M.; Gallia, G.L.; et al. An Integrated Genomic Analysis of Human Glioblastoma Multiforme. Science 2008, 321, 1807-1812. [CrossRef] [PubMed]

23. Navin, N.; Kendall, J.; Troge, J.; Andrews, P.; Rodgers, L.; McIndoo, J.; Cook, K.; Stepansky, A.; Levy, D.; Esposito, D.; et al. Tumour evolution inferred by single-cell sequencing. Nature 2011, 472, 90-94. [CrossRef] [PubMed]

24. Gerlinger, M.; Rowan, A.J.; Horswell, S.; Math, M.; Larkin, J.; Endesfelder, D.; Gronroos, E.; Martinez, P.; Matthews, N.; Stewart, A.; et al. Intratumor Heterogeneity and Branched Evolution Revealed by Multiregion Sequencing. N. Engl. J. Med. 2012, 366, 883-892. [CrossRef] [PubMed]

25. Bedard, P.L.; Hansen, A.R.; Ratain, M.J.; Siu, L.L. Tumour heterogeneity in the clinic. Nature 2013, 501, 355-364. [CrossRef] [PubMed]

26. Patel, A.P.; Tirosh, I.; Trombetta, J.J.; Shalek, A.K.; Gillespie, S.M.; Wakimoto, H.; Cahill, D.P.; Nahed, B.V.; Curry, W.T.; Martuza, R.L.; et al. Single-cell RNA-seq highlights intratumoral heterogeneity in primary glioblastoma. Science 2014, 344, 1396-1401. [CrossRef]

27. Wang, J.; Cazzato, E.; Ladewig, E.; Frattini, V.; Rosenbloom, D.I.S.; Zairis, S.; Abate, F.; Liu, Z.; Elliott, O.; Shin, Y.-J.; et al. Clonal evolution of glioblastoma under therapy. Nat. Genet. 2016, 48, 768-776. [CrossRef]

28. Sottoriva, A.; Spiteri, I.; Piccirillo, S.G.M.; Touloumis, A.; Collins, V.P.; Marioni, J.C.; Curtis, C.; Watts, C.; Tavaré, S. Intratumor heterogeneity in human glioblastoma reflects cancer evolutionary dynamics. Proc. Natl. Acad. Sci. USA 2013, 110, 4009-4014. [CrossRef]

29. Wang, X.; Prager, B.C.; Wu, Q.; Kim, L.J.Y.; Gimple, R.C.; Shi, Y.; Yang, K.; Morton, A.R.; Zhou, W.; Zhu, Z.; et al. Reciprocal Signaling between Glioblastoma Stem Cells and Differentiated Tumor Cells Promotes Malignant Progression. Cell Stem Cell 2018, 22, 514-528.e5. [CrossRef]

30. Calabrese, C.; Poppleton, H.; Kocak, M.; Hogg, T.L.; Fuller, C.; Hamner, B.; Oh, E.Y.; Gaber, M.W.; Finklestein, D.; Allen, M.; et al. A Perivascular Niche for Brain Tumor Stem Cells. Cancer Cell 2007, 11, 69-82. [CrossRef]

31. Seidel, S.; Garvalov, B.K.; Wirta, V.; von Stechow, L.; Schänzer, A.; Meletis, K.; Wolter, M.; Sommerlad, D.; Henze, A.-T.; Nistér, M.; et al. A hypoxic niche regulates glioblastoma stem cells through hypoxia inducible factor $2 \alpha$. Brain 2010, 133, 983-995. [CrossRef]

32. Li, Z.; Bao, S.; Wu, Q.; Wang, H.; Eyler, C.; Sathornsumetee, S.; Shi, Q.; Cao, Y.; Lathia, J.; McLendon, R.E.; et al. Hypoxia-Inducible Factors Regulate Tumorigenic Capacity of Glioma Stem Cells. Cancer Cell 2009, 15, 501-513. [CrossRef] [PubMed]

33. Najafi, M.; Farhood, B.; Mortezaee, K.; Kharazinejad, E.; Majidpoor, J.; Ahadi, R. Hypoxia in solid tumors: A key promoter of cancer stem cell (CSC) resistance. J. Cancer Res. Clin. Oncol. 2020, 146, 19-31. [CrossRef] [PubMed] 
34. Yan, K.; Wu, Q.; Yan, D.H.; Lee, C.H.; Rahim, N.; Tritschler, I.; DeVecchio, J.; Kalady, M.F.; Hjelmeland, A.B.; Rich, J.N. Glioma cancer stem cells secrete Gremlin1 to promote their maintenance within the tumor hierarchy. Genes Dev. 2014. [CrossRef] [PubMed]

35. Wang, H.; Lathia, J.D.; Wu, Q.; Wang, J.; Li, Z.; Heddleston, J.M.; Eyler, C.E.; Elderbroom, J.; Gallagher, J.; Schuschu, J.; et al. Targeting Interleukin 6 Signaling Suppresses Glioma Stem Cell Survival and Tumor Growth. Stem Cells 2009, 27, 2393-2404. [CrossRef] [PubMed]

36. Charles, N.; Ozawa, T.; Squatrito, M.; Bleau, A.-M.; Brennan, C.W.; Hambardzumyan, D.; Holland, E.C. Perivascular Nitric Oxide Activates Notch Signaling and Promotes Stem-like Character in PDGF-Induced Glioma Cells. Cell Stem Cell 2010, 6, 141-152. [CrossRef]

37. Zhu, T.; Costello, M.A.; Talsma, C.E.; Flack, C.G.; Crowley, J.G.; Hamm, L.L.; He, X.; Umper, S.L.H.-J.; Heth, J.A.; Muraszko, K.M.; et al. Endothelial cells create a stem cell niche in glioblastoma by providing Notch ligands that nurture self-renewal of cancer stem-like cells. Cancer Res. 2011. [CrossRef] [PubMed]

38. Lathia, J.D.; Heddleston, J.M.; Venere, M.; Rich, J.N. Deadly Teamwork: Neural Cancer Stem Cells and the Tumor Microenvironment. Cell Stem Cell 2011, 8, 482-485. [CrossRef] [PubMed]

39. Bao, S.; Wu, Q.; Sathornsumetee, S.; Hao, Y.; Li, Z.; Hjelmeland, A.B.; Shi, Q.; McLendon, R.E.; Bigner, D.D.; Rich, J.N. Stem Cell-like Glioma Cells Promote Tumor Angiogenesis through Vascular Endothelial Growth Factor. Cancer Res. 2006, 66, 7843-7848. [CrossRef] [PubMed]

40. Cheng, L.; Huang, Z.; Zhou, W.; Wu, Q.; Donnola, S.; Liu, J.K.; Fang, X.; Sloan, A.E.; Mao, Y.; Lathia, J.D.; et al. Glioblastoma Stem Cells Generate Vascular Pericytes to Support Vessel Function and Tumor Growth. Cell 2013, 153, 139-152. [CrossRef]

41. Dirkse, A.; Golebiewska, A.; Buder, T.; Nazarov, P.V.; Muller, A.; Poovathingal, S.; Brons, N.H.C.; Leite, S.; Sauvageot, N.; Sarkisjan, D.; et al. Stem cell-associated heterogeneity in Glioblastoma results from intrinsic tumor plasticity shaped by the microenvironment. Nat. Commun. 2019, 10, 1787. [CrossRef]

42. Bar-Ephraim, Y.E.; Kretzschmar, K.; Clevers, H. Organoids in immunological research. Nat. Rev. Immunol. 2020, 20, 279-293. [CrossRef] [PubMed]

43. Darmanis, S.; Sloan, S.A.; Croote, D.; Mignardi, M.; Chernikova, S.; Samghababi, P.; Zhang, Y.; Neff, N.; Kowarsky, M.; Caneda, C.; et al. Single-Cell RNA-Seq Analysis of Infiltrating Neoplastic Cells at the Migrating Front of Human Glioblastoma. Cell Rep. 2017, 21, 1399-1410. [CrossRef] [PubMed]

44. Neftel, C.; Laffy, J.; Filbin, M.G.; Hara, T.; Shore, M.E.; Rahme, G.J.; Richman, A.R.; Silverbush, D.; Shaw, M.L.; Hebert, C.M.; et al. An Integrative Model of Cellular States, Plasticity, and Genetics for Glioblastoma. Cell 2019, 178, 835-849.e21. [CrossRef] [PubMed]

45. Wang, L.; Babikir, H.; Muller, S.; Yagnik, G.; Shamardani, K.; Catalan, F.; Kohanbash, G.; Alvarado, B.; Lullo, E.D.; Kriegstein, A.; et al. The phenotypes of proliferating glioblastoma cells reside on a single axis of variation. Cancer Discov. 2019. [CrossRef] [PubMed]

46. Behnan, J.; Stangeland, B.; Hosainey, S.A.M.; Joel, M.; Olsen, T.K.; Micci, F.; Glover, J.C.; Isakson, P.; Brinchmann, J.E. Differential propagation of stroma and cancer stem cells dictates tumorigenesis and multipotency. Oncogene 2017, 36, 570-584. [CrossRef] [PubMed]

47. Xiao, W.; Sohrabi, A.; Seidlits, S.K. Integrating the glioblastoma microenvironment into engineered experimental models. Future Sci. OA 2017, 3, FSO189. [CrossRef] [PubMed]

48. Bhaduri, A.; Di Lullo, E.; Jung, D.; Müller, S.; Crouch, E.E.; Espinosa, C.S.; Ozawa, T.; Alvarado, B.; Spatazza, J.; Cadwell, C.R.; et al. Outer Radial Glia-like Cancer Stem Cells Contribute to Heterogeneity of Glioblastoma. Cell Stem Cell 2020, 26, 48-63. [CrossRef]

49. Pollen, A.A.; Nowakowski, T.J.; Chen, J.; Retallack, H.; Sandoval-Espinosa, C.; Nicholas, C.R.; Shuga, J.; Liu, S.J.; Oldham, M.C.; Diaz, A.; et al. Molecular Identity of Human Outer Radial Glia during Cortical Development. Cell 2015, 163, 55-67. [CrossRef]

50. Ostrem, B.; Di Lullo, E.; Kriegstein, A. oRGs and mitotic somal translocation-A role in development and disease. Curr. Opin. Neurobiol. 2017, 42, 61-67. [CrossRef]

51. Cancer Genome Atlas Research Network. Comprehensive genomic characterization defines human glioblastoma genes and core pathways. Nature 2008, 455, 1061-1068. [CrossRef]

52. Madhavan, S.; Zenklusen, J.C.; Kotliarov, Y.; Sahni, H.; Fine, H.A.; Buetow, K. Rembrandt: Helping Personalized Medicine Become a Reality through Integrative Translational Research. Mol. Cancer Res. 2009. [CrossRef] [PubMed] 
53. Puchalski, R.B.; Shah, N.; Miller, J.; Dalley, R.; Nomura, S.R.; Yoon, J.-G.; Smith, K.A.; Lankerovich, M.; Bertagnolli, D.; Bickley, K.; et al. An anatomic transcriptional atlas of human glioblastoma. Science 2018, 360, 660-663. [CrossRef] [PubMed]

54. Hegi, M.E.; Diserens, A.-C.; Gorlia, T.; Hamou, M.-F.; de Tribolet, N.; Weller, M.; Kros, J.M.; Hainfellner, J.A.; Mason, W.; Mariani, L.; et al. MGMT Gene Silencing and Benefit from Temozolomide in Glioblastoma. N. Engl. J. Med. 2005, 352, 997-1003. [CrossRef]

55. Shah, N.; Schroeder, B.; Cobbs, C. MGMT methylation in glioblastoma: Tale of the tail. Neuro-oncology 2015, 17, 167-168. [CrossRef] [PubMed]

56. Wick, W.; Weller, M.; van den Bent, M.; Sanson, M.; Weiler, M.; von Deimling, A.; Plass, C.; Hegi, M.; Platten, M.; Reifenberger, G. MGMT testing-The challenges for biomarker-based glioma treatment. Nat. Rev. Neurol. 2014, 10, 372-385. [CrossRef]

57. Robertson, F.L.; Marqués-Torrejón, M.-A.; Morrison, G.M.; Pollard, S.M. Experimental models and tools to tackle glioblastoma. Dis. Models Mech. 2019, 12. [CrossRef]

58. Hackam, D.G.; Redelmeier, D.A. Translation of research evidence from animals to humans. JAMA 2006, 296, 1731-1732. [CrossRef]

59. Shanks, N.; Greek, R.; Greek, J. Are animal models predictive for humans? Philos. Ethics Humanit. Med. 2009, 4, 2. [CrossRef]

60. van der Worp, H.B.; Howells, D.W.; Sena, E.S.; Porritt, M.J.; Rewell, S.; O'Collins, V.; Macleod, M.R. Can animal models of disease reliably inform human studies? PLoS Med. 2010, 7, e1000245. [CrossRef]

61. Ben-David, U.; Ha, G.; Tseng, Y.-Y.; Greenwald, N.F.; Oh, C.; Shih, J.; McFarland, J.M.; Wong, B.; Boehm, J.S.; Beroukhim, R.; et al. Patient-derived xenografts undergo mouse-specific tumor evolution. Nat. Genet. 2017, 49, 1567-1575. [CrossRef]

62. Hubert, C.G.; Rivera, M.; Spangler, L.C.; Wu, Q.; Mack, S.C.; Prager, B.C.; Couce, M.; McLendon, R.E.; Sloan, A.E.; Rich, J.N. A Three-Dimensional Organoid Culture System Derived from Human Glioblastomas Recapitulates the Hypoxic Gradients and Cancer Stem Cell Heterogeneity of Tumors Found In Vivo. Cancer Res. 2016, 76, 2465-2477. [CrossRef] [PubMed]

63. Ogawa, J.; Pao, G.M.; Shokhirev, M.N.; Verma, I.M. Glioblastoma Model Using Human Cerebral Organoids. Cell Rep. 2018, 23, 1220-1229. [CrossRef] [PubMed]

64. Linkous, A.; Balamatsias, D.; Snuderl, M.; Edwards, L.; Miyaguchi, K.; Milner, T.; Reich, B.; Cohen-Gould, L.; Storaska, A.; Nakayama, Y.; et al. Modeling Patient-Derived Glioblastoma with Cerebral Organoids. Cell Rep. 2019, 26, 3203-3211. [CrossRef] [PubMed]

65. Lancaster, M.A.; Knoblich, J.A. Generation of cerebral organoids from human pluripotent stem cells. Nat. Protoc. 2014, 9, 2329-2340. [CrossRef]

66. Mansour, A.A.; Gonçalves, J.T.; Bloyd, C.W.; Li, H.; Fernandes, S.; Quang, D.; Johnston, S.; Parylak, S.L.; Jin, X.; Gage, F.H. An in vivo model of functional and vascularized human brain organoids. Nat. Biotechnol. 2018, 36, 432-441. [CrossRef]

67. Jacob, F.; Salinas, R.D.; Zhang, D.Y.; Nguyen, P.T.T.; Schnoll, J.G.; Wong, S.Z.H.; Thokala, R.; Sheikh, S.; Saxena, D.; Prokop, S.; et al. A Patient-Derived Glioblastoma Organoid Model and Biobank Recapitulates Inter- and Intra-tumoral Heterogeneity. Cell 2020, 180, 188-204.e22. [CrossRef]

68. Ling, H.; Fabbri, M.; Calin, G.A. MicroRNAs and other non-coding RNAs as targets for anticancer drug development. Nat. Rev. Drug Discov. 2013, 12, 847-865. [CrossRef]

69. Catalanotto, C.; Cogoni, C.; Zardo, G. MicroRNA in Control of Gene Expression: An Overview of Nuclear Functions. Int. J. Mol. Sci. 2016, 17, 1712. [CrossRef]

70. Forero, D.A.; González-Giraldo, Y.; Castro-Vega, L.J.; Barreto, G.E. qPCR-based methods for expression analysis of miRNAs. BioTechniques 2019, 67, 192-199. [CrossRef]

71. Goldman, J.G.; Andrews, H.; Amara, A.; Naito, A.; Alcalay, R.N.; Shaw, L.M.; Taylor, P.; Xie, T.; Tuite, P.; Henchcliffe, C.; et al. Cerebrospinal fluid, plasma, and saliva in the BioFIND study: Relationships among biomarkers and Parkinson's disease Features. Mov. Disord. 2018, 33, 282-288. [CrossRef]

72. Urbanek, M.O.; Nawrocka, A.U.; Krzyzosiak, W.J. Small RNA Detection by in Situ Hybridization Methods. Int. J. Mol. Sci. 2015, 16, 13259-13286. [CrossRef] [PubMed]

73. Eyileten, C.; Wicik, Z.; De Rosa, S.; Mirowska-Guzel, D.; Soplinska, A.; Indolfi, C.; Jastrzebska-Kurkowska, I.; Czlonkowska, A.; Postula, M. MicroRNAs as Diagnostic and Prognostic Biomarkers in Ischemic Stroke-A Comprehensive Review and Bioinformatic Analysis. Cells 2018, 7, 249. [CrossRef] [PubMed] 
74. Halle, B.; Marcusson, E.G.; Aaberg-Jessen, C.; Jensen, S.S.; Meyer, M.; Schulz, M.K.; Andersen, C.; Kristensen, B.W. Convection-enhanced delivery of an anti-miR is well-tolerated, preserves anti-miR stability and causes efficient target de-repression: A proof of concept. J. Neuro-Oncol. 2016, 126, 47-55. [CrossRef] [PubMed]

75. Shaji, S.K.; Sunilkumar, D.; Mahalakshmi, N.V.; Kumar, G.B.; Nair, B.G. Analysis of microarray data for identification of key microRNA signatures in glioblastoma multiforme. Oncol. Lett. 2019, 18, 1938-1948. [CrossRef] [PubMed]

76. Møller, H.G.; Rasmussen, A.P.; Andersen, H.H.; Johnsen, K.B.; Henriksen, M.; Duroux, M. A Systematic Review of MicroRNA in Glioblastoma Multiforme: Micro-modulators in the Mesenchymal Mode of Migration and Invasion. Mol. Neurobiol. 2013, 47, 131-144. [CrossRef] [PubMed]

77. Shea, A.; Harish, V.; Afzal, Z.; Chijioke, J.; Kedir, H.; Dusmatova, S.; Roy, A.; Ramalinga, M.; Harris, B.; Blancato, J.; et al. MicroRNAs in glioblastoma multiforme pathogenesis and therapeutics. Cancer Med. 2016, 5, 1917-1946. [CrossRef]

78. Malzkorn, B.; Wolter, M.; Liesenberg, F.; Grzendowski, M.; Stühler, K.; Meyer, H.E.; Reifenberger, G. Identification and Functional Characterization of microRNAs Involved in the Malignant Progression of Gliomas. Brain Pathol. 2010, 20, 539-550. [CrossRef]

79. Wang, B.-C.; Ma, J. Role of MicroRNAs in Malignant Glioma. Chin. Med. J. (Engl.) 2015, 128, 1238-1244. [CrossRef]

80. Condrat, C.E.; Thompson, D.C.; Barbu, M.G.; Bugnar, O.L.; Boboc, A.; Cretoiu, D.; Suciu, N.; Cretoiu, S.M.; Voinea, S.C. miRNAs as Biomarkers in Disease: Latest Findings Regarding Their Role in Diagnosis and Prognosis. Cells 2020, 9, 276. [CrossRef]

81. Hübner, M.; Moellhoff, N.; Effinger, D.; Hinske, C.L.; Hirschberger, S.; Wu, T.; Müller, M.B.; Strauß, G.; Kreth, F.-W.; Kreth, S. MicroRNA-93 acts as an "anti-inflammatory tumor suppressor" in glioblastoma. Neuro-Oncol. Adv. 2020, 2. [CrossRef]

82. Buruiană, A.; Florian, Ș.I.; Florian, A.I.; Timiș, T.-L.; Mihu, C.M.; Miclăuș, M.; Oșan, S.; Hrapșa, I.; Cataniciu, R.C.; Farcaș, M.; et al. The Roles of miRNA in Glioblastoma Tumor Cell Communication: Diplomatic and Aggressive Negotiations. Int. J. Mol. Sci. 2020, 21, 1950. [CrossRef] [PubMed]

83. Beyer, S.; Fleming, J.; Meng, W.; Singh, R.; Haque, S.J.; Chakravarti, A. The Role of miRNAs in Angiogenesis, Invasion and Metabolism and Their Therapeutic Implications in Gliomas. Cancers 2017, 9, 85. [CrossRef] [PubMed]

84. Yu, X.; Wang, W. Tumor suppressor microRNA-613 inhibits glioma cell proliferation, invasion and angiogenesis by targeting vascular endothelial growth factor A. Mol. Med. Rep. 2017, 16, 6729-6735. [CrossRef] [PubMed]

85. Wang, Z.-F.; Liao, F.; Wu, H.; Dai, J. Glioma stem cells-derived exosomal miR-26a promotes angiogenesis of microvessel endothelial cells in glioma. J. Exp. Clin. Cancer Res. 2019, 38, 201. [CrossRef]

86. Chen, X.; Yang, F.; Zhang, T.; Wang, W.; Xi, W.; Li, Y.; Zhang, D.; Huo, Y.; Zhang, J.; Yang, A.; et al. MiR-9 promotes tumorigenesis and angiogenesis and is activated by MYC and OCT4 in human glioma. J. Exp. Clin. Cancer Res. 2019, 38, 99. [CrossRef]

87. Svensson, A.; Özen, I.; Genové, G.; Paul, G.; Bengzon, J. Endogenous Brain Pericytes Are Widely Activated and Contribute to Mouse Glioma Microvasculature. PLoS ONE 2015, 10, e0123553. [CrossRef]

88. Jin, Y.; An, X.; Ye, Z.; Cully, B.; Wu, J.; Li, J. RGS5, a Hypoxia-inducible Apoptotic Stimulator in Endothelial Cells. J. Biol. Chem. 2009, 284, 23436-23443. [CrossRef]

89. Matias, D.; Balça-Silva, J.; da Graça, G.C.; Wanjiru, C.M.; Macharia, L.W.; Nascimento, C.P.; Roque, N.R.; Coelho-Aguiar, J.M.; Pereira, C.M.; Dos Santos, M.F.; et al. Microglia/Astrocytes-Glioblastoma Crosstalk: Crucial Molecular Mechanisms and Microenvironmental Factors. Front. Cell. Neurosci. 2018, 12. [CrossRef]

90. Groblewska, M.; Litman-Zawadzka, A.; Mroczko, B. The Role of Selected Chemokines and Their Receptors in the Development of Gliomas. Int. J. Mol. Sci. 2020, 21, 3704. [CrossRef]

91. Morimura, T.; Neuchrist, C.; Kitz, K.; Budka, H.; Scheiner, O.; Kraft, D.; Lassmann, H. Monocyte subpopulations in human gliomas: Expression of $\mathrm{FC}_{\mathrm{C}}$ and complement receptors and correlation with tumor proliferation. Acta Neuropathol. 1990, 80, 287-294. [CrossRef]

92. Roggendorf, W.; Strupp, S.; Paulus, W. Distribution and characterization of microglia/macrophages in human brain tumors. Acta Neuropathol. 1996, 92, 288-293. [CrossRef] [PubMed] 
93. Graeber, M.B.; Scheithauer, B.W.; Kreutzberg, G.W. Microglia in brain tumors. Glia 2002, 40, $252-259$. [CrossRef] [PubMed]

94. Wei, J.; Gabrusiewicz, K.; Heimberger, A. The Controversial Role of Microglia in Malignant Gliomas. Clin. Dev. Immunol. 2013, 2013. [CrossRef] [PubMed]

95. Tili, E.; Michaille, J.-J.; Wernicke, D.; Alder, H.; Costinean, S.; Volinia, S.; Croce, C.M. Mutator activity induced by microRNA-155 (miR-155) links inflammation and cancer. Proc. Natl. Acad. Sci. USA 2011, 108, 4908-4913. [CrossRef] [PubMed]

96. Prabowo, A.S.; van Scheppingen, J.; Iyer, A.M.; Anink, J.J.; Spliet, W.G.M.; van Rijen, P.C.; Meeteren, A.Y.N.S.; Aronica, E. Differential expression and clinical significance of three inflammation-related microRNAs in gangliogliomas. J. Neuroinflamm. 2015, 12. [CrossRef]

97. Iyer, A.; Zurolo, E.; Prabowo, A.; Fluiter, K.; Spliet, W.G.M.; van Rijen, P.C.; Gorter, J.A.; Aronica, E. MicroRNA-146a: A Key Regulator of Astrocyte-Mediated Inflammatory Response. PLoS ONE 2012, 7. [CrossRef]

98. Li, Y.; Wang, Y.; Yu, L.; Sun, C.; Cheng, D.; Yu, S.; Wang, Q.; Yan, Y.; Kang, C.; Jin, S.; et al. miR-146b-5p inhibits glioma migration and invasion by targeting MMP16. Cancer Lett. 2013, 339, 260-269. [CrossRef]

99. Würdinger, T.; Tannous, B.A.; Saydam, O.; Skog, J.; Grau, S.; Soutschek, J.; Weissleder, R.; Breakefield, X.O.; Krichevsky, A.M. miR-296 Regulates Growth Factor Receptor Overexpression in Angiogenic Endothelial Cells. Cancer Cell 2008, 14, 382-393. [CrossRef]

100. Karsy, M.; Arslan, E.; Moy, F. Current Progress on Understanding MicroRNAs in Glioblastoma Multiforme. Genes Cancer 2012, 3, 3-15. [CrossRef]

101. Nikaki, A.; Piperi, C.; Papavassiliou, A.G. Role of microRNAs in gliomagenesis: Targeting miRNAs in glioblastoma multiforme therapy. Expert Opin. Investig. Drugs 2012, 21, 1475-1488. [CrossRef]

102. Silber, J.; James, C.D.; Hodgson, J.G. microRNAs in Gliomas: Small Regulators of a Big Problem. Neuromol. Med. 2009, 11, 208-222. [CrossRef]

103. Chen, F.; Chen, L.; He, H.; Huang, W.; Zhang, R.; Li, P.; Meng, Y.; Jiang, X. Up-regulation of microRNA-16 in Glioblastoma Inhibits the Function of Endothelial Cells and Tumor Angiogenesis by Targeting Bmi-1. Anti-Cancer Agents Med. Chem. 2016, 16, 609-620. [CrossRef]

104. Lucero, R.; Zappulli, V.; Sammarco, A.; Murillo, O.D.; Cheah, P.S.; Srinivasan, S.; Tai, E.; Ting, D.T.; Wei, Z.; Roth, M.E.; et al. Glioma-Derived miRNA-Containing Extracellular Vesicles Induce Angiogenesis by Reprogramming Brain Endothelial Cells. Cell Rep. 2020, 30, 2065-2074.e4. [CrossRef] [PubMed]

105. Sakata, J.; Sasayama, T.; Tanaka, K.; Nagashima, H.; Nakada, M.; Tanaka, H.; Hashimoto, N.; Kagawa, N.; Kinoshita, M.; Nakamizo, S.; et al. MicroRNA regulating stanniocalcin-1 is a metastasis and dissemination promoting factor in glioblastoma. J. Neuro-Oncol. 2019, 142, 241-251. [CrossRef] [PubMed]

106. Dudvarski Stanković, N.; Bicker, F.; Keller, S.; Jones, D.T.; Harter, P.N.; Kienzle, A.; Gillmann, C.; Arnold, P.; Golebiewska, A.; Keunen, O.; et al. EGFL7 enhances surface expression of integrin $\alpha 5 \beta 1$ to promote angiogenesis in malignant brain tumors. EMBO Mol. Med. 2018, 10. [CrossRef] [PubMed]

107. Zhang, G.; Chen, L.; Khan, A.A.; Li, B.; Gu, B.; Lin, F.; Su, X.; Yan, J. miRNA-124-3p/neuropilin-1(NRP-1) axis plays an important role in mediating glioblastoma growth and angiogenesis. Int. J. Cancer 2018, 143, 635-644. [CrossRef]

108. Zeng, A.; Yin, J.; Li, Y.; Li, R.; Wang, Z.; Zhou, X.; Jin, X.; Shen, F.; Yan, W.; You, Y. miR-129-5p targets Wnt5a to block PKC/ERK/NF-кB and JNK pathways in glioblastoma. Cell Death Dis. 2018, 9, 1-16. [CrossRef]

109. Li, W.; Liu, Y.; Yang, W.; Han, X.; Li, S.; Liu, H.; Gerweck, L.E.; Fukumura, D.; Loeffler, J.S.; Yang, B.B.; et al. MicroRNA-378 enhances radiation response in ectopic and orthotopic implantation models of glioblastoma. J. Neuro-Oncol. 2018, 136, 63-71. [CrossRef]

110. Xu, X.; Zhang, F.; Chen, X.; Ying, Q. MicroRNA-518b functions as a tumor suppressor in glioblastoma by targeting PDGFRB. Mol. Med. Rep. 2017, 16, 5326-5332. [CrossRef]

111. Chung, H.J.; Choi, Y.E.; Kim, E.S.; Han, Y.-H.; Park, M.-J.; Bae, I.H. miR-29b attenuates tumorigenicity and stemness maintenance in human glioblastoma multiforme by directly targeting BCL2L2. Oncotarget 2015, 6, 18429-18444. [CrossRef]

112. Zhi, T.; Jiang, K.; Xu, X.; Yu, T.; Wu, W.; Nie, E.; Zhou, X.; Jin, X.; Zhang, J.; Wang, Y.; et al. MicroRNA-520d-5p inhibits human glioma cell proliferation and induces cell cycle arrest by directly targeting PTTG1. Am. J. Transl. Res. 2017, 9, 4872-4887. [PubMed] 
113. Wong, H.-K.A.; Fatimy, R.E.; Onodera, C.; Wei, Z.; Yi, M.; Mohan, A.; Gowrisankaran, S.; Karmali, P.; Marcusson, E.; Wakimoto, H.; et al. The Cancer Genome Atlas Analysis Predicts MicroRNA for Targeting Cancer Growth and Vascularization in Glioblastoma. Mol. Ther. 2015, 23, 1234-1247. [CrossRef] [PubMed]

114. Rabé, M.; Dumont, S.; Álvarez-Arenas, A.; Janati, H.; Belmonte-Beitia, J.; Calvo, G.F.; Thibault-Carpentier, C.; Séry, Q.; Chauvin, C.; Joalland, N.; et al. Identification of a transient state during the acquisition of temozolomide resistance in glioblastoma. Cell Death Dis. 2020, 11, 1-14. [CrossRef] [PubMed]

115. Jiapaer, S.; Furuta, T.; Tanaka, S.; Kitabayashi, T.; Nakada, M. Potential Strategies Overcoming the Temozolomide Resistance for Glioblastoma. Neurol. Med. Chir. (Tokyo) 2018, 58, 405-421. [CrossRef] [PubMed]

116. Aasland, D.; Götzinger, L.; Hauck, L.; Berte, N.; Meyer, J.; Effenberger, M.; Schneider, S.; Reuber, E.E.; Roos, W.P.; Tomicic, M.T; et al. Temozolomide induces senescence and repression of DNA repair pathways in glioblastoma cells via activation of ATR-CHK1, p21, and NF-kB. Cancer Res. 2018. [CrossRef] [PubMed]

117. Kanazawa, T.; Minami, Y.; Jinzaki, M.; Toda, M.; Yoshida, K.; Sasaki, H. Predictive markers for MGMT promoter methylation in glioblastomas. Neurosurg. Rev. 2019, 42, 867-876. [CrossRef]

118. Fan, C.-H.; Liu, W.-L.; Cao, H.; Wen, C.; Chen, L.; Jiang, G. O ${ }^{6}$-methylguanine DNA methyltransferase as a promising target for the treatment of temozolomide-resistant gliomas. Cell Death Dis. 2013, 4, e876. [CrossRef]

119. Jalili, C.; Rashidi, I.; Pazhouhi, M. Novel approaches to reduce temozolomide resistance in glioblastoma multiforme: A review of the literature. World Cancer Res. J. 2019, 6. [CrossRef]

120. Higuchi, F.; Nagashima, H.; Ning, J.; Koerner, M.V.A.; Wakimoto, H.; Cahill, D.P. Restoration of Temozolomide Sensitivity by Poly(ADP-Ribose) Polymerase inhibitors in Mismatch Repair Deficient Glioblastoma is Independent of Base Excision Repair. Clin. Cancer Res. 2020. [CrossRef]

121. Gupta, S.K.; Smith, E.J.; Mladek, A.C.; Tian, S.; Decker, P.A.; Kizilbash, S.H.; Kitange, G.J.; Sarkaria, J.N. PARP Inhibitors for Sensitization of Alkylation Chemotherapy in Glioblastoma: Impact of Blood-Brain Barrier and Molecular Heterogeneity. Front. Oncol. 2019, 8. [CrossRef]

122. Chen, X.; Zhang, M.; Gan, H.; Wang, H.; Lee, J.-H.; Fang, D.; Kitange, G.J.; He, L.; Hu, Z.; Parney, I.F.; et al. A novel enhancer regulates MGMT expression and promotes temozolomide resistance in glioblastoma. Nat. Commun. 2018, 9, 2949. [CrossRef] [PubMed]

123. Strobel, H.; Baisch, T.; Fitzel, R.; Schilberg, K.; Siegelin, M.D.; Karpel-Massler, G.; Debatin, K.-M.; Westhoff, M.-A. Temozolomide and Other Alkylating Agents in Glioblastoma Therapy. Biomedicines 2019, 7, 69. [CrossRef]

124. Belter, A.; Barciszewski, J.; Barciszewska, A.-M. Revealing the epigenetic effect of temozolomide on glioblastoma cell lines in therapeutic conditions. PLoS ONE 2020, 15. [CrossRef] [PubMed]

125. Lin, C.-J.; Lee, C.-C.; Shih, Y.-L.; Lin, C.-H.; Wang, S.-H.; Chen, T.-H.; Shih, C.-M. Inhibition of Mitochondriaand Endoplasmic Reticulum Stress-Mediated Autophagy Augments Temozolomide-Induced Apoptosis in Glioma Cells. PLoS ONE 2012, 7. [CrossRef] [PubMed]

126. He, Y.; Su, J.; Lan, B.; Gao, Y.; Zhao, J. Targeting off-target effects: Endoplasmic reticulum stress and autophagy as effective strategies to enhance temozolomide treatment. Onco Targets Ther. 2019, 12, 1857-1865. [CrossRef]

127. Yi, G.; Huang, G.; Guo, M.; Zhang, X.; Wang, H.; Deng, S.; Li, Y.; Xiang, W.; Chen, Z.; Pan, J.; et al. Acquired temozolomide resistance in MGMT-deficient glioblastoma cells is associated with regulation of DNA repair by DHC2. Brain 2019, 142, 2352-2366. [CrossRef]

128. Sun, D.-P.; Lee, Y.-W.; Chen, J.-T.; Lin, Y.-W.; Chen, R.-M. The Bradykinin-BDKRB1 Axis Regulates Aquaporin 4 Gene Expression and Consequential Migration and Invasion of Malignant Glioblastoma Cells via a Ca2+-MEK1-ERK1/2-NF-кB Mechanism. Cancers 2020, 12, 667. [CrossRef]

129. Kim, M.; Umemura, Y.; Leung, D. Bevacizumab and Glioblastoma: Past, Present, and Future Directions. Cancer J. 2018, 24, 180-186. [CrossRef]

130. Wick, W.; Gorlia, T.; Bendszus, M.; Taphoorn, M.; Sahm, F.; Harting, I.; Brandes, A.A.; Taal, W.; Domont, J.; Idbaih, A.; et al. Lomustine and Bevacizumab in Progressive Glioblastoma. N. Engl. J. Med. 2017, 377, 1954-1963. [CrossRef]

131. Herrlinger, U.; Tzaridis, T.; Mack, F.; Steinbach, J.; Schlegel, U.; Sabel, M.; Hau, P.; Kortman, R.D.; Krex, D.; Grauer, O.; et al. Phase III Trial of CCNU/Temozolomide (TMZ) Combination Therapy vs. Standard TMZ Therapy for Newly Diagnosed MGMT-methylated Glioblastoma Patients. Neuro-oncology 2017, 19, vi13-vi14. [CrossRef] 
132. Herrlinger, U.; Tzaridis, T.; Mack, F.; Steinbach, J.P.; Schlegel, U.; Sabel, M.; Hau, P.; Kortmann, R.-D.; Krex, D.; Grauer, O.; et al. Lomustine-temozolomide combination therapy versus standard temozolomide therapy in patients with newly diagnosed glioblastoma with methylated MGMT promoter (CeTeG/NOA-09): A randomised, open-label, phase 3 trial. Lancet 2019, 393, 678-688. [CrossRef]

133. Lombardi, G.; Salvo, G.L.D.; Brandes, A.A.; Eoli, M.; Rudà, R.; Faedi, M.; Lolli, I.; Pace, A.; Daniele, B.; Pasqualetti, F.; et al. Regorafenib compared with lomustine in patients with relapsed glioblastoma (REGOMA): A multicentre, open-label, randomised, controlled, phase 2 trial. Lancet Oncol. 2019, 20, 110-119. [CrossRef]

134. An, Z.; Aksoy, O.; Zheng, T.; Fan, Q.-W.; Weiss, W.A. Epidermal growth factor receptor (EGFR) and EGFRvIII in glioblastoma (GBM): Signaling pathways and targeted therapies. Oncogene 2018, 37, 1561-1575. [CrossRef] [PubMed]

135. Nimotuzumab Plus Radiotherapy with Concomitant and Adjuvant Temozolomide for Cerebral Glioblastoma-Full Text View-ClinicalTrials.gov. Available online: https://clinicaltrials.gov/ct2/show/ NCT03388372 (accessed on 11 July 2020).

136. Du, X.-J.; Li, X.-M.; Cai, L.-B.; Sun, J.-C.; Wang, S.-Y.; Wang, X.-C.; Pang, X.-L.; Deng, M.-L.; Chen, F.-F.; Wang, Z.-Q.; et al. Efficacy and safety of nimotuzumab in addition to radiotherapy and temozolomide for cerebral glioblastoma: A phase II multicenter clinical trial. J. Cancer 2019, 10, 3214-3223. [CrossRef]

137. Yuan, A.L.; Ricks, C.B.; Bohm, A.K.; Lun, X.; Maxwell, L.; Safdar, S.; Bukhari, S.; Gerber, A.; Sayeed, W.; Bering, E.A.; et al. ABT-888 restores sensitivity in temozolomide resistant glioma cells and xenografts. PLoS ONE 2018, 13, e0202860. [CrossRef]

138. Lemasson, B.; Wang, H.; Galbán, S.; Li, Y.; Zhu, Y.; Heist, K.A.; Tsein, C.; Chenevert, T.L.; Rehemtulla, A.; Galbán, C.J.; et al. Evaluation of Concurrent Radiation, Temozolomide and ABT-888 Treatment Followed by Maintenance Therapy with Temozolomide and ABT-888 in a Genetically Engineered Glioblastoma Mouse Model. Neoplasia 2016, 18, 82-89. [CrossRef]

139. Gupta, S.K.; Kizilbash, S.H.; Carlson, B.L.; Mladek, A.C.; Boakye-Agyeman, F.; Bakken, K.K.; Pokorny, J.L.; Schroeder, M.A.; Decker, P.A.; Cen, L.; et al. Delineation of MGMT Hypermethylation as a Biomarker for Veliparib-Mediated Temozolomide-Sensitizing Therapy of Glioblastoma. J. Natl. Cancer Inst. 2016, 108. [CrossRef]

140. Khasraw, M.; McDonald, K.L.; Rosenthal, M.; Lwin, Z.; Ashley, D.M.; Wheeler, H.; Barnes, E.; Foote, M.C.; Koh, E.-S.; Sulman, E.P.; et al. A randomized phase II trial of veliparib (V), radiotherapy (RT) and temozolomide (TMZ) in patients (pts) with unmethylated MGMT (uMGMT) glioblastoma (GBM). J. Clin. Oncol. 2019, 37, 2011. [CrossRef]

141. National Cancer Institute (NCI). A Phase II/III Randomized Trial of Veliparib or Placebo in Combination with Adjuvant Temozolomide in Newly Diagnosed Glioblastoma with MGMT Promoter Hypermethylation. U.S. National Library of Medicine Homepage. Available online: https://clinicaltrials.gov/.

142. Hanna, C.; Kurian, K.M.; Williams, K.; Watts, C.; Jackson, A.; Carruthers, R.; Strathdee, K.; Cruickshank, G.; Dunn, L.; Erridge, S.; et al. Pharmacokinetics, safety and tolerability of olaparib and temozolomide for recurrent glioblastoma: Results of the phase I OPARATIC trial. Neuro-oncology 2020. [CrossRef]

143. Kiyokawa, J.; Wakimoto, H. Preclinical and Clinical Development of Oncolytic Adenovirus for The Treatment of Malignant Glioma. Oncolytic Virotherapy 2019, 8, 27-37. [CrossRef]

144. Tejada, S.; Valle, R.D.; Gallego, J.; Alonso, M.M.; Peterkin, J. ACTR-15. A phase I study of the oncolytic virus DNX-2401 and a short course temozolomide for glioblastoma at first recurrence. Neuro-oncology 2016, 18, vi4. [CrossRef]

145. Virus DNX2401 and Temozolomide in Recurrent Glioblastoma-Full Text View-ClinicalTrials.gov. Available online: https://clinicaltrials.gov/ct2/show/NCT01956734 (accessed on 11 July 2020).

146. Radiation Therapy with Temozolomide and Pembrolizumab in Treating Patients with Newly Diagnosed Glioblastoma-Full Text View-ClinicalTrials.gov. Available online: https:/clinicaltrials.gov/ct2/show/ NCT02530502 (accessed on 11 July 2020).

147. National Cancer Institute (NCI). A Randomized, Double Blind. Phase II Trial of Surgery, Radiation Therapy Plus Temozolomide and Pembrolizumab with and without HSPPC-96 in Newly Diagnosed Glioblastoma (GBM). U.S. National Library of Medicine Homepage. Available online: https://clinicaltrials.gov/.

148. Park, J.-H.; Ryu, C.H.; Kim, M.J.; Jeun, S.-S. Combination Therapy for Gliomas Using Temozolomide and Interferon-Beta Secreting Human Bone Marrow Derived Mesenchymal Stem Cells. J. Korean Neurosurg. Soc. 2015, 57, 323-328. [CrossRef] [PubMed] 
149. Liu, T.; Li, A.; Xu, Y.; Xin, Y. Momelotinib sensitizes glioblastoma cells to temozolomide by enhancement of autophagy via JAK2/STAT3 inhibition. Oncol. Rep. 2019, 41, 1883-1892. [CrossRef] [PubMed]

150. Valtorta, S.; Dico, A.L.; Raccagni, I.; Gaglio, D.; Belloli, S.; Politi, L.S.; Martelli, C.; Diceglie, C.; Bonanomi, M.; Ercoli, G.; et al. Metformin and temozolomide, a synergic option to overcome resistance in glioblastoma multiforme models. Oncotarget 2017, 8, 113090-113104. [CrossRef]

151. Mazurek, M.; Litak, J.; Kamieniak, P.; Kulesza, B.; Jonak, K.; Baj, J.; Grochowski, C. Metformin as Potential Therapy for High-Grade Glioma. Cancers 2020, 12, 210. [CrossRef] [PubMed]

152. Temozolomide, Memantine Hydrochloride, Mefloquine, and Metformin Hydrochloride in Treating Patients with Glioblastoma Multiforme After Radiation Therapy-Full Text View-ClinicalTrials.gov. Available online: https://clinicaltrials.gov/ct2/show/NCT01430351 (accessed on 11 July 2020).

153. Shenouda, G. Metformin and Neo-adjuvant Temozolomide and Hypofractionated Accelerated Limited-margin Radiotherapy Followed by Adjuvant Temozolomide in Patients with Glioblastoma Multiforme (M-HARTT STUDY). U.S. National Library of Medicine Homepage. Available online: https://clinicaltrials.gov/.

154. Study on Low Dose Temozolomide Plus Metformin or Placebo in Patient with Recurrent or Refractory Glioblastoma-Full Text View-ClinicalTrials.gov. Available online: https://clinicaltrials.gov/ct2/show/ NCT03243851 (accessed on 11 July 2020).

155. Yu, Z.; Zhao, G.; Zhang, Z.; Li, Y.; Chen, Y.; Wang, N.; Zhao, Z.; Xie, G. Efficacy and safety of bevacizumab for the treatment of glioblastoma (Review). Exp. Ther. Med. 2016, 11, 371-380. [CrossRef]

156. Garcia, J.; Hurwitz, H.I.; Sandler, A.B.; Miles, D.; Coleman, R.L.; Deurloo, R.; Chinot, O.L. Bevacizumab (Avastin ${ }^{\circledR}$ ) in cancer treatment: A review of 15 years of clinical experience and future outlook. Cancer Treat. Rev. 2020, 86. [CrossRef]

157. Bevacizumab and Temozolomide in Treating Older Patients with Newly-Diagnosed Glioblastoma Multiforme or Gliosarcoma-Full Text View—ClinicalTrials.gov. Available online: https:/clinicaltrials.gov/ct2/show/ NCT01149850 (accessed on 11 July 2020).

158. Grupo Español de Investigación en Neurooncología a Phase II Open Label. Randomised Multicentric Study in Patients with Unresectable Glioblastoma Using Neo-adjuvant Treatment with Two Cycles of Temozolomide Previous Temozolomide Plus Radiation Therapy and Adjuvant Temozolomide vs. Neo-adjuvant Treatment with Two Cycles of Temozolomide Plus Bevacizumab Previous Temozolomide, Bevacizumab and Radiation Therapy and Adjuvant Temozolomide. U.S. National Library of Medicine Homepage. Available online: https://clinicaltrials.gov/.

159. Robins, H.I.; Zhang, P.; Gilbert, M.R.; Chakravarti, A.; de Groot, J.F.; Grimm, S.A.; Wang, F.; Lieberman, F.S.; Krauze, A.; Trotti, A.M.; et al. A randomized phase I/II study of ABT-888 in combination with temozolomide in recurrent temozolomide resistant glioblastoma: An NRG oncology RTOG group study. J. Neurooncol. 2016, 126, 309-316. [CrossRef]

160. Cancer Research UK A Cancer Research UK Phase I Trial of Olaparib (AZD2281), an Oral PARP Inhibitor, in Combination with Extended Low-Dose Oral Temozolomide in Patients with Relapsed Glioblastoma. U.S. National Library of Medicine Homepage. Available online: https://clinicaltrials.gov.

161. Reardon, D.A.; Brandes, A.A.; Omuro, A.; Mulholland, P.; Lim, M.; Wick, A.; Baehring, J.; Ahluwalia, M.S.; Roth, P.; Bähr, O.; et al. Effect of Nivolumab vs. Bevacizumab in Patients with Recurrent Glioblastoma: The CheckMate 143 Phase 3 Randomized Clinical Trial. JAMA Oncol. 2020. [CrossRef]

162. Bristol-Myers Squibb A Randomized Phase 3 Open Label. Study of Nivolumab Versus Bevacizumab and Multiple Phase 1 Safety Cohorts of Nivolumab or Nivolumab in Combination with Ipilimumab Across Different Lines of Glioblastoma. U.S. National Library of Medicine Homepage. Available online: https://clinicaltrials.gov/.

163. National Cancer Institute (NCI). A Phase II Trial of Nivolumab for IDH-mutated Gliomas with Hypermutator Phenotype. U.S. National Library of Medicine Homepage. Available online: https:/clinicaltrials.gov/.

164. Machida, Y.; Nakagawa, M.; Matsunaga, H.; Yamaguchi, M.; Ogawara, Y.; Shima, Y.; Yamagata, K.; Katsumoto, T.; Hattori, A.; Itoh, M.; et al. A Potent Blood-Brain Barrier-Permeable Mutant IDH1 Inhibitor Suppresses the Growth of Glioblastoma with IDH1 Mutation in a Patient-Derived Orthotopic Xenograft Model. Mol. Cancer Ther. 2019. [CrossRef]

165. Study of DS-1001b in Patients with Gene IDH1-Mutated Gliomas-Full Text View-ClinicalTrials.gov. Available online: https://clinicaltrials.gov/ct2/show/NCT03030066 (accessed on 11 July 2020). 
166. Natsume, A.; Wakabayashi, T.; Miyakita, Y.; Narita, Y.; Mineharu, Y.; Arakawa, Y.; Yamasaki, F.; Sugiyama, K.; Hata, N.; Muragaki, Y.; et al. Phase I study of a brain penetrant mutant IDH1 inhibitor DS-1001b in patients with recurrent or progressive IDH1 mutant gliomas. J. Clin. Oncol. 2019, 37, 2004. [CrossRef]

167. Reardon, D.A.; De Groot, J.F.; Colman, H.; Jordan, J.T.; Daras, M.; Clarke, J.L.; Nghiemphu, P.L.; Gaffey, S.C.; Peters, K.B. Safety of pembrolizumab in combination with bevacizumab in recurrent glioblastoma (rGBM). J. Clin. Oncol. 2016, 34, 2010. [CrossRef]

168. MD, D.R. Phase II Study of Pembrolizumab (MK-3475) With and Without Bevacizumab for Recurrent Glioblastoma. U.S. National Library of Medicine Homepage. Available online: https:/clinicaltrials.gov/.

169. Kim, J.E.; Patel, M.A.; Mangraviti, A.; Kim, E.S.; Theodros, D.; Velarde, E.; Liu, A.; Sankey, E.W.; Tam, A.; $\mathrm{Xu}, \mathrm{H}$.; et al. Combination Therapy with Anti-PD-1, Anti-TIM-3, and Focal Radiation Results in Regression of Murine Gliomas. Clin. Cancer Res. 2016. [CrossRef] [PubMed]

170. Hung, A.L.; Maxwell, R.; Theodros, D.; Belcaid, Z.; Mathios, D.; Luksik, A.S.; Kim, E.; Wu, A.; Xia, Y.; Garzon-Muvdi, T.; et al. TIGIT and PD-1 dual checkpoint blockade enhances antitumor immunity and survival in GBM. Oncoimmunology 2018, 7, e1466769. [CrossRef]

171. Hanif, F.; Muzaffar, K.; Perveen, K.; Malhi, S.M.; Simjee, S.U. Glioblastoma Multiforme: A Review of its Epidemiology and Pathogenesis through Clinical Presentation and Treatment. Asian Pac. J. Cancer Prev. 2017, 18, 3-9. [CrossRef]

172. Yin, J.; Zeng, A.; Zhang, Z.; Shi, Z.; Yan, W.; You, Y. Exosomal transfer of miR-1238 contributes to temozolomide-resistance in glioblastoma. EBioMedicine 2019, 42, 238-251. [CrossRef]

173. Zeng, A.; Wei, Z.; Yan, W.; Yin, J.; Huang, X.; Zhou, X.; Li, R.; Shen, F.; Wu, W.; Wang, X.; et al. Exosomal transfer of miR-151a enhances chemosensitivity to temozolomide in drug-resistant glioblastoma. Cancer Lett. 2018, 436, 10-21. [CrossRef]

174. Figueroa, J.; Phillips, L.M.; Shahar, T.; Hossain, A.; Gumin, J.; Kim, H.; Bean, A.J.; Calin, G.A.; Fueyo, J.; Walters, E.T.; et al. Exosomes from Glioma-Associated Mesenchymal Stem Cells Increase the Tumorigenicity of Glioma Stem-like Cells via Transfer of miR-1587. Cancer Res. 2017, 77, 5808-5819. [CrossRef]

175. Seymour, T.; Nowak, A.; Kakulas, F. Targeting Aggressive Cancer Stem Cells in Glioblastoma. Front. Oncol. 2015, 5. [CrossRef]

176. Yang, L.; Li, N.; Yan, Z.; Li, C.; Zhao, Z. MiR-29a-Mediated CD133 Expression Contributes to Cisplatin Resistance in CD133+ Glioblastoma Stem Cells. J. Mol. Neurosci. 2018, 66, 369-377. [CrossRef]

177. Xiao, S.; Yang, Z.; Qiu, X.; Lv, R.; Liu, J.; Wu, M.; Liao, Y.; Liu, Q. miR-29c contribute to glioma cells temozolomide sensitivity by targeting $\mathrm{O} 6$-methylguanine-DNA methyltransferases indirectly. Oncotarget 2016, 7, 50229-50238. [CrossRef] [PubMed]

178. Li, S.; Zeng, A.; Hu, Q.; Yan, W.; Liu, Y.; You, Y. miR-423-5p contributes to a malignant phenotype and temozolomide chemoresistance in glioblastomas. Neuro-oncology 2017, 19, 55-65. [CrossRef] [PubMed]

179. Yan, W.; Liu, Y.; Yang, P.; Wang, Z.; You, Y.; Jiang, T. MicroRNA profiling of Chinese primary glioblastoma reveals a temozolomide-chemoresistant subtype. Oncotarget 2015, 6, 11676-11682. [CrossRef] [PubMed]

180. Luo, W.; Yan, D.; Song, Z.; Zhu, X.; Liu, X.; Li, X.; Zhao, S. miR-126-3p sensitizes glioblastoma cells to temozolomide by inactivating $\mathrm{Wnt} / \beta$-catenin signaling via targeting SOX2. Life Sci. 2019, 226, 98-106. [CrossRef] [PubMed]

181. Liu, J.; Xu, J.; Li, H.; Sun, C.; Yu, L.; Li, Y.; Shi, C.; Zhou, X.; Bian, X.; Ping, Y.; et al. miR-146b-5p functions as a tumor suppressor by targeting TRAF6 and predicts the prognosis of human gliomas. Oncotarget 2015, 6, 29129-29142. [CrossRef]

182. Lin, Y.; Qiu, Y.; Xu, C.; Liu, Q.; Peng, B.; Kaufmann, G.F.; Chen, X.; Lan, B.; Wei, C.; Lu, D.; et al. Functional Role of Asparaginyl Endopeptidase Ubiquitination by TRAF6 in Tumor Invasion and Metastasis. J. Natl. Cancer Inst. 2014, 106. [CrossRef]

183. Sun, H.; Li, X.; Fan, L.; Wu, G.; Li, M.; Fang, J. TRAF6 is upregulated in colon cancer and promotes proliferation of colon cancer cells. Int. J. Biochem. Cell Biol. 2014, 53, 195-201. [CrossRef]

184. Yan, Y.; Xu, Z.; Dai, S.; Qian, L.; Sun, L.; Gong, Z. Targeting autophagy to sensitive glioma to temozolomide treatment. J. Exp. Clin. Cancer Res. 2016, 35, 23. [CrossRef]

185. Huang, B.-S.; Luo, Q.-Z.; Han, Y.; Huang, D.; Tang, Q.-P.; Wu, L.-X. MiR-223/PAX6 Axis Regulates Glioblastoma Stem Cell Proliferation and the Chemo Resistance to TMZ via Regulating PI3K/Akt Pathway. J. Cell. Biochem. 2017, 118, 3452-3461. [CrossRef] 
186. Cheng, Q.; Ma, X.; Cao, H.; Chen, Z.; Wan, X.; Chen, R.; Peng, R.; Huang, J.; Jiang, B. Role of miR-223/paired box 6 signaling in temozolomide chemoresistance in glioblastoma multiforme cells. Mol. Med. Rep. 2017, 15, 597-604. [CrossRef]

187. Munoz, J.L.; Walker, N.D.; Mareedu, S.; Pamarthi, S.H.; Sinha, G.; Greco, S.J.; Rameshwar, P. Cycling Quiescence in Temozolomide Resistant Glioblastoma Cells Is Partly Explained by microRNA-93 and -193-Mediated Decrease of Cyclin, D. Front. Pharmacol. 2019, 10. [CrossRef] [PubMed]

188. Jia, B.; Liu, W.; Gu, J.; Wang, J.; Lv, W.; Zhang, W.; Hao, Q.; Pang, Z.; Mu, N.; Zhang, W.; et al. MiR-7-5p suppresses stemness and enhances temozolomide sensitivity of drug-resistant glioblastoma cells by targeting Yin Yang 1. Exp. Cell Res. 2019, 375, 73-81. [CrossRef] [PubMed]

189. Sarvagalla, S.; Kolapalli, S.P.; Vallabhapurapu, S. The Two Sides of YY1 in Cancer: A Friend and a Foe. Front. Oncol. 2019, 9. [CrossRef]

190. Li, J.; Song, J.; Guo, F. miR-186 reverses cisplatin resistance and inhibits the formation of the glioblastoma-initiating cell phenotype by degrading Yin Yang 1 in glioblastoma. Int. J. Mol. Med. 2019, 43, 517-524. [CrossRef] [PubMed]

191. Huang, S.; Qi, P.; Zhang, T.; Li, F.; He, X. The HIF-1 $\alpha /$ miR-224-3p/ATG5 axis affects cell mobility and chemosensitivity by regulating hypoxia-induced protective autophagy in glioblastoma and astrocytoma. Oncol. Rep. 2019, 41, 1759-1768. [CrossRef] [PubMed]

192. Li, H.; Chen, L.; Li, J.; Zhou, Q.; Huang, A.; Liu, W.; Wang, K.; Gao, L.; Qi, S.; Lu, Y. miR-519a enhances chemosensitivity and promotes autophagy in glioblastoma by targeting STAT3/Bcl2 signaling pathway. J. Hematol. Oncol. 2018, 11, 70. [CrossRef]

193. Stojcheva, N.; Schechtmann, G.; Sass, S.; Roth, P.; Florea, A.-M.; Stefanski, A.; Stühler, K.; Wolter, M.; Müller, N.S.; Theis, F.J.; et al. MicroRNA-138 promotes acquired alkylator resistance in glioblastoma by targeting the Bcl-2-interacting mediator BIM. Oncotarget 2016, 7, 12937-12950. [CrossRef]

194. Zhou, D.; Wan, Y.; Xie, D.; Wang, Y.; Wei, J.; Yan, Q.; Lu, P.; Mo, L.; Xie, J.; Yang, S.; et al. DNMT1 mediates chemosensitivity by reducing methylation of miRNA-20a promoter in glioma cells. Exp. Mol. Med. 2015, 47, e182. [CrossRef]

195. Vietheer, J.-M.; Rieger, J.; Wagner, M.; Senft, C.; Tichy, J.; Foerch, C. Serum concentrations of glial fibrillary acidic protein (GFAP) do not indicate tumor recurrence in patients with glioblastoma. J. Neurooncol. 2017, 135, 193-199. [CrossRef]

196. Fortier, A.-M.; Asselin, E.; Cadrin, M. Keratin 8 and 18 loss in epithelial cancer cells increases collective cell migration and cisplatin sensitivity through claudin1 up-regulation. J. Biol. Chem. 2013, 288, 11555-11571. [CrossRef]

197. Chattopadhyay, R.; Das, S.; Maiti, A.K.; Boldogh, I.; Xie, J.; Hazra, T.K.; Kohno, K.; Mitra, S.; Bhakat, K.K. Regulatory role of human AP-endonuclease (APE1/Ref-1) in YB-1-mediated activation of the multidrug resistance gene MDR1. Mol. Cell. Biol. 2008, 28, 7066-7080. [CrossRef] [PubMed]

198. Fantini, D.; Vascotto, C.; Deganuto, M.; Bivi, N.; Gustincich, S.; Marcon, G.; Quadrifoglio, F.; Damante, G.; Bhakat, K.K.; Mitra, S.; et al. APE1/Ref-1 regulates PTEN expression mediated by Egr-1. Free Radic. Res. 2008, 42, 20-29. [CrossRef] [PubMed]

199. Chun-Zhi, Z.; Lei, H.; An-Ling, Z.; Yan-Chao, F.; Xiao, Y.; Guang-Xiu, W.; Zhi-Fan, J.; Pei-Yu, P.; Qing-Yu, Z.; Chun-Sheng, K. MicroRNA-221 and microRNA-222 regulate gastric carcinoma cell proliferation and radioresistance by targeting PTEN. BMC Cancer 2010, 10, 367. [CrossRef] [PubMed]

200. Zhao, J.-J.; Lin, J.; Yang, H.; Kong, W.; He, L.; Ma, X.; Coppola, D.; Cheng, J.Q. MicroRNA-221/222 negatively regulates estrogen receptor $\alpha$ and is associated with tamoxifen resistance in breast cancer. J. Biol. Chem. 2016, 291, 22859. [CrossRef]

201. Acunzo, M.; Visone, R.; Romano, G.; Veronese, A.; Lovat, F.; Palmieri, D.; Bottoni, A.; Garofalo, M.; Gasparini, P.; Condorelli, G.; et al. miR-130a targets MET and induces TRAIL-sensitivity in NSCLC by downregulating miR-221 and 222. Oncogene 2012, 31, 634-642. [CrossRef]

202. Zhang, C.; Kang, C.; Wang, P.; Cao, Y.; Lv, Z.; Yu, S.; Wang, G.; Zhang, A.; Jia, Z.; Han, L.; et al. MicroRNA-221 and -222 Regulate Radiation Sensitivity by Targeting the PTEN Pathway. Int. J. Radiat. Oncol. Biol. Phys. 2011, 80, 240-248. [CrossRef]

203. Miller, T.E.; Ghoshal, K.; Ramaswamy, B.; Roy, S.; Datta, J.; Shapiro, C.L.; Jacob, S.; Majumder, S. MicroRNA-221/222 Confers Tamoxifen Resistance in Breast Cancer by Targeting p27Kip1. J. Biol. Chem. 2008, 283, 29897-29903. [CrossRef] 
204. Li, R.; Gao, K.; Luo, H.; Wang, X.; Shi, Y.; Dong, Q.; Luan, W.; You, Y. Identification of intrinsic subtype-specific prognostic microRNAs in primary glioblastoma. J. Exp. Clin. Cancer Res. 2014, 33, 9. [CrossRef]

205. Tivnan, A.; Heilinger, T.; Ramsey, J.M.; O'Connor, G.; Pokorny, J.L.; Sarkaria, J.N.; Stringer, B.W.; Day, B.W.; Boyd, A.W.; Kim, E.L.; et al. Anti-GD2-ch14.18/CHO coated nanoparticles mediate glioblastoma (GBM)-specific delivery of the aromatase inhibitor, Letrozole, reducing proliferation, migration and chemoresistance in patient-derived GBM tumor cells. Oncotarget 2017, 8, 16605-16620. [CrossRef]

206. Di Leva, G.; Piovan, C.; Gasparini, P.; Ngankeu, A.; Taccioli, C.; Briskin, D.; Cheung, D.G.; Bolon, B.; Anderlucci, L.; Alder, H.; et al. Estrogen mediated-activation of miR-191/425 cluster modulates tumorigenicity of breast cancer cells depending on estrogen receptor status. PLoS Genet. 2013, 9, e1003311. [CrossRef]

207. Pyko, I.V.; Nakada, M.; Sabit, H.; Teng, L.; Furuyama, N.; Hayashi, Y.; Kawakami, K.; Minamoto, T.; Fedulau, A.S.; Hamada, J. Glycogen synthase kinase $3 \beta$ inhibition sensitizes human glioblastoma cells to temozolomide by affecting O6-methylguanine DNA methyltransferase promoter methylation via c-Myc signaling. Carcinogenesis 2013, 34, 2206-2217. [CrossRef] [PubMed]

208. Fu, Y.; Hu, D.; Qiu, J.; Xie, X.; Ye, F.; Lu, W.-G. Overexpression of glycogen synthase kinase-3 in ovarian carcinoma cells with acquired paclitaxel resistance. Int. J. Gynecol. Cancer 2011, 21, 439-444. [CrossRef] [PubMed]

209. Grassilli, E.; Ianzano, L.; Bonomo, S.; Missaglia, C.; Cerrito, M.G.; Giovannoni, R.; Masiero, L.; Lavitrano, M. GSK3A is redundant with GSK3B in modulating drug resistance and chemotherapy-induced necroptosis. PLoS ONE 2014, 9, e100947. [CrossRef] [PubMed]

210. Tian, T.; Mingyi, M.; Qiu, X.; Qiu, Y. MicroRNA-101 reverses temozolomide resistance by inhibition of GSK3 $\beta$ in glioblastoma. Oncotarget 2016, 7, 79584-79595. [CrossRef] [PubMed]

211. Salvatore, D.; Lo Dico, A.; Martelli, C.; Diceglie, C.; Ottobrini, L. PET biomarkers and probes for treatment response assessment in glioblastoma: A work in progress. Clin. Transl. Imaging 2019, 7, 285-294. [CrossRef]

212. John, F.; Bosnyák, E.; Robinette, N.L.; Amit-Yousif, A.J.; Barger, G.R.; Shah, K.D.; Michelhaugh, S.K.; Klinger, N.V.; Mittal, S.; Juhász, C. Multimodal imaging-defined subregions in newly diagnosed glioblastoma: Impact on overall survival. Neuro-oncology 2019, 21, 264-273. [CrossRef]

213. Verduin, M.; Compter, I.; Steijvers, D.; Postma, A.A.; Eekers, D.B.P.; Anten, M.M.; Ackermans, L.; Ter Laan, M.; Leijenaar, R.T.H.; van de Weijer, T.; et al. Noninvasive Glioblastoma Testing: Multimodal Approach to Monitoring and Predicting Treatment Response. Dis. Markers 2018, 2018, 2908609. [CrossRef]

214. Ata, E.S.; Turgut, M.; Eraslan, C.; Dayanır, Y.Ö. Comparison between dynamic susceptibility contrast magnetic resonance imaging and arterial spin labeling techniques in distinguishing malignant from benign brain tumors. Eur. J. Radiol. 2016, 85, 1545-1553. [CrossRef]

215. Pope, W.B.; Brandal, G. Conventional and advanced magnetic resonance imaging in patients with high-grade glioma. Q. J. Nucl. Med. Mol. Imaging 2018, 62, 239-253. [CrossRef]

216. Zhang, H.; Ma, L.; Shu, C.; Wang, Y.; Dong, L. Diagnostic accuracy of diffusion MRI with quantitative ADC measurements in differentiating glioma recurrence from radiation necrosis. J. Neurol. Sci. 2015, 351, 65-71. [CrossRef]

217. Valtorta, S.; Nicolini, G.; Tripodi, F.; Meregalli, C.; Cavaletti, G.; Avezza, F.; Crippa, L.; Bertoli, G.; Sanvito, F.; Fusi, P.; et al. A novel AMPK activator reduces glucose uptake and inhibits tumor progression in a mouse xenograft model of colorectal cancer. Investig. New Drugs 2014, 32, 1123-1133. [CrossRef] [PubMed]

218. Venneti, S.; Dunphy, M.P.; Zhang, H.; Pitter, K.L.; Zanzonico, P.; Campos, C.; Carlin, S.D.; La Rocca, G.; Lyashchenko, S.; Ploessl, K.; et al. Glutamine-based PET imaging facilitates enhanced metabolic evaluation of gliomas in vivo. Sci. Transl. Med. 2015, 7, 274ra17. [CrossRef] [PubMed]

219. Miner, M.W.; Liljenbäck, H.; Virta, J.; Merisaari, J.; Oikonen, V.; Westermarck, J.; Li, X.-G.; Roivainen, A. (2S, 4R)-4-[18F]Fluoroglutamine for In vivo PET Imaging of Glioma Xenografts in Mice: An Evaluation of Multiple Pharmacokinetic Models. Mol. Imaging Biol. 2020, 22, 969-978. [CrossRef]

220. Dunphy, M.P.S.; Harding, J.J.; Venneti, S.; Zhang, H.; Burnazi, E.M.; Bromberg, J.; Omuro, A.M.; Hsieh, J.J.; Mellinghoff, I.K.; Staton, K.; et al. In Vivo PET Assay of Tumor Glutamine Flux and Metabolism: In-Human Trial of ${ }^{18} \mathrm{~F}-(2 \mathrm{~S}, 4$ R)-4-Fluoroglutamine. Radiology 2018, 287, 667-675. [CrossRef] [PubMed]

221. Kim, S.; Kim, D.; Kim, S.H.; Park, M.; Chang, J.H.; Yun, M. The roles of 11C-acetate PET/CT in predicting tumor differentiation and survival in patients with cerebral glioma. Eur. J. Nucl. Med. Mol. Imaging 2018, 45, 1012-1020. [CrossRef] [PubMed] 
222. Koyasu, S.; Shimizu, Y.; Morinibu, A.; Saga, T.; Nakamoto, Y.; Togashi, K.; Harada, H. Increased 14C-acetate accumulation in IDH-mutated human glioblastoma: Implications for detecting IDH-mutated glioblastoma with 11C-acetate PET imaging. J. Neurooncol. 2019, 145, 441-447. [CrossRef]

223. Lukas, R.V.; Juhász, C.; Wainwright, D.A.; James, C.D.; Kennedy, E.; Stupp, R.; Lesniak, M.S. Imaging tryptophan uptake with positron emission tomography in glioblastoma patients treated with indoximod. J. Neurooncol. 2019, 141, 111-120. [CrossRef]

224. Guastella, A.R.; Michelhaugh, S.K.; Klinger, N.V.; Kupsky, W.J.; Polin, L.A.; Muzik, O.; Juhász, C.; Mittal, S. Tryptophan PET Imaging of the Kynurenine Pathway in Patient-Derived Xenograft Models of Glioblastoma. Mol. Imaging 2016. [CrossRef]

225. Bosnyák, E.; Michelhaugh, S.K.; Klinger, N.V.; Kamson, D.O.; Barger, G.R.; Mittal, S.; Juhász, C. Prognostic Molecular and Imaging Biomarkers in Primary Glioblastoma. Clin. Nucl. Med. 2017, 42, 341-347. [CrossRef]

226. John, F.; Robinette, N.L.; Amit-Yousif, A.J.; Bosnyák, E.; Barger, G.R.; Shah, K.D.; Mittal, S.; Juhász, C. Multimodal Imaging of Nonenhancing Glioblastoma Regions. Mol. Imaging 2019, 18. [CrossRef]

227. Xin, Y.; Gao, X.; Liu, L.; Ge, W.-P.; Jain, M.K.; Cai, H. Evaluation of 1-1-[ ${ }^{18}$ F] Fluoroethyl-Tryptophan for PET Imaging of Cancer. Mol. Imaging Biol. 2019, 21. [CrossRef] [PubMed]

228. Henderson, F.; Brem, S.; O’Rourke, D.M.; Nasrallah, M.; Buch, V.P.; Young, A.J.; Doot, R.K.; Pantel, A.; Desai, A.; Bagley, S.J.; et al. ${ }^{18} \mathrm{~F}-\mathrm{Fluciclovine} \mathrm{PET} \mathrm{to} \mathrm{distinguish} \mathrm{treatment-related} \mathrm{effects} \mathrm{from} \mathrm{disease}$ progression in recurrent glioblastoma: PET fusion with MRI guides neurosurgical sampling. Neuro-Oncol. Pract. 2020, 7, 152-157. [CrossRef] [PubMed]

229. Verhoeven, J.; Hulpia, F.; Kersemans, K.; Bolcaen, J.; De Lombaerde, S.; Goeman, J.; Descamps, B.; Hallaert, G.; Van den Broecke, C.; Deblaere, K.; et al. New fluoroethyl phenylalanine analogues as potential LAT1-targeting PET tracers for glioblastoma. Sci. Rep. 2019, 9, 2878. [CrossRef] [PubMed]

230. Nozaki, S.; Nakatani, Y.; Mawatari, A.; Shibata, N.; Hume, W.E.; Hayashinaka, E.; Wada, Y.; Doi, H.; Watanabe, Y.18 F-FIMP: A LAT1-specific PET probe for discrimination between tumor tissue and inflammation. Sci. Rep. 2019, 9, 15718. [CrossRef]

231. Schwarzenberg, J.; Czernin, J.; Cloughesy, T.F.; Ellingson, B.M.; Pope, W.B.; Geist, C.; Dahlbom, M.; Silverman, D.H.S.; Satyamurthy, N.; Phelps, M.E.; et al. 3'-deoxy-3'-18F-fluorothymidine PET and MRI for early survival predictions in patients with recurrent malignant glioma treated with bevacizumab. J. Nucl. Med. 2012, 53, 29-36. [CrossRef]

232. Viel, T.; Schelhaas, S.; Wagner, S.; Wachsmuth, L.; Schwegmann, K.; Kuhlmann, M.; Faber, C.; Kopka, K.; Schäfers, M.; Jacobs, A.H. Early assessment of the efficacy of temozolomide chemotherapy in experimental glioblastoma using $\left[{ }^{18} \mathrm{~F}\right.$ ] FLT-PET imaging. PLoS ONE 2013, 8, e67911. [CrossRef]

233. O'Halloran, P.J.; Viel, T.; Murray, D.W.; Wachsmuth, L.; Schwegmann, K.; Wagner, S.; Kopka, K.; Jarzabek, M.A.; Dicker, P.; Hermann, S.; et al. Mechanistic interrogation of combination bevacizumab/dual PI3K/mTOR inhibitor response in glioblastoma implementing novel MR and PET imaging biomarkers. Eur. J. Nucl. Med. Mol. Imaging 2016, 43, 1673-1683. [CrossRef]

234. Lo Dico, A.; Martelli, C.; Valtorta, S.; Raccagni, I.; Diceglie, C.; Belloli, S.; Gianelli, U.; Vaira, V.; Politi, L.S.; Bosari, S.; et al. Identification of imaging biomarkers for the assessment of tumour response to different treatments in a preclinical glioma model. Eur. J. Nucl. Med. Mol. Imaging 2015, 42, 1093-1105. [CrossRef]

235. Corroyer-Dulmont, A.; Pérès, E.A.; Gérault, A.N.; Savina, A.; Bouquet, F.; Divoux, D.; Toutain, J.; Ibazizène, M.; MacKenzie, E.T.; Barré, L.; et al. Multimodal imaging based on MRI and PET reveals [(18)F]FLT PET as a specific and early indicator of treatment efficacy in a preclinical model of recurrent glioblastoma. Eur. J. Nucl. Med. Mol. Imaging 2016, 43, 682-694. [CrossRef]

236. Lo Dico, A.; Valtorta, S.; Martelli, C.; Belloli, S.; Gianelli, U.; Tosi, D.; Bosari, S.; Degrassi, A.; Russo, M.; Raccagni, I.; et al. Validation of an engineered cell model for in vitro and in vivo HIF-1 $\alpha$ evaluation by different imaging modalities. Mol. Imaging Biol. 2014, 16, 210-223. [CrossRef]

237. Wehrl, H.F.; Schwab, J.; Hasenbach, K.; Reischl, G.; Tabatabai, G.; Quintanilla-Martinez, L.; Jiru, F.; Chughtai, K.; Kiss, A.; Cay, F.; et al. Multimodal elucidation of choline metabolism in a murine glioma model using magnetic resonance spectroscopy and 11C-choline positron emission tomography. Cancer Res. 2013, 73, 1470-1480. [CrossRef] [PubMed]

238. Takei, H.; Shinoda, J.; Ikuta, S.; Maruyama, T.; Muragaki, Y.; Kawasaki, T.; Ikegame, Y.; Okada, M.; Ito, T.; Asano, Y.; et al. Usefulness of positron emission tomography for differentiating gliomas according to the 
2016 World Health Organization classification of tumors of the central nervous system. J. Neurosurg. 2019, 1-10. [CrossRef] [PubMed]

239. Raccagni, I.; Valtorta, S.; Moresco, R.M.; Belloli, S. Tumour hypoxia: Lessons learnt from preclinical imaging. Clin. Transl. Imaging 2017, 5, 407-425. [CrossRef]

240. Gangemi, V.; Mignogna, C.; Guzzi, G.; Lavano, A.; Bongarzone, S.; Cascini, G.L.; Sabatini, U. Impact of [ $\left[{ }^{64} \mathrm{Cu}\right]$ [Cu(ATSM)] PET/CT in the evaluation of hypoxia in a patient with Glioblastoma: A case report. BMC Cancer 2019, 19, 1197. [CrossRef] [PubMed]

241. Toriihara, A.; Ohtake, M.; Tateishi, K.; Hino-Shishikura, A.; Yoneyama, T.; Kitazume, Y.; Inoue, T.; Kawahara, N.; Tateishi, U. Prognostic implications of ${ }^{62} \mathrm{Cu}$-diacetyl-bis (N4-methylthiosemicarbazone) PET/CT in patients with glioma. Ann. Nucl. Med. 2018, 32, 264-271. [CrossRef]

242. Jin, Z.-H.; Tsuji, A.B.; Degardin, M.; Sugyo, A.; Yoshii, Y.; Nagatsu, K.; Zhang, M.-R.; Fujibayashi, Y.; Dumy, P.; Boturyn, D.; et al. Uniform intratumoral distribution of radioactivity produced using two different radioagents, ${ }^{64} \mathrm{Cu}$-cyclam-RAFT-c(-RGDfK-) 4 and ${ }^{64} \mathrm{Cu}-\mathrm{ATSM}$, improves therapeutic efficacy in a small animal tumor model. EJNMMI Res. 2018, 8, 54. [CrossRef]

243. Yoshii, Y.; Matsumoto, H.; Yoshimoto, M.; Zhang, M.-R.; Oe, Y.; Kurihara, H.; Narita, Y.; Jin, Z.-H.; Tsuji, A.B.; Yoshinaga, K.; et al. Multiple Administrations of ${ }^{64} \mathrm{Cu}$-ATSM as a Novel Therapeutic Option for Glioblastoma: A Translational Study Using Mice with Xenografts. Transl. Oncol. 2017, 11, 24-30. [CrossRef]

244. Pérès, E.A.; Toutain, J.; Paty, L.-P.; Divoux, D.; Ibazizène, M.; Guillouet, S.; Barré, L.; Vidal, A.; Cherel, M.; Bourgeois, M.; et al. ${ }^{64} \mathrm{Cu}-\mathrm{ATSM} /{ }^{64} \mathrm{Cu}-\mathrm{Cl}^{2}$ and their relationship to hypoxia in glioblastoma: A preclinical study. EJNMMI Res. 2019, 9, 114. [CrossRef]

245. Su, Z.; Roncaroli, F.; Durrenberger, P.F.; Coope, D.J.; Karabatsou, K.; Hinz, R.; Thompson, G.; Turkheimer, F.E.; Janczar, K.; Du Plessis, D.; et al. The 18-kDa mitochondrial translocator protein in human gliomas: An 11C-(R)PK11195 PET imaging and neuropathology study. J. Nucl. Med. 2015, 56, 512-517. [CrossRef]

246. Zinnhardt, B.; Pigeon, H.; Thézé, B.; Viel, T.; Wachsmuth, L.; Fricke, I.B.; Schelhaas, S.; Honold, L.; Schwegmann, K.; Wagner, S.; et al. Combined PET Imaging of the Inflammatory Tumor Microenvironment Identifies Margins of Unique Radiotracer Uptake. Cancer Res. 2017, 77, 1831-1841. [CrossRef]

247. Zinnhardt, B.; Müther, M.; Roll, W.; Backhaus, P.; Jeibmann, A.; Foray, C.; Barca, C.; Döring, C.; Tavitian, B.; Dollé, F.; et al. TSPO imaging-guided characterization of the immunosuppressive myeloid tumor microenvironment in patients with malignant glioma. Neuro-oncology 2020, 22, 1030-1043. [CrossRef] [PubMed]

248. Pigeon, H.; Pérès, E.A.; Truillet, C.; Jego, B.; Boumezbeur, F.; Caillé, F.; Zinnhardt, B.; Jacobs, A.H.; Le Bihan, D.; Winkeler, A. TSPO-PET and diffusion-weighted MRI for imaging a mouse model of infiltrative human glioma. Neuro-oncology 2019, 21, 755-764. [CrossRef] [PubMed]

249. Belloli, S.; Zanotti, L.; Murtaj, V.; Mazzon, C.; Di Grigoli, G.; Monterisi, C.; Masiello, V.; Iaccarino, L.; Cappelli, A.; Poliani, P.L.; et al. 18F-VC701-PET and MRI in the in vivo neuroinflammation assessment of a mouse model of multiple sclerosis. J. Neuroinflamm. 2018, 15, 33. [CrossRef] [PubMed]

250. Albert, N.L.; Unterrainer, M.; Fleischmann, D.F.; Lindner, S.; Vettermann, F.; Brunegraf, A.; Vomacka, L.; Brendel, M.; Wenter, V.; Wetzel, C.; et al. TSPO PET for glioma imaging using the novel ligand 18F-GE-180: First results in patients with glioblastoma. Eur. J. Nucl. Med. Mol. Imaging 2017, 44, 2230-2238. [CrossRef] [PubMed]

251. Unterrainer, M.; Fleischmann, D.F.; Vettermann, F.; Ruf, V.; Kaiser, L.; Nelwan, D.; Lindner, S.; Brendel, M.; Wenter, V.; Stöcklein, S.; et al. TSPO PET, tumour grading and molecular genetics in histologically verified glioma: A correlative 18F-GE-180 PET study. Eur. J. Nucl. Med. Mol. Imaging 2020, 47, 1368-1380. [CrossRef] [PubMed]

252. Blair, A.; Zmuda, F.; Malviya, G.; Tavares, A.A.S.; Tamagnan, G.D.; Chalmers, A.J.; Dewar, D.; Pimlott, S.L.; Sutherland, A. A novel 18F-labelled high affinity agent for PET imaging of the translocator protein. Chem. Sci. 2015, 6, 4772-4777. [CrossRef]

253. Perrone, M.; Moon, B.S.; Park, H.S.; Laquintana, V.; Jung, J.H.; Cutrignelli, A.; Lopedota, A.; Franco, M.; Kim, S.E.; Lee, B.C.; et al. A Novel PET Imaging Probe for the Detection and Monitoring of Translocator Protein $18 \mathrm{kDa}$ Expression in Pathological Disorders. Sci. Rep. 2016, 6, 20422. [CrossRef]

254. Sasikumar, A.; Joy, A.; Pillai, M.R.A.; Nanabala, R.; Thomas, B. 68Ga-PSMA PET/CT Imaging in Multiple Myeloma. Clin. Nucl. Med. 2017, 42, e126-e127. [CrossRef] 
255. Fragomeni, R.A.S.; Menke, J.R.; Holdhoff, M.; Ferrigno, C.; Laterra, J.J.; Solnes, L.B.; Javadi, M.S.; Szabo, Z.; Pomper, M.G.; Rowe, S.P. Prostate-Specific Membrane Antigen-Targeted Imaging With $\left[{ }^{18} \mathrm{~F}\right]$ DCFPyL in High-Grade Gliomas. Clin. Nucl. Med. 2017, 42, e433-e435. [CrossRef]

256. Unterrainer, M.; Niyazi, M.; Ruf, V.; Bartenstein, P.; Albert, N.L. The endothelial prostate-specific membrane antigen is highly expressed in gliosarcoma and visualized by $\left[{ }^{68} \mathrm{Ga}\right]-P S M A-11$ PET: A theranostic outlook for brain tumor patients? Neuro-oncology 2017, 19, 1698-1699. [CrossRef]

257. Matsuda, M.; Ishikawa, E.; Yamamoto, T.; Hatano, K.; Joraku, A.; Iizumi, Y.; Masuda, Y.; Nishiyama, H.; Matsumura, A. Potential use of prostate specific membrane antigen (PSMA) for detecting the tumor neovasculature of brain tumors by PET imaging with 89Zr-Df-IAB2M anti-PSMA minibody. J. Neurooncol. 2018, 138, 581-589. [CrossRef] [PubMed]

258. Verma, P.; Malhotra, G.; Agrawal, R.; Sonavane, S.; Meshram, V.; Asopa, R.V. Evidence of Prostate-Specific Membrane Antigen Expression in Metastatic Differentiated Thyroid Cancer Using 68Ga-PSMA-HBED-CC PET/CT. Clin. Nucl. Med. 2018, 43, e265-e268. [CrossRef] [PubMed]

259. Sasikumar, A.; Kashyap, R.; Joy, A.; Charan Patro, K.; Bhattacharya, P.; Reddy Pilaka, V.K.; Oommen, K.E.; Pillai, M.R.A. Utility of 68Ga-PSMA-11 PET/CT in Imaging of Glioma-A Pilot Study. Clin. Nucl. Med. 2018, 43, e304-e309. [CrossRef] [PubMed]

260. Salas Fragomeni, R.A.; Pienta, K.J.; Pomper, M.G.; Gorin, M.A.; Rowe, S.P. Uptake of Prostate-Specific Membrane Antigen-Targeted 18F-DCFPyL in Cerebral Radionecrosis: Implications for Diagnostic Imaging of High-Grade Gliomas. Clin. Nucl. Med. 2018, 43, e419-e421. [CrossRef]

261. Verma, P.; Malhotra, G.; Goel, A.; Rakshit, S.; Chandak, A.; Chedda, R.; Banerjee, S.; Asopa, R.V. Differential Uptake of 68Ga-PSMA-HBED-CC (PSMA-11) in Low-Grade Versus High-Grade Gliomas in Treatment-Naive Patients. Clin. Nucl. Med. 2019, 44, e318-e322. [CrossRef]

262. Marafi, F.; Sasikumar, A.; Fathallah, W.; Esmail, A. ${ }^{18}$ F-PSMA 1007 Brain PET/CT Imaging in Glioma Recurrence. Clin. Nucl. Med. 2020, 45, e61-e62. [CrossRef]

263. Kunikowska, J.; Kuliński, R.; Muylle, K.; Koziara, H.; Królicki, L. ${ }^{68}$ Ga-Prostate-Specific Membrane Antigen-11 PET/CT: A New Imaging Option for Recurrent Glioblastoma Multiforme? Clin. Nucl. Med. 2020, 45, 11-18. [CrossRef]

264. Gupta, M.; Choudhury, P.S.; Premsagar, I.C.; Gairola, M.; Ahlawat, P. Role of ${ }^{68}$ Ga-Prostate-Specific Membrane Antigen PET/CT in Disease Assessment in Glioblastoma Within 48 Hours of Surgery. Clin. Nucl. Med. 2020, 45, 204-205. [CrossRef]

265. Van de Wiele, C.; Sathekge, M.; de Spiegeleer, B.; de Jonghe, P.J.; Beels, L.; Maes, A. PSMA-Targeting Positron Emission Agents for Imaging Solid Tumors Other Than Non-Prostate Carcinoma: A Systematic Review. Int. J. Mol. Sci. 2019, 20, 4886. [CrossRef]

266. Oliveira, D.; Stegmayr, C.; Heinzel, A.; Ermert, J.; Neumaier, B.; Shah, N.J.; Mottaghy, F.M.; Langen, K.-J.; Willuweit, A. High uptake of ${ }^{68} \mathrm{Ga}-\mathrm{PSMA}$ and ${ }^{18} \mathrm{~F}-\mathrm{DCFPyL}$ in the peritumoral area of rat gliomas due to activated astrocytes. EJNMMI Res. 2020, 10, 55. [CrossRef]

267. de Lucas, A.G.; Schuhmacher, A.J.; Oteo, M.; Romero, E.; Cámara, J.A.; de Martino, A.; Arroyo, A.G.; Morcillo, M.Á.; Squatrito, M.; Martinez-Torrecuadrada, J.L.; et al. Targeting MT1-MMP as an ImmunoPET-Based Strategy for Imaging Gliomas. PLoS ONE 2016, 11, e0158634. [CrossRef] [PubMed]

268. Wang, L.-J.; Li, H.-S.; Wang, Q.-S.; Wu, H.-B.; Han, Y.-J.; Zhou, W.-L.; Wang, M.; Huang, S. Construction and Evaluation of the Tumor-Targeting, Cell-Penetrating Multifunctional Molecular Probe iCREKA. Contrast Media Mol. Imaging 2018, 2018, 7929617. [CrossRef] [PubMed]

269. Zhao, J.; Wang, Y.-L.; Li, X.-B.; Gao, S.-Y.; Liu, S.-Y.; Song, Y.-K.; Wang, J.-Y.; Xiong, Y.; Ma, H.; Jiang, L.; et al. Radiosynthesis and Preliminary Biological Evaluation of 18F-Fluoropropionyl-Chlorotoxin as a Potential PET Tracer for Glioma Imaging. Contrast Media Mol. Imaging 2018, 2018, 8439162. [CrossRef] [PubMed]

270. Kasten, B.B.; Jiang, K.; Cole, D.; Jani, A.; Udayakumar, N.; Gillespie, G.Y.; Lu, G.; Dai, T.; Rosenthal, E.L.; Markert, J.M.; et al. Targeting MMP-14 for dual PET and fluorescence imaging of glioma in preclinical models. Eur. J. Nucl. Med. Mol. Imaging 2020, 47, 1412-1426. [CrossRef] [PubMed]

271. Röhrich, M.; Loktev, A.; Wefers, A.K.; Altmann, A.; Paech, D.; Adeberg, S.; Windisch, P.; Hielscher, T.; Flechsig, P.; Floca, R.; et al. IDH-wildtype glioblastomas and grade III/IV IDH-mutant gliomas show elevated tracer uptake in fibroblast activation protein-specific PET/CT. Eur. J. Nucl. Med. Mol. Imaging 2019, 46, 2569-2580. [CrossRef]

272. Warburg, O. On the Origin of Cancer Cells. Science 1956, 123, 309-314. [CrossRef] 
273. Moreno-Sánchez, R.; Rodríguez-Enríquez, S.; Marín-Hernández, A.; Saavedra, E. Energy metabolism in tumor cells. FEBS J. 2007, 274, 1393-1418. [CrossRef]

274. Jung, J.; Ahn, B.-C. Current Radiopharmaceuticals for Positron Emission Tomography of Brain Tumors. Brain Tumor Res. Treat. 2018, 6, 47-53. [CrossRef]

275. Masui, K.; Onizuka, H.; Cavenee, W.K.; Mischel, P.S.; Shibata, N. Metabolic reprogramming in the pathogenesis of glioma: Update. Neuropathology 2019, 39, 3-13. [CrossRef]

276. Cruzat, V.; Macedo Rogero, M.; Noel Keane, K.; Curi, R.; Newsholme, P. Glutamine: Metabolism and Immune Function, Supplementation and Clinical Translation. Nutrients 2018, 10, 1564. [CrossRef]

277. Feron, O. Pyruvate into lactate and back: From the Warburg effect to symbiotic energy fuel exchange in cancer cells. Radiother. Oncol. 2009, 92, 329-333. [CrossRef]

278. Tardito, S.; Oudin, A.; Ahmed, S.U.; Fack, F.; Keunen, O.; Zheng, L.; Miletic, H.; Sakariassen, P.Ø.; Weinstock, A.; Wagner, A.; et al. Glutamine synthetase activity fuels nucleotide biosynthesis and supports growth of glutamine-restricted glioblastoma. Nat. Cell Biol. 2015, 17, 1556-1568. [CrossRef] [PubMed]

279. Rosati, A.; Poliani, P.L.; Todeschini, A.; Cominelli, M.; Medicina, D.; Cenzato, M.; Simoncini, E.L.; Magrini, S.M.; Buglione, M.; Grisanti, S.; et al. Glutamine synthetase expression as a valuable marker of epilepsy and longer survival in newly diagnosed glioblastoma multiforme. Neuro-oncology 2013, 15, 618-625. [CrossRef] [PubMed]

280. Zhou, R.; Pantel, A.R.; Li, S.; Lieberman, B.P.; Ploessl, K.; Choi, H.; Blankemeyer, E.; Lee, H.; Kung, H.F.; Mach, R.H.; et al. [ $\left.{ }^{18} \mathrm{~F}\right](2 \mathrm{~S}, 4 \mathrm{R}) 4$-Fluoroglutamine PET Detects Glutamine Pool Size Changes in Triple-Negative Breast Cancer in Response to Glutaminase Inhibition. Cancer Res. 2017, 77, 1476-1484. [CrossRef] [PubMed]

281. Price, S.J.; Young, A.M.H.; Scotton, W.J.; Ching, J.; Mohsen, L.A.; Boonzaier, N.R.; Lupson, V.C.; Griffiths, J.R.; McLean, M.A.; Larkin, T.J. Multimodal MRI can identify perfusion and metabolic changes in the invasive margin of glioblastomas. J. Magn. Reson. Imaging 2016, 43, 487-494. [CrossRef]

282. Nagashima, H.; Sasayama, T.; Tanaka, K.; Kyotani, K.; Sato, N.; Maeyama, M.; Kohta, M.; Sakata, J.; Yamamoto, Y.; Hosoda, K.; et al. Myo-inositol concentration in MR spectroscopy for differentiating high grade glioma from primary central nervous system lymphoma. J. Neurooncol. 2018, 136, 317-326. [CrossRef] [PubMed]

283. Andronesi, O.C.; Arrillaga-Romany, I.C.; Ly, K.I.; Bogner, W.; Ratai, E.M.; Reitz, K.; Iafrate, A.J.; Dietrich, J.; Gerstner, E.R.; Chi, A.S.; et al. Pharmacodynamics of mutant-IDH1 inhibitors in glioma patients probed by in vivo 3D MRS imaging of 2-hydroxyglutarate. Nat. Commun. 2018, 9, 1474. [CrossRef]

284. Bisdas, S.; Chadzynski, G.L.; Braun, C.; Schittenhelm, J.; Skardelly, M.; Hagberg, G.E.; Ethofer, T.; Pohmann, R.; Shajan, G.; Engelmann, J.; et al. MR spectroscopy for in vivo assessment of the oncometabolite 2-hydroxyglutarate and its effects on cellular metabolism in human brain gliomas at 9.4T. J. Magn. Reson. Imaging 2016, 44, 823-833. [CrossRef]

285. Heiland, D.H.; Mader, I.; Schlosser, P.; Pfeifer, D.; Carro, M.S.; Lange, T.; Schwarzwald, R.; Vasilikos, I.; Urbach, H.; Weyerbrock, A. Integrative Network-based Analysis of Magnetic Resonance Spectroscopy and Genome Wide Expression in Glioblastoma multiforme. Sci. Rep. 2016, 6, 29052. [CrossRef]

286. Hangel, G.; Jain, S.; Springer, E.; Hečková, E.; Strasser, B.; Považan, M.; Gruber, S.; Widhalm, G.; Kiesel, B.; Furtner, J.; et al. High-resolution metabolic mapping of gliomas via patch-based super-resolution magnetic resonance spectroscopic imaging at 7T. Neuroimage 2019, 191, 587-595. [CrossRef]

287. Kant, S.; Kesarwani, P.; Prabhu, A.; Graham, S.F.; Buelow, K.L.; Nakano, I.; Chinnaiyan, P. Enhanced fatty acid oxidation provides glioblastoma cells metabolic plasticity to accommodate to its dynamic nutrient microenvironment. Cell Death Dis. 2020, 11, 253. [CrossRef] [PubMed]

288. Strickland, M.; Stoll, E.A. Metabolic Reprogramming in Glioma. Front. Cell Dev. Biol. 2017, 5. [CrossRef] [PubMed]

289. Maher, E.A.; Marin-Valencia, I.; Bachoo, R.M.; Mashimo, T.; Raisanen, J.; Hatanpaa, K.J.; Jindal, A.; Jeffrey, F.M.; Choi, C.; Madden, C.; et al. Metabolism of $\left[\mathrm{U}^{13} \mathrm{C}\right]$ glucose in human brain tumors in vivo. NMR Biomed. 2012, 25, 1234-1244. [CrossRef] [PubMed]

290. Mashimo, T.; Pichumani, K.; Vemireddy, V.; Hatanpaa, K.J.; Singh, D.K.; Sirasanagandla, S.; Nannepaga, S.; Piccirillo, S.G.; Kovacs, Z.; Foong, C.; et al. Acetate Is a Bioenergetic Substrate for Human Glioblastoma and Brain Metastases. Cell 2014, 159, 1603-1614. [CrossRef]

291. Grube, S.; Göttig, T.; Freitag, D.; Ewald, C.; Kalff, R.; Walter, J. Selection of suitable reference genes for expression analysis in human glioma using RT-qPCR. J. Neurooncol. 2015, 123, 35-42. [CrossRef] 
292. Lin, H.; Patel, S.; Affleck, V.S.; Wilson, I.; Turnbull, D.M.; Joshi, A.R.; Maxwell, R.; Stoll, E.A. Fatty acid oxidation is required for the respiration and proliferation of malignant glioma cells. Neuro-oncology 2017, 19, 43-54. [CrossRef]

293. Tee, S.-S.; Keshari, K.R. Novel Approaches to Imaging Tumor Metabolism. Cancer J. 2015, 21, $165-173$. [CrossRef]

294. Kesarwani, P.; Prabhu, A.; Kant, S.; Chinnaiyan, P. Metabolic remodeling contributes towards an immune-suppressive phenotype in glioblastoma. Cancer Immunol. Immunother. 2019, 68, 1107-1120. [CrossRef]

295. Peters, J.C. Tryptophan nutrition and metabolism: An overview. Adv. Exp. Med. Biol. 1991, 294, 345-358. [CrossRef]

296. Frumento, G.; Rotondo, R.; Tonetti, M.; Damonte, G.; Benatti, U.; Ferrara, G.B. Tryptophan-derived catabolites are responsible for inhibition of $\mathrm{T}$ and natural killer cell proliferation induced by indoleamine 2,3-dioxygenase. J. Exp. Med. 2002, 196, 459-468. [CrossRef]

297. Sordillo, P.P.; Sordillo, L.A.; Helson, L. The Kynurenine Pathway: A Primary Resistance Mechanism in Patients with Glioblastoma. Anticancer Res. 2017, 37, 2159-2171. [CrossRef] [PubMed]

298. Ozawa, Y.; Yamamuro, S.; Sano, E.; Tatsuoka, J.; Hanashima, Y.; Yoshimura, S.; Sumi, K.; Hara, H.; Nakayama, T.; Suzuki, Y.; et al. Indoleamine 2,3-dioxygenase 1 is highly expressed in glioma stem cells. Biochem. Biophys. Res. Commun. 2020, 524, 723-729. [CrossRef] [PubMed]

299. Bosnyák, E.; Kamson, D.O.; Guastella, A.R.; Varadarajan, K.; Robinette, N.L.; Kupsky, W.J.; Muzik, O.; Michelhaugh, S.K.; Mittal, S.; Juhász, C. Molecular imaging correlates of tryptophan metabolism via the kynurenine pathway in human meningiomas. Neuro-oncology 2015, 17, 1284-1292. [CrossRef] [PubMed]

300. Krasikova, R.; Kondrashov, M.; Avagliano, C.; Petukhov, M.; Vazquez-Romero, A.; Revunov, E.; Johnström, P.; Tari, L.; Tóth, M.; Häggkvist, J.; et al. Synthesis and Preclinical Evaluation of 6- $\left[{ }^{18} \mathrm{~F}\right]$ Fluorine- $\alpha$-methyl-l-tryptophan, a Novel PET Tracer for Measuring Tryptophan Uptake. ACS Chem. Neurosci. 2020, 11, 1756-1761. [CrossRef]

301. Lewis, J.S.; Keshari, K.R. Imaging and Metabolism; Springer: Berlin/Heidelberg, Germany, 2017; ISBN 978-3-319-61401-4.

302. Moreau, A.; Febvey, O.; Mognetti, T.; Frappaz, D.; Kryza, D. Contribution of Different Positron Emission Tomography Tracers in Glioma Management: Focus on Glioblastoma. Front. Oncol. 2019, 9. [CrossRef]

303. Götz, I.; Grosu, A.L. $\left[{ }^{18}\right.$ F] FET-PET Imaging for Treatment and Response Monitoring of Radiation Therapy in Malignant Glioma Patients-A Review. Front. Oncol. 2013, 3. [CrossRef]

304. Nelson, S.J.; Kadambi, A.K.; Park, I.; Li, Y.; Crane, J.; Olson, M.; Molinaro, A.; Roy, R.; Butowski, N.; Cha, S.; et al. Association of early changes in $1 \mathrm{H}$ MRSI parameters with survival for patients with newly diagnosed glioblastoma receiving a multimodality treatment regimen. Neuro-oncology 2017, 19, 430-439. [CrossRef]

305. Lo Dico, A.; Valtorta, S.; Ottobrini, L.; Moresco, R.M. Role of Metformin and AKT Axis Modulation in the Reversion of Hypoxia Induced TMZ-Resistance in Glioma Cells. Front. Oncol. 2019, 9, 463. [CrossRef]

306. Poon, C.C.; Sarkar, S.; Yong, V.W.; Kelly, J.J.P. Glioblastoma-associated microglia and macrophages: Targets for therapies to improve prognosis. Brain 2017, 140, 1548-1560. [CrossRef]

307. Roesch, S.; Rapp, C.; Dettling, S.; Herold-Mende, C. When Immune Cells Turn Bad-Tumor-Associated Microglia/Macrophages in Glioma. Int. J. Mol. Sci. 2018, 19, 436. [CrossRef]

308. Liu, T.; Han, C.; Wang, S.; Fang, P.; Ma, Z.; Xu, L.; Yin, R. Cancer-associated fibroblasts: An emerging target of anti-cancer immunotherapy. J. Hematol. Oncol. 2019, 12, 86. [CrossRef]

309. Hambardzumyan, D.; Gutmann, D.H.; Kettenmann, H. The role of microglia and macrophages in glioma maintenance and progression. Nat. Neurosci. 2016, 19, 20-27. [CrossRef] [PubMed]

310. Venneti, S.; Lopresti, B.J.; Wiley, C.A. The peripheral benzodiazepine receptor (Translocator protein 18kDa) in microglia: From pathology to imaging. Prog. Neurobiol. 2006, 80, 308-322. [CrossRef] [PubMed]

311. Vlodavsky, E.; Soustiel, J.F. Immunohistochemical expression of peripheral benzodiazepine receptors in human astrocytomas and its correlation with grade of malignancy, proliferation, apoptosis and survival. J. Neurooncol. 2007, 81, 1-7. [CrossRef] [PubMed]

312. Evans, J.C.; Malhotra, M.; Cryan, J.F.; O'Driscoll, C.M. The therapeutic and diagnostic potential of the prostate specific membrane antigen/glutamate carboxypeptidase II (PSMA/GCPII) in cancer and neurological disease. Br. J. Pharmacol. 2016, 173, 3041-3079. [CrossRef] 
313. Pastorino, S.; Riondato, M.; Uccelli, L.; Giovacchini, G.; Giovannini, E.; Duce, V.; Ciarmiello, A. Toward the Discovery and Development of PSMA Targeted Inhibitors for Nuclear Medicine Applications. Curr. Radiopharm. 2020, 13, 63-79. [CrossRef]

314. Nomura, N.; Pastorino, S.; Jiang, P.; Lambert, G.; Crawford, J.R.; Gymnopoulos, M.; Piccioni, D.; Juarez, T.; Pingle, S.C.; Makale, M.; et al. Prostate specific membrane antigen (PSMA) expression in primary gliomas and breast cancer brain metastases. Cancer Cell Int. 2014, 14, 26. [CrossRef]

315. Sasikumar, A.; Joy, A.; Pillai, M.R.; Bindu, S.; Sudin, S.R. 68Ga-PSMA Uptake in an Incidentally Detected Gastrointestinal Stromal Tumor in a Case of Suspected Carcinoma Prostate. Clin. Nucl. Med. 2017, 42, e447-e448. [CrossRef]

316. Wang, L.; Yuan, J.; Tu, Y.; Mao, X.; He, S.; Fu, G.; Zong, J.; Zhang, Y. Co-expression of MMP-14 and MMP-19 predicts poor survival in human glioma. Clin. Transl. Oncol. 2013, 15, 139-145. [CrossRef]

317. Itoh, Y.; Ito, N.; Nagase, H.; Evans, R.D.; Bird, S.A.; Seiki, M. Cell surface collagenolysis requires homodimerization of the membrane-bound collagenase MT1-MMP. Mol. Biol. Cell 2006, 17, 5390-5399. [CrossRef]

318. Röhrich, M.; Floca, R.; Loi, L.; Adeberg, S.; Windisch, P.; Giesel, F.L.; Kratochwil, C.; Flechsig, P.; Rathke, H.; Lindner, T.; et al. FAP-specific PET signaling shows a moderately positive correlation with relative CBV and no correlation with ADC in 13 IDH wildtype glioblastomas. Eur. J. Radiol. 2020, 127, 109021. [CrossRef] [PubMed]

319. Chaddad, A.; Kucharczyk, M.J.; Daniel, P.; Sabri, S.; Jean-Claude, B.J.; Niazi, T.; Abdulkarim, B. Radiomics in Glioblastoma: Current Status and Challenges Facing Clinical Implementation. Front. Oncol. 2019, 9. [CrossRef] [PubMed]

320. Zanfardino, M.; Franzese, M.; Pane, K.; Cavaliere, C.; Monti, S.; Esposito, G.; Salvatore, M.; Aiello, M. Bringing radiomics into a multi-omics framework for a comprehensive genotype-phenotype characterization of oncological diseases. J. Transl. Med. 2019, 17. [CrossRef] [PubMed]

321. Bell, M.; Turkbey, E.B.; Escorcia, F.E. Radiomics, Radiogenomics, and Next-Generation Molecular Imaging to Augment Diagnosis of Hepatocellular Carcinoma. Cancer J. 2020, 26, 108-115. [CrossRef]

322. Gallivanone, F.; Cava, C.; Corsi, F.; Bertoli, G.; Castiglioni, I. In Silico Approach for the Definition of radiomiRNomic Signatures for Breast Cancer Differential Diagnosis. Int. J. Mol. Sci. 2019, 20, 5825. [CrossRef]

323. Prins, R.M.; Soto, H.; Konkankit, V.; Odesa, S.K.; Eskin, A.; Yong, W.H.; Nelson, S.F.; Liau, L.M. Gene Expression Profile Correlates with T-Cell Infiltration and Relative Survival in Glioblastoma Patients Vaccinated with Dendritic Cell Immunotherapy. Clin. Cancer Res. 2011, 17, 1603-1615. [CrossRef]

324. Klughammer, J.; Kiesel, B.; Roetzer, T.; Fortelny, N.; Nemc, A.; Nenning, K.-H.; Furtner, J.; Sheffield, N.C.; Datlinger, P.; Peter, N.; et al. The DNA methylation landscape of glioblastoma disease progression shows extensive heterogeneity in time and space. Nat. Med. 2018, 24, 1611-1624. [CrossRef]

325. Elkhaled, A.; Jalbert, L.E.; Phillips, J.J.; Yoshihara, H.A.I.; Parvataneni, R.; Srinivasan, R.; Bourne, G.; Berger, M.S.; Chang, S.M.; Cha, S.; et al. Magnetic resonance of 2-hydroxyglutarate in IDH1-mutated low-grade gliomas. Sci. Transl. Med. 2012, 4, 116ra5. [CrossRef]

326. Choi, C.; Ganji, S.K.; DeBerardinis, R.J.; Hatanpaa, K.J.; Rakheja, D.; Kovacs, Z.; Yang, X.-L.; Mashimo, T.; Raisanen, J.M.; Marin-Valencia, I.; et al. 2-hydroxyglutarate detection by magnetic resonance spectroscopy in IDH-mutated glioma patients. Nat. Med. 2012, 18, 624-629. [CrossRef]

327. Kong, D.-S.; Kim, J.; Ryu, G.; You, H.-J.; Sung, J.K.; Han, Y.H.; Shin, H.-M.; Lee, I.-H.; Kim, S.-T.; Park, C.-K.; et al. Quantitative radiomic profiling of glioblastoma represents transcriptomic expression. Oncotarget 2018, 9, 6336-6345. [CrossRef]

328. Verhaak, R.G.W.; Hoadley, K.A.; Purdom, E.; Wang, V.; Qi, Y.; Wilkerson, M.D.; Miller, C.R.; Ding, L.; Golub, T.; Mesirov, J.P.; et al. Integrated Genomic Analysis Identifies Clinically Relevant Subtypes of Glioblastoma Characterized by Abnormalities in PDGFRA, IDH1, EGFR, and NF1. Cancer Cell 2010, 17, 98-110. [CrossRef] [PubMed]

329. Verger, A.; Langen, K.-J. PET Imaging in Glioblastoma: Use in Clinical Practice. In Glioblastoma; De Vleeschouwer, S., Ed.; Codon Publications: Brisbane, Australia, 2017; ISBN 978-0-9944381-2-6.

330. Kopkova, A.; Sana, J.; Machackova, T.; Vecera, M.; Radova, L.; Trachtova, K.; Vybihal, V.; Smrcka, M.; Kazda, T.; Slaby, O.; et al. Cerebrospinal Fluid MicroRNA Signatures as Diagnostic Biomarkers in Brain Tumors. Cancers 2019, 11, 1546. [CrossRef] [PubMed] 
331. Ebrahimkhani, S.; Vafaee, F.; Hallal, S.; Wei, H.; Lee, M.Y.T.; Young, P.E.; Satgunaseelan, L.; Beadnall, H.; Barnett, M.H.; Shivalingam, B.; et al. Deep sequencing of circulating exosomal microRNA allows non-invasive glioblastoma diagnosis. NPJ Precis. Oncol. 2018, 2, 1-9. [CrossRef]

332. Qu, S.; Guan, J.; Liu, Y. Identification of microRNAs as novel biomarkers for glioma detection: A meta-analysis based on 11 articles. J. Neurol. Sci. 2015, 348, 181-187. [CrossRef] [PubMed]

333. Costa, P.M.; Cardoso, A.L.; Custódia, C.; Cunha, P.; Pereira de Almeida, L.; Pedroso de Lima, M.C. MiRNA-21 silencing mediated by tumor-targeted nanoparticles combined with sunitinib: A new multimodal gene therapy approach for glioblastoma. J. Control. Release 2015, 207, 31-39. [CrossRef]

334. Shukla, A.; Gupta, P.; Singh, R.; Mishra, D.P. Glycolytic inhibitor 2-Deoxy-d-Glucose activates migration and invasion in glioblastoma cells through modulation of the miR-7-5p/TFF3 signaling pathway. Biochem. Biophys. Res. Commun. 2018, 499, 829-835. [CrossRef]

335. Siegal, T.; Charbit, H.; Paldor, I.; Zelikovitch, B.; Canello, T.; Benis, A.; Wong, M.L.; Morokoff, A.P.; Kaye, A.H.; Lavon, I. Dynamics of circulating hypoxia-mediated miRNAs and tumor response in patients with high-grade glioma treated with bevacizumab. J. Neurosurg. 2016, 125, 1008-1015. [CrossRef]

336. Liu, H.; Liu, Z.; Jiang, B.; Huo, L.; Liu, J.; Lu, J. Synthetic miR-145 Mimic Enhances the Cytotoxic Effect of the Antiangiogenic Drug Sunitinib in Glioblastoma. Cell Biochem. Biophys. 2015, 72, 551-557. [CrossRef]

337. Wei, X.; Schlenkhoff, C.; Schwarz, B.; Essler, M.; Ahmadzadehfar, H. Combination of 177Lu-PSMA-617 and External Radiotherapy for the Treatment of Cerebral Metastases in Patients with Castration-Resistant Metastatic Prostate Cancer. Clin. Nucl. Med. 2017, 42, 704-706. [CrossRef]

(C) 2020 by the authors. Licensee MDPI, Basel, Switzerland. This article is an open access article distributed under the terms and conditions of the Creative Commons Attribution (CC BY) license (http://creativecommons.org/licenses/by/4.0/). 